\title{
An energy-based approach to predict debris flow mobility and analyze empirical relationships
}

\author{
Francesco Federico and Chiara Cesali
}

\begin{abstract}
Several empirical relationships allowing a preliminary estimate of debris flow runout distances have been proposed to correlate the runout length to the volume of the sliding granular mass, delimit potentially hazardous areas, and design safeguarding measures. To overcome their large variability and define their fields of applicability, an energy-based model, predicting debris flow mobility, is developed. The power balance of a granular mass sliding along two planar surfaces is written by taking into account the volume of the debris mass, the slopes of the sliding surfaces, an assigned interstitial pressure, the possible mass variation along the motion, the energy dissipation due to the grain inelastic collisions ("granular temperature" within a basal "shear layer"), and friction. A system of ordinary differential equations is obtained; its numerical solution allows, through parametrical analyses: (i) highlighting of the role of physical and mechanical parameters on the runout distance, such as grain size material, interstitial pressures, grain collisions, and erodibility of the crossed channel; and (ii) defining of the favourable conditions for debris flows mechanism generation. Finally, through the back-analysis of some cases, an original relationship to estimate the runout length, as well as to interpret the results of the empirical formulas, is proposed.
\end{abstract}

Key words: sliding granular mass, granular temperature, shear layer, collisions, empirical relationships.

Résumé : Plusieurs relations empiriques permettant d'effectuer une estimation préalable des distances parcourues par les écoulements de débris ont été proposées pour mettre en corrélation la distance parcourue par les écoulements et le volume de masse granulaire glissante, délimiter les zones potentiellement dangereuses et mettre en place des mesures de protection. Pour compenser la grande variabilité de ces relations et définir leurs champs d'application, on conçoit un modèle basé sur l'énergie, capable de prédire la mobilité des écoulements de débris. On décrit l'équilibre des forces d'une masse granulaire glissant sur deux surfaces planes en tenant compte du volume de la masse de débris, de l'inclinaison des surfaces de glissement, d'une valeur déterminée de pression interstitielle, de la possible variation de masse sur le parcours de l'écoulement, de la dissipation d'énergie due aux collisions inélastiques entre grains (" température granulaire » au sein d'une " couche de cisaillement » basale) et des frottements. On obtient un système d'équations différentielles ordinaires; la solution de ce dernier permet, par le biais d'analyses paramétriques : (i) de souligner le rôle des paramètres physiques et mécaniques (tels que la taille des grains de la masse glissante, les pressions interstitielles, les collisions entre grains, l'érodabilité du canal croisé) sur la distance du parcours des écoulements; (ii) de déterminer les conditions favorables au déclenchement du mécanisme d'écoulement de débris. Enfin, grâce à l'analyse rétrospective de certains cas, on propose une nouvelle corrélation permettant d'estimer la distance de parcours des écoulements et d’interpréter les résultats des formules empiriques. [Traduit par la Rédaction]

Mots-clés : masse granulaire glissante, température granulaire, couche de cisaillement, collisions, relations empiriques.

\section{Introduction}

Analytical methods to determinate the distance traveled by a debris flow can be classified either as empirical or dynamic. Empirical methods (or criteria) can be divided into three main categories: "angle of reach" models, "area inundation" models, and "mass (or volume) balance" models. "Angle of reach" criteria estimate the total travel distance $(\bar{L})$ of debris flows (projected on a horizontal plane) through the elevation difference $(H)$ between the highest point of the granular mass before sliding and the more advanced point of deposit after sliding, and the empirically derived reach angle $(\beta)$, conventionally defined as (Heim 1932)

(1) $\quad \tan (\beta)=\frac{H}{\bar{L}}$

where $\bar{L}$ and $H$ are measured variables (Fig. 1). According to known empirical criteria (Scheidegger 1973; Davies 1982; Corominas 1996; Rickenmann 1999), $\beta$ is related to the volume $(V)$ of the sliding mass; debris flows with larger volume generally travel farther than smaller ones. For a given volume, $V$, debris flows usually show a larger mobility, or lower travel angles, than those characterizing landslides and rock falls (Iverson 1997; Legros 2002).

"Inundation area" models are based on the research by Iverson et al. (1998), who introduced semi-empirical equations to predict inundated valley cross-sectional and planimetric areas as functions of landslide volume $(V)$, while "mass (or volume) balance" approaches (Benda and Cundy 1990; Cannon 1993) are based on the "yield rate" concept, defined as the rate of volume change per unit length (Hungr et al. 1984). Unlike dynamic models, empirical approaches neglect the rheology of the debris flows and are based on geometrical or morphological parameters.

"Dynamic" models may refer to a rigid-body analysis, such as mass-based methods (Perla et al. 1980; Van Gassen and Cruden 1989), or energy-based approaches (Heim 1932; Körner 1980; Erismann and Abele 2001).

Received 7 March 2015. Accepted 26 May 2015.

F. Federico and C. Cesali. University of Rome Tor Vergata, Rome, Italy. Corresponding author: Francesco Federico (e-mail: fdrfnc@gmail.com). 
Fig. 1. Definition of reach angle.

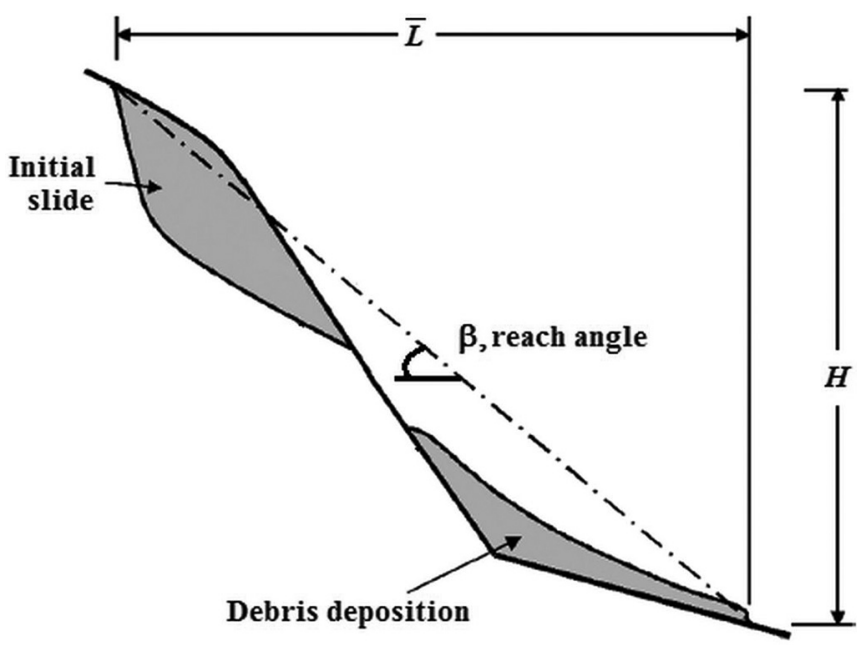

More advanced dynamic models are founded on a deformablebody approach, based on the principles of continuum mechanics (Savage and Hutter 1989; Hungr 1995). The energy-based models allow realistic results to be obtained (Park et al. 2013); the energy balance equation is typically expressed as follows:

$$
E_{\mathrm{k}}^{i}=E_{\mathrm{k}}^{0}+\Delta E_{\mathrm{p}}^{i}-E_{\mathrm{f}}^{i}
$$

where $E_{\mathrm{k}}^{i}$ is the kinetic energy at time step $i$; $E_{\mathrm{k}}^{0}$ is the initial kinetic energy; $\Delta E_{\mathrm{p}}^{i}$ is the change in potential energy; $E_{\mathrm{f}}^{i}$ is the energy lost due to dissipation. All the involved energies refer to the center of gravity of the sliding mass. To estimate a realistic kinetic energy, $E_{\mathrm{k}}$ is limited by an upper velocity threshold, deduced from observed maximum velocity of the flow (Horton et al. 2008). Rapid granular masses are generally affected by a complex kinematics deriving from a "fluidification" effect (Hungr and Evans 1996), coupled with energy dissipations, due to the high speed relative motion and collisions between grains as well as to their chaotic velocity fluctuations (granular temperature) within the shear layer at the base of the sliding granular mass (Hungr 1995). Because these effects are rationally expressed in terms of energy (Ogawa 1978; Jenkins and Savage 1983), an "advanced" energy-based model, instead of a continuum approach, is developed to describe the mobility of a debris flow.

\section{Empirical angle of reach criteria}

The angle of reach $(\beta)$, or the travel angle (Cruden and Varnes 1996) and the travel distance angle (Hunter and Fell 2003), obtained in the past several interpretations, have been considered as a measure of the relative mobility of a landslide (Corominas 1996) and the coefficient of friction of the sliding surface (Scheidegger 1973). However, Scheidegger's assumption is valid only if $\beta$ represents the slope of the line linking the centers of gravity of the landslide before sliding and after deposition. To better understand this last interpretation, it is necessary to state the energy balance (eq. (2)), by considering an elementary portion $(d x)$ of the sliding surface (average slope $\delta$ ) (Fig. 2)

$$
\mathrm{d}\left(\frac{1}{2} m \dot{x}^{2}\right)=m g \sin (\delta) \mathrm{d} x-m g \cos (\delta) \tan \left(\varphi_{\mathrm{b}}\right) \mathrm{d} x
$$

and assuming that the energy dissipation is only due to the friction $\left(\varphi_{\mathrm{b}}\right.$ is the dynamic friction angle) acting along the basal surface (dissipation associated with the collisions between the grains is neglected). The mass $(m)$ is constant and the process is isother-
Fig. 2. Definition of parameters figuring in empirical criteria.

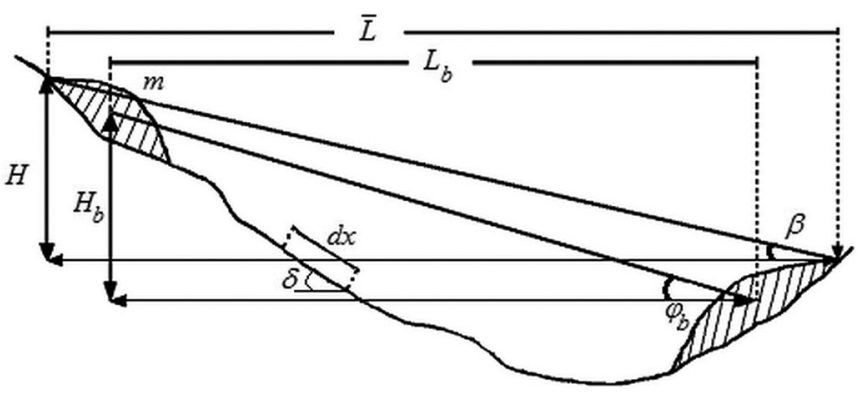

mal: during the motion, there is no conversion of potential energy into thermal energy. Experimental observations show that the component of the potential energy that transforms into heat is equal to about $10 \mathrm{~J} / \mathrm{kg}$, corresponding to an increase in temperature about equal to $0.005{ }^{\circ} \mathrm{C}$ for the most common debris flows (Iverson 1997). If eq. (3) is integrated between the initial $(x=0)$ and final $\left(x=L_{b}\right)$ positions of the center of mass (initial and final rate $\dot{x}$ are null),

$$
\tan \left(\varphi_{\mathrm{b}}\right)=\frac{H_{\mathrm{b}}}{L_{\mathrm{b}}}
$$

where $H_{\mathbf{b}}$ is the difference in elevation and $L_{\mathbf{b}}$ is the travel distance projected on a horizontal plane between the centers of mass in their initial and final positions.

Then, with fixed $H_{\mathrm{b}}$ (the available potential energy), the travel distance $L_{\mathrm{b}}$ decreases with increasing $\varphi_{\mathrm{b}}$ (Fig. 3). To simplify the development of empirical relationships, $H_{b}$ and $L_{b}$ have been replaced with the more easily recognizable variables $H$ and $\bar{L}$, obtaining, in general, smaller values of $\beta$ than of $\varphi_{\mathrm{b}}$.

During the motion, the occurrence of grain collisions induces a redistribution of the total energy of the system, determining the greater displacements of some debris than others. Therefore, it is reasonable to considerer $H$ and $\bar{L}$ instead of $H_{b}$ and $L_{b}$ in the definition of the reach angle, because $(i)$ it is necessary to know the position of the front of the mass rather than its center of gravity to delimit potentially hazardous areas and (ii) the relative error related to the "exchange" of $\beta$ with $\varphi_{\mathrm{b}}$ is estimated to be less than $20 \%$ in most cases and it is much smaller for many larger debris flows (Legros 2002).

So, by recalling eq. (1), the reach angle, $\beta$, provides an estimate of the "conventional" dynamic friction angle, $\varphi_{\mathrm{b}}$ (by neglecting the effects of collisions). Many authors have proposed empirical expressions based on the functional relationship between the tangent of the reach angle $(H / \bar{L})$ and the volume of the granular mass, $V$. Scheidegger (1973) noted that the ratio $H / \bar{L}$ decreases with an increase of volume and proposed the following relationship:

$$
\frac{H}{\bar{L}}=4.207 V^{-0.1566}
$$

with coefficient of regression $\left(R^{2}\right)$ equal to 0.82 .

By imposing the conditions $\beta<\varphi_{\mathrm{b}}$ and $\varphi_{\mathrm{b}}=30^{\circ}-35^{\circ}$ (maximum values assumed by $\varphi_{\mathrm{b}}$, for debris flows), it is obtained that eq. (5) can be applied for $V>10^{5} \mathrm{~m}^{3}$; for lower volumes, the author assumed the ratio $H / \bar{L}$ to be independent of $V$. Li (1983) proposed the following relationships $\left(R^{2}=0.78\right)$ :

(6) $\quad \frac{H}{\bar{L}}=4.613 V^{-0.1529}$ 
Fig. 3. Travel distance $L_{\mathbf{b}}$ versus dynamic friction angle $\varphi_{\mathrm{b}}$, for different values of $H_{b}$.

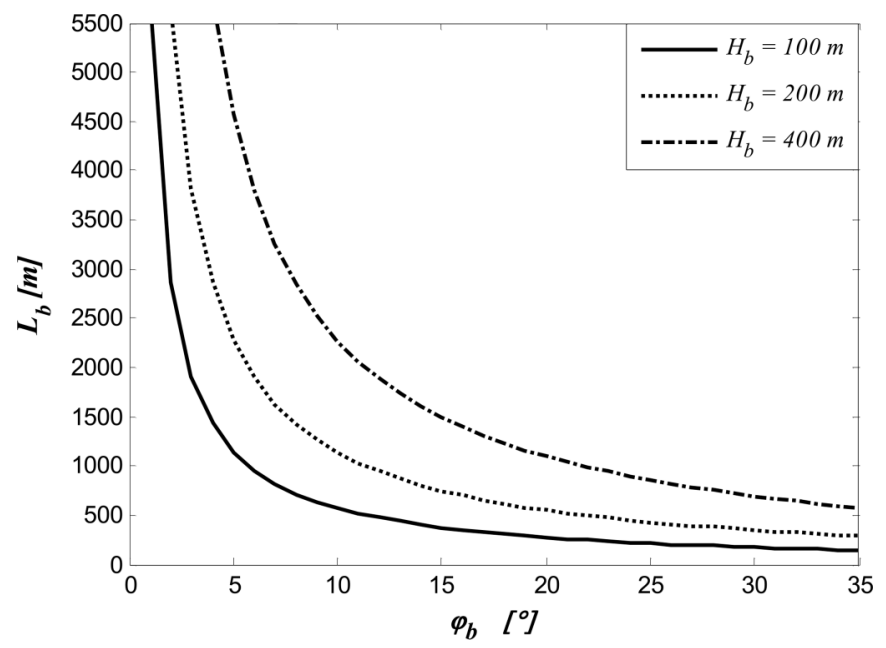

As for eq. (5), if $\beta<\varphi_{\mathrm{b}}$ (for $\varphi_{\mathrm{b}}=30^{\circ}-35^{\circ}$ ) is imposed, eq. (6) is valid for $V>\sim 2 \times 10^{5} \mathrm{~m}^{3}$ and provides greater values of $\beta\left(\right.$ or $\varphi_{\mathrm{b}}$ ) than those obtained through the Scheidegger relationship (Fig. 4).

Through a careful analysis of data concerning 204 landslides in soil and rock materials (their volumes mainly ranging between $10^{2}$ and $10^{6} \mathrm{~m}^{3}$ ), Corominas (1996) noted that the reach angle also depends on volume, $V$, in the case of small landslides and developed some valuable relationships between the ratio $H / \bar{L}$ and the volume $V$ :

$$
\frac{H}{\bar{L}}=0.897 V^{-0.085}
$$

applicable to all types of landslide (translational slides, rockfall avalanches, debris flows, mudflows), with $R^{2}$ equal to 0.625 ;

(8) $\frac{H}{\bar{L}}=0.973 V^{-0.105}$

applicable to all debris flows $\left(R^{2}=0.763\right)$; and

(9) $\quad \frac{H}{\bar{L}}=0.893 V^{-0.108}$

for obstructed (i.e., path with obstacles and restrictions) debris flows $\left(R^{2}=0.85\right)$. It is observed that the reach angle remarkably decreases for small landslides $\left(10^{2}<V<10^{4} \mathrm{~m}^{3}\right)$, corresponding friction angles ranging between $31^{\circ}$ and $22^{\circ}$ (Fig. 5); the presence of obstacles or restrictions along the path greatly influences the reach angle for small volumes and, at fixed $V$, the ratio $H / \bar{L}$ assumes smaller values than those corresponding to other types of landslides.

Through the regression analysis of data related to 154 debris flow events, the following equation was obtained by Rickenmann (1999):

$$
\bar{L}=1.9 V^{0.16} H^{0.83}
$$

for values of the volume, $V$, ranging between $7 \times 10^{2}$ and $10^{6} \mathrm{~m}^{3}$ and for $H$ between 110 and $1820 \mathrm{~m}$, with coefficient of regression equal to 0.75 (Fig. 6).

According to a relationship proposed by Davies (1982), $\bar{L}$ also depends (in addition to $V$ and $H$ ) on $\varphi_{\mathrm{b}}$ and it is equal to the sum of two lengths: $L_{1}\left(=H / \tan \varphi_{\mathrm{b}}\right)$, the distance travelled by the center of
Fig. 4. Scheidegger and Li relationships: $H / \bar{L}$ versus $V$.

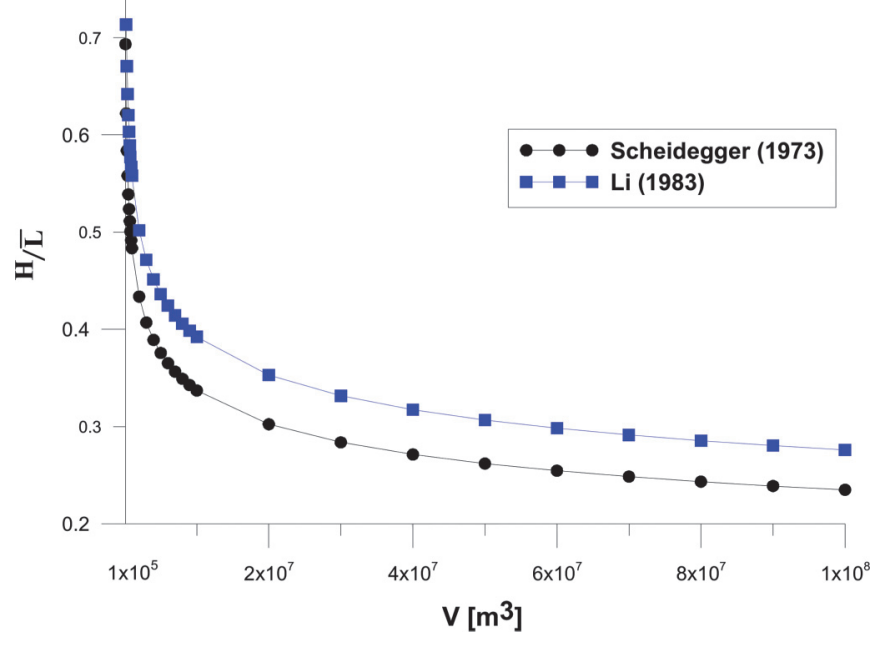

Fig. 5. Corominas relationships: $H / \bar{L}$ versus $V$, according to type of landslide and characteristics of path.

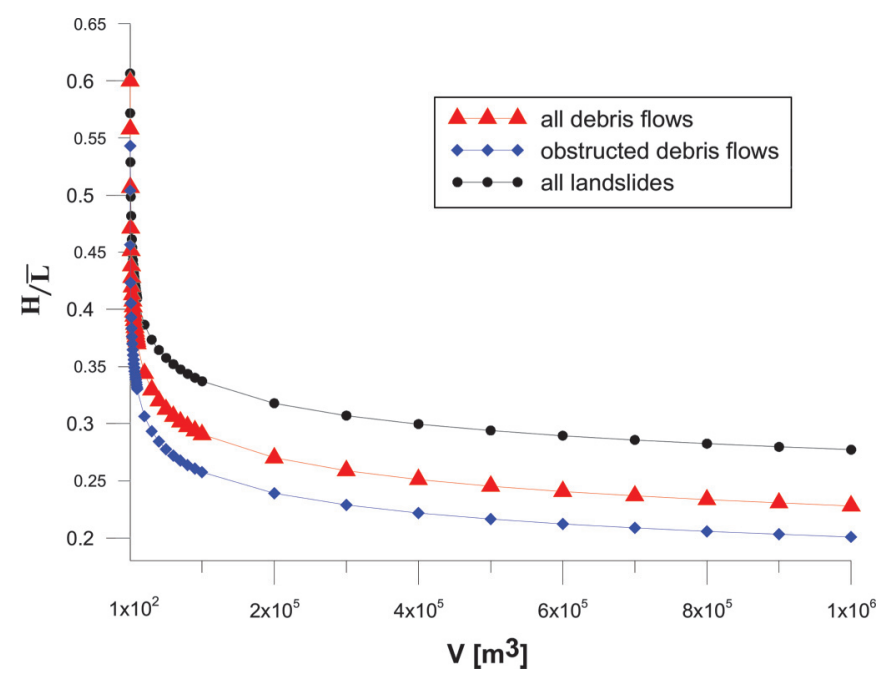

Fig. 6. Field data of $\bar{L}$ in relation to eq. (10) obtained from regression analyses (Rickenmann 1999).

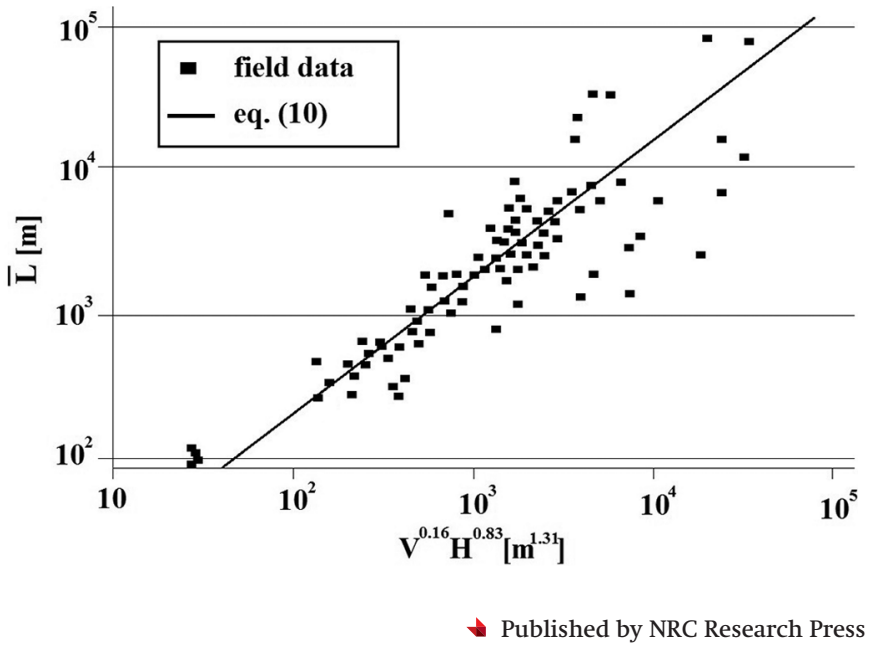




\section{Pagination not final (cite DOI) / Pagination provisoire (citer le DOI)}

mass; $L_{2}$, the half of the longitudinal extension $(l)$ of the deposit $(l=$ $9.98 V^{0.32}$, with $R^{2}=0.92$ ).

$$
\bar{L}=\frac{H}{\tan \varphi_{\mathrm{b}}}+0.5\left(9.98 \mathrm{~V}^{0.32}\right)
$$

which is only applicable to granular debris flows with very large volumes $\left(>10^{5} \mathrm{~m}^{3}\right)$. A comparison between the relationships proposed by Rickenmann and Davies is shown in Fig. 7 (computations for fixed $H=300 \mathrm{~m}$ ): although $\varphi_{\mathrm{b}}$ assumes small values, eq. (11) by Davies provides smaller values of $\bar{L}$ than those obtained through Rickenmann's relationships for high values of $V$; the two relationships (from eqs. (10) and (11)) are comparable for small volumes.

A remarkable difference between the computed values of $\bar{L}$ is observed (Figs. 4, 5, and 7). Owing to this appreciable variability, the empirical relationships may hardly be used to estimate the runout length; empirical approaches are easily applicable only in under conditions similar to those through which their development is based.

Therefore, in general, these relationships get an estimate of the debris flow runout length, but they cannot provide an accurate prediction. In addition to the volume, the role of interstitial pressure, the effect of material mechanical parameters, and the influence of the mass variability on debris flow behaviour need a careful evaluation.

\section{Mechanical behaviour of rapid sliding granular masses}

In a rapid granular mass running along mountain streams, normal and shear stresses, associated with friction and a collisional regimes, respectively, simultaneously occur (Zhang and Foda 1999). In the conventional friction regime, the stresses are not governed by the magnitude of the applied rate of deformation; the shear stress along the sliding surface satisfies the MohrCoulomb resistance law:

$$
\tau_{\mathrm{fr}}=\sigma \tan \varphi_{\mathrm{b}}
$$

where $\sigma$ is the effective normal stress, and $\varphi_{\mathrm{b}}$ is the dynamic friction angle at the base of the granular mass. In the collisional regime, widely spaced particles move at high speed; their contact is almost instantaneous and the momentum is transferred through collisions (Fig. 8). Bagnold (1954) proposed the following relationships for the stress component normal to the boundary (“dispersive pressure") and the shear stress component:

$$
\begin{aligned}
& p_{\text {disp }}=a_{\mathrm{i}} \rho_{\mathrm{s}} \lambda^{2} d_{\mathrm{p}}^{2} \cos \phi\left(\frac{\mathrm{d} u}{\mathrm{~d} y}\right)^{2} \\
& \tau_{\text {disp }}=a_{\mathrm{i}} \rho_{\mathrm{s}} \lambda^{2} d_{\mathrm{p}}^{2} \sin \phi\left(\frac{\mathrm{d} u}{\mathrm{~d} y}\right)^{2}
\end{aligned}
$$

where $a_{\mathrm{i}}$ is the "Bagnold coefficient" (suggested value 0.042); $\rho_{\mathrm{s}}$ is the solid fraction mass density; $\lambda$ is the "linear concentration", a function of solid fraction $\nu_{\mathrm{s}}\left(\lambda=1 /\left[\left(\nu_{\max } / \nu_{\mathrm{s}}\right)^{1 / 3}-1\right], \nu_{\max }\right.$ being the maximum solid fraction equal to 0.74 for spherical grains); $d_{\mathrm{p}}$ is the average grain diameter; $(d u / d y)^{2}$ is the square of the velocity gradient; $\phi$ is the internal dynamic friction angle of granular bulk (Bagnold proposed $\tan (\phi)=0.32$ ); and $y$ is normal to the shear direction.

To synthetically represent the grain motion within the shear layer, the granular temperature $\left(T_{g}\right)$ is introduced (Ogawa 1978). $T_{g}$ can be generated and maintained by continuous and partial conversion of bulk volume translational energy into grain fluctuation energy, due to grains' rotations and impacts along irregular sliding surface (Fig. 8).
Fig. 7. Rickenmann and Davies relationships: $\bar{L}$ versus $V$.

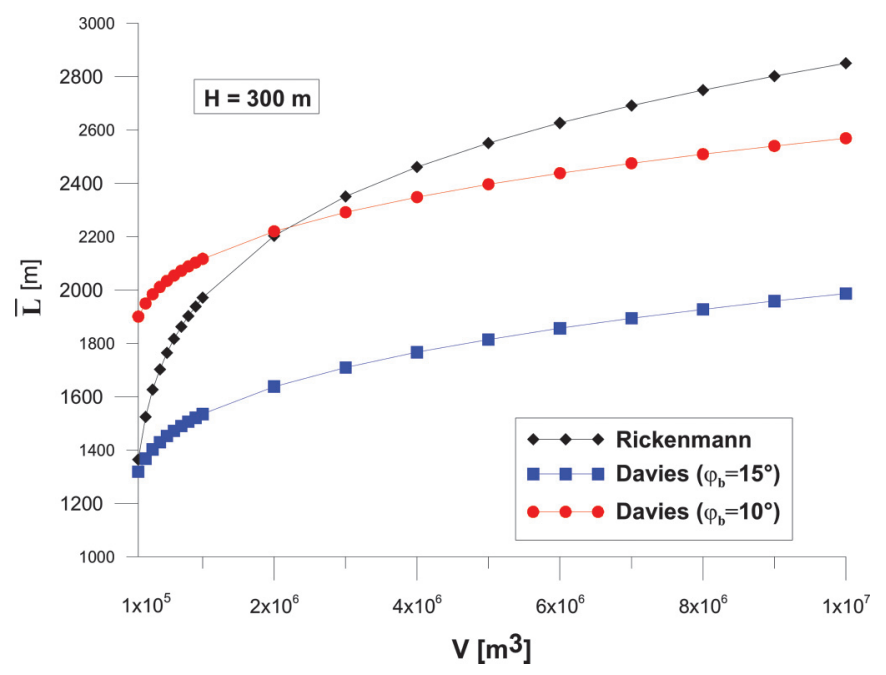

$T_{g}$ is proportional to the average value of the square of the grains' velocity fluctuations, with respect to their mean velocity (Lun et al. 1984): $T_{g}=(1 / 3)\left\langle\delta v^{2}\right\rangle$.

Furthermore, the average interstitial pressure at the base of the granular mass, which can vary between null and higher than hydrostatic values, due to the rapid change of pores volume related to the continuous rearrangement of grains, localized within the shear layer (Musso et al. 2004), remarkably influences the runout length.

\section{Proposed energy-based model}

The validity of empirical relationships for predicting runout length is difficult to verify for several reasons: $(i) H$ is not always known a priori: a relation between $\bar{L}$ and $H$, describing the longitudinal profile of the expected flow path, has to be defined; (ii) erosion and deposition phenomena are neglected; and (iii) the variety of material properties, and thus the possible development of the mechanism affecting a debris flow, could limit their applicability. To take into account some of these aspects, an energy approach, based on simplified assumptions, is adopted and an original model is developed. The model aims to predict debris flow mobility (Federico and Cesali 2013), to back-analyze documented cases, to interpret the results of previously introduced empirical relationships. The hypotheses concern:

- Geometry of the sliding mass - The granular sliding body is composed of two layers of equal basal area, $\Omega$, and length $l$; they represent the "shear layer" (thickness $s^{s}$ ) and the overlying mass (thickness $s^{\mathrm{b}}$, "block"), respectively. The shear layer is composed of particles that, moving and colliding at high velocity, induce appreciable fluctuations of their velocities (granular temperature); the "block" is dominated by inertial forces and quasi-static stresses.

- Sliding surface - The granular mass runs along planar surfaces of constant slope $\zeta(\zeta=\theta$, runout; $\zeta=\alpha$, runup). The total distance traveled by a rapid sliding granular mass is obtained through the analysis of three sliding phases: $(i)$ the sliding along the first slope ( $\theta$ and length $L$ are assigned); (ii) the granular mass runs at the same time along both slopes $(\theta$ and $\alpha$, see Fig. 9); and (iii) the sliding only along the counterslope $(\alpha)$.

- Energy dissipation - Dissipation is due to collisions occurring within the shear layer and friction, along the basal surface.

- Mass changes - The mass of a debris flow may change due to erosion or deposition processes. Typically, the erosion phenomenon mainly occurs at high elevation, induced by the high slope and the great travel speed, while the deposition, caused 
Fig. 8. Particles colliding with an irregular sliding surface: fluctuations of their velocity vector occur.

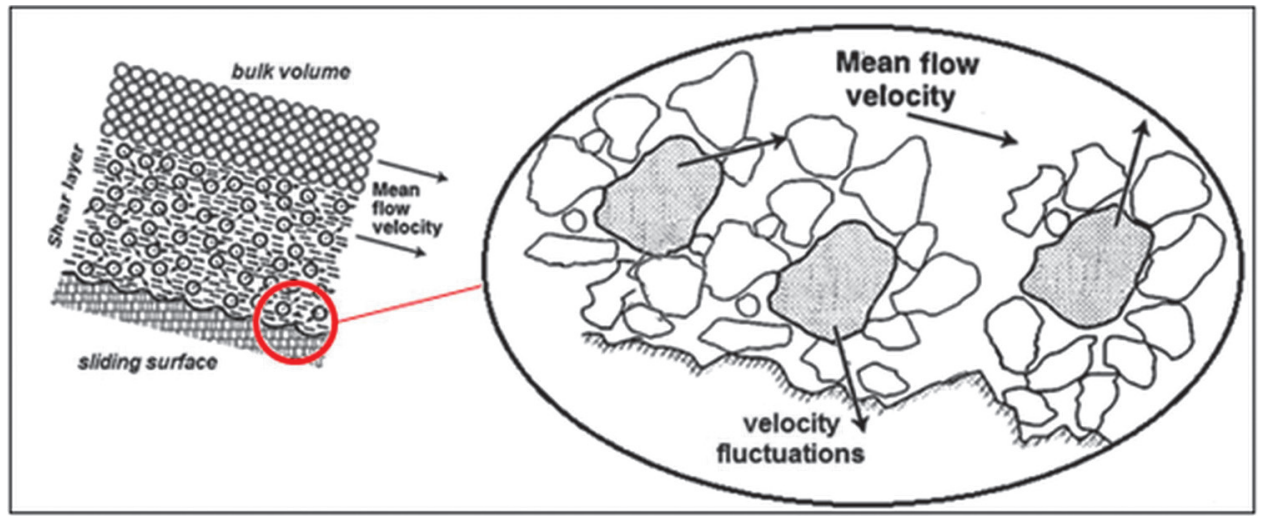

Fig. 9. Problem's setting and reference systems.

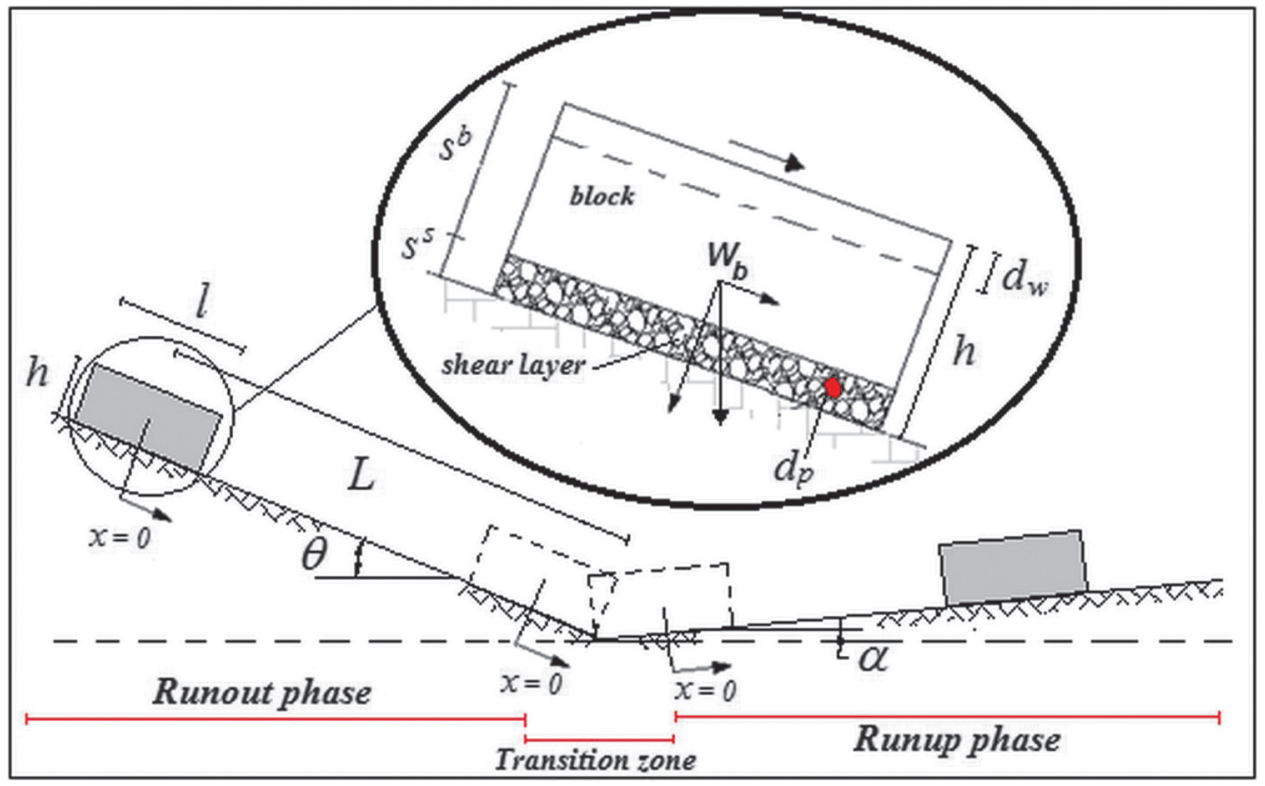

by the slowdown due in turn to the reduction of slope, downstream occurs. A linear change of the granular mass geometry (sizes $h$ and $l$, height and length, respectively, see Fig. 9) is assumed:

$$
\left\{\begin{aligned}
h[x(t)] & =h_{0}+C_{\mathrm{h}}\left[x(t)-x_{\mathrm{e}}\right] \\
l[x(t)] & =l_{0}+C_{\mathrm{l}}\left[x(t)-x_{\mathrm{e}}\right]
\end{aligned}\right.
$$

where $x_{\mathrm{e}}$ is the abscissa at which the sliding granular mass reaches the erosion critical velocity $\left(v_{\mathrm{cr}, \mathrm{e}}\right)$ and, then, the erosion process begins to occur; $C_{\mathrm{h}}$ and $C_{1}$ are the height and length rate, respectively $(\mathrm{m} / \mathrm{m}) ; h_{0}$ and $l_{0}$ are the initial height and length, respectively, of the mass. If $B_{c}$ (the width of the channel) is assumed constant, the basal area $\Omega[x(t)]$ and the volume $V[x(t)]$ of the debris flow can be expressed as follows:

$$
\begin{aligned}
& \Omega[x(t)]=B_{\mathrm{c}} l[x(t)]=\Omega_{0}+C_{\Omega}\left[x(t)-x_{\mathrm{e}}\right] \\
& V[x(t)]=h[x(t)] \Omega[x(t)]=V_{0}\left\{f_{1}\left[x(t)-x_{\mathrm{e}}\right]^{2}+f_{2}\left[x(t)-x_{\mathrm{e}}\right]+1\right\}
\end{aligned}
$$

where $\Omega_{0}$ and $V_{0}$ are the initial values of the basal area and the volume, respectively; $C_{\Omega}=C_{1} B_{\mathrm{c}}\left(\mathrm{m}^{2} / \mathrm{m}\right) ; f_{1}=\left(h_{0} C_{\Omega}+\Omega_{0} C_{\mathrm{h}}\right) / V_{0}$; and $f_{2}=\left(C_{\mathrm{h}} C_{\Omega}\right) / V_{0}$. Equation (17) resembles that proposed by Cellino et al. (1994).
Thus, the mass change function is expressed as

$$
m[x(t)]=m_{0}\left\{f_{1}\left[x(t)-x_{\mathrm{e}}\right]^{2}+f_{2}\left[x(t)-x_{\mathrm{e}}\right]+1\right\}
$$

where $m_{0}$ is the initial mass of the debris flow. Furthermore, it is assumed that the erosion process $\left(C_{\mathrm{h}}>0, C_{1}>0\right)$ occurs during the runout phase, starting from the abscissa $x_{\mathrm{e}}$, while the deposition $\left(C_{\mathrm{h}}<0, C_{1}<0\right)$, during the runup phase, or along the second slope if the angle $\alpha$ assumes greater values (even negative) than the critical slope $\alpha_{\mathrm{c}} \in\left[-7^{\circ},-2^{\circ}\right]$, which defines the transition from the area of erosion to that of deposition (Seminara and Tubino 1993); otherwise, the erosion occurs (also along the second slope) until the velocity of the debris flow is not less than $v_{\mathrm{cr}, \mathrm{e}}$ and, at this time, the deposition process occurs until the debris flow arrest.

\section{Equilibrium equation}

By imposing the equilibrium orthogonally to the sliding surfaces, the resulting force $N_{\text {tot }}\left(=W_{\mathrm{b}} \cos \zeta, \zeta=\theta\right.$ or $\alpha$, Fig. 9) must be balanced by the lithostatic (total) stresses, $\sigma_{\text {lit }}=\rho^{\mathrm{b}} g h(x) \cos \zeta$, coupled to the dispersive pressures, $p_{\text {dis }}$ (eq. (13)):

$$
W_{\mathrm{b}} \cos \zeta=\rho^{\mathrm{b}} g \mathrm{~s}^{\mathrm{b}} \Omega \cos \zeta=\sigma_{\mathrm{lit}} \bar{r}(\dot{x}) \Omega+p_{\mathrm{dis}} r(\dot{x}) \Omega
$$




\section{Pagination not final (cite DOI) / Pagination provisoire (citer le DOI)}

The two functions $r$ and $\bar{r}$ allow a "weighted" balance of the force $N_{\text {tot }}$ according to the lithostatic force and the resultant of the colliding forces statistically acting along the irregular sliding surface:

$$
\begin{aligned}
& r(\dot{x})=\frac{1}{\pi}\left\{\arctan \left[\eta\left(\dot{x}-v_{\mathrm{cr}}\right)\right]-\arctan \left[-\eta\left(\dot{x}+v_{\mathrm{cr}}\right)\right]\right\} \\
& \bar{r}(\dot{x})=1-r(\dot{x})
\end{aligned}
$$

where $\eta$ is a parameter falling in the range [0.005, 0.5], which allows modelling of the shape of $r(\dot{x}) ; v_{\mathrm{cr}}$ is the critical value of the speed for which the regime dominated by the inertial forces becomes a collisional regime. It is assumed $v_{\mathrm{cr}}=\sqrt{\left[\left(\rho^{\mathrm{s}}-\rho_{\mathrm{w}}\right) N_{\mathrm{sav}} b_{\mathrm{s}}^{2} g h_{0}\right] /\left(\rho^{\mathrm{s}} d_{\mathrm{p}}^{2}\right)}$, where $N_{\text {sav }}$ is the Savage number equal to 0.1 (Iverson 1997), and $b_{\mathrm{s}}$ is the average shear layer thickness equal to $\sim 15 d_{\mathrm{p}}$ (Straub 1998).

Equilibrium eq. (19) allows determination of the thickness of the block (if a linear change of velocity along $y$ is assumed, $p_{\text {dis }} \sim \dot{x}^{2}$ is obtained)

$$
s^{\mathrm{b}}(\dot{x})=\bar{r}(\dot{x}) h(x)+r(\dot{x}) Q_{1} \lambda^{2} \dot{x}^{2}
$$

where $Q_{1}=a_{\mathrm{i}} \rho^{\mathrm{s}} d_{\mathrm{p}}^{2} \cos \phi /\left(\rho^{\mathrm{b}} g \cos \zeta\right)$.

The sum of the masses of the shear layer $\left(\mathrm{m}^{\mathrm{s}}\right)$ and the overlying block $\left(m^{b}\right)$ equals the total sliding mass, $m$,

$$
m(x)=m^{\mathrm{b}}(x)+m^{\mathrm{s}}(x)=\rho^{\mathrm{b}} s^{\mathrm{b}} \Omega+\rho^{\mathrm{s}} s^{\mathrm{s}} \Omega
$$

where $\rho^{\mathrm{s}}$ and $\rho^{\mathrm{b}}$ simply assume constant values, although it is possible to define their dependence upon the sliding rate (Mills et al. 1999). Thus, the thickness of the shear layer is finally expressed as

$$
s^{\mathrm{s}}(\dot{x})=\frac{m(x)-\rho^{\mathrm{b}} s^{\mathrm{b}}(\dot{x}) \Omega(x)}{\rho^{\mathrm{s}} \Omega(x)}
$$

Power balance equation

The power balance of the sliding mass is

$$
\dot{\mathrm{E}}_{\mathrm{p}}(t)+\dot{\mathrm{E}}_{\mathrm{k}}(t)+\dot{\mathrm{E}}_{\mathrm{r}}(t)+\dot{\mathrm{E}}_{\mathrm{coll}}(t)+\dot{\mathrm{E}}_{\mathrm{gt}}(t)+\dot{\mathrm{E}}_{\mathrm{m}}(t)=0
$$

where $\dot{E}_{\mathrm{p}}$ is the potential power; $\dot{E}_{\mathrm{k}}$ is the kinetic power of the sliding mass; $\dot{E}_{\mathrm{r}}$ is the power related to the energies dissipated along the sliding surface due to friction and dispersive pressures (collisional behaviour); $\dot{E}_{\text {coll }}$ is the power dissipated due to grain collisions; $\dot{E}_{\mathrm{gt}}$ is the power stored as "granular temperature"; and $\dot{\mathrm{E}}_{\mathrm{m}}$ is the power related to the change of the inertial mass due to the increase (erosion) or decrease (deposition) of the granular material.

The potential power is given by

$$
\dot{\mathrm{E}}_{\mathrm{p}}=\dot{\mathrm{E}}_{\mathrm{p}}^{\mathrm{b}}+\dot{\mathrm{E}}_{\mathrm{p}}^{\mathrm{s}}
$$

where $\dot{E}_{\mathrm{p}}^{\mathrm{b}}$ is the potential power of the block

$$
\begin{aligned}
& \dot{E}_{\mathrm{p}}^{\mathrm{b}}=\frac{\mathrm{d}}{\mathrm{d} t}\left\langle m^{\mathrm{b}}(t) g\left\{[L-x(t)] \sin \theta+\left[s^{\mathrm{s}}(t)+\frac{s^{\mathrm{b}}(t)}{2}\right] \cos \theta\right\}\right\rangle \\
& \dot{E}_{\mathrm{p}}^{\mathrm{b}}=\frac{\mathrm{d}}{\mathrm{d} t}\left\langle m^{\mathrm{b}}(t) g\left\{\left[x(t)+\frac{l}{2}\right] \sin \alpha+\left[s^{\mathrm{s}}(t)+\frac{s^{\mathrm{b}}(t)}{2}\right] \cos \alpha\right\}\right\rangle
\end{aligned}
$$

for the first slope (eq. (27)) and the second slope (eq. (28)); $\dot{E}_{\mathrm{p}}^{\mathrm{s}}$, the potential power of the shear layer

$$
\begin{aligned}
& \dot{E}_{\mathrm{p}}^{\mathrm{s}}=\frac{\mathrm{d}}{\mathrm{d} t}\left\langle m^{\mathrm{s}}(t) g\left\{[L-x(t)] \sin \theta+\left[\frac{s^{\mathrm{s}}(t)}{2}\right] \cos \theta\right\}\right\rangle \\
& \dot{E}_{\mathrm{p}}^{\mathrm{s}}=\frac{\mathrm{d}}{\mathrm{d} t}\left\langle m^{\mathrm{s}}(t) g\left\{\left[x(t)+\frac{l}{2}\right] \sin \alpha+\left[\frac{s^{\mathrm{s}}(t)}{2}\right] \cos \alpha\right\}\right\rangle
\end{aligned}
$$

The kinetic power is

$$
\dot{\mathrm{E}}_{\mathrm{k}}=\dot{\mathrm{E}}_{\mathrm{k}}^{\mathrm{b}}+\dot{\mathrm{E}}_{\mathrm{k}}^{\mathrm{s}}
$$

being

$$
\begin{aligned}
& \dot{E}_{\mathrm{k}}^{\mathrm{b}}=\frac{1}{2} \rho^{\mathrm{b}} \Omega\left(\dot{s}^{\mathrm{b}} \dot{x}^{2}+2 s^{\mathrm{b}} \dot{x} \ddot{x}\right) \\
& \dot{E}_{\mathrm{k}}^{\mathrm{s}}=\frac{1}{2} \rho^{\mathrm{s}} \Omega\left(\dot{s}^{\mathrm{s}} \dot{x}^{2}+2 s^{\mathrm{s}} \dot{x} \ddot{x}\right)
\end{aligned}
$$

Ogawa (1978) noted that the energy stored in the grain-inertial regime $\left(E_{g t}\right)$ is proportional to the granular temperature $\left(E_{g t} \sim T_{g}\right)$; several authors showed that granular temperature is proportional to the mean grain velocity and that it occurs along a thin layer in proximity of the sliding surface (shear layer). Experimental analyses (Armanini 2010) revealed the following relation:

$$
\mathrm{T}_{\mathrm{g}}=\frac{1}{15(1-e)}\left[1+\frac{\pi}{12}\left(1+\frac{5}{8 \nu_{\mathrm{s}} g_{0}}\right)^{2}\right]\left(d_{\mathrm{p}} \frac{\mathrm{d} u}{\mathrm{~d} y}\right)^{2}
$$

where $e$ is the restitution coefficient of the granular phase $\in[0,1]$ (if $e$ assumes the value 1 (elastic collisions), $T_{\mathrm{g}}$ assumes infinite value); $u(y)$ is the grain velocity profile; $d_{\mathrm{p}}$ is the average grain diameter; $\nu_{\mathrm{s}}$ is the solid fraction, which may assume the maximum value, $\nu_{\max } ; g_{0}$ is the radial distribution function, expressed as (Savage and Lun 1988)

$$
g_{0}=\left(1-\frac{\nu_{s}}{\nu_{\max }}\right)^{-2.5 \nu_{\max }}
$$

Furthermore, the following dimensionless parameter was introduced (Savage and Jeffrey 1981):

$$
\omega=\frac{d_{\mathrm{p}} \dot{x}}{s^{\mathrm{s}} \sqrt{\mathrm{T}_{\mathrm{g}}}}
$$

which depends on the restitution coefficient, $e$, and the solid fraction, $\nu_{\mathrm{s}}$ (Zhang and Foda 1999). Recalling eq. (34), it is possible to define

$$
\omega=\sqrt{\frac{15(1-e)}{1+(\pi / 12)\left[1+\left(5 / 8 \nu_{\mathrm{s}} g_{0}\right)^{2}\right]}}
$$

Thus, $T_{g}$ can be rewritten as

(38) $\quad T_{\mathrm{g}}=\frac{d_{\mathrm{p}}^{2} \dot{x}^{2}}{s_{\mathrm{s}}^{2} \omega^{2}}$

$E_{\text {gt }}$ can be considered as kinetic energy related to the grains' velocity fluctuations with respect to their mean velocity

$$
E_{\mathrm{gt}}=\frac{1}{2} m_{\mathrm{g}}^{\mathrm{s}}\left\langle\delta v^{2}\right\rangle
$$




\section{Pagination not final (cite DOI) / Pagination provisoire (citer le DOI)}

where $m_{\mathrm{g}}^{\mathrm{s}}$ is the grains' mass in the shear layer, depending on the solid fraction, $\nu_{\mathrm{s}}$, defined as the ratio between the grains' volume and the total volume

$$
m_{\mathrm{g}}^{\mathrm{s}}=\nu_{\mathrm{s}} \rho_{\mathrm{s}} \Omega \mathrm{s}^{\mathrm{s}}
$$

Thus, if $T_{g}=(1 / 3)\left\langle\delta v^{2}\right\rangle, E_{g t}$ assumes the following expression:

$$
E_{\mathrm{gt}}=\frac{3}{2} \nu_{\mathrm{s}} \rho_{\mathrm{s}} \Omega \frac{d_{\mathrm{p}}^{2} x^{2}}{s^{\mathrm{s}} \omega^{2}}
$$

The power $\dot{E}_{\mathrm{gt}}$ has been expressed as follows:

$$
\dot{E}_{\mathrm{gt}}=\frac{3}{2} \frac{\nu_{\mathrm{s}} \rho_{\mathrm{s}} \Omega d_{\mathrm{p}}^{2}}{\omega^{2}} \frac{\left(2 \dot{x} \ddot{x} s^{\mathrm{s}}-\dot{s}^{\mathrm{s}} \dot{x}^{2}\right)}{s_{\mathrm{s}}^{2}}
$$

where $\rho_{\mathrm{s}}$ is the density of the shear layer.

Jenkins and Savage (1983) proposed the following relationship for the power of the energy $\left(\dot{\gamma}_{\text {coll }}\right)$ lost in granular inelastic collisions, within the shear layer, for unit of volume

$$
\dot{\gamma}_{\text {coll }}=24(1-e) \frac{\nu_{\mathrm{s}}^{2} \mathrm{~g}_{0}}{d_{\mathrm{p}} \pi^{0.5}} \rho_{\mathrm{s}} T_{\mathrm{g}}^{3 / 2}
$$

which shows that $\dot{\gamma}_{\text {coll }}$ is related to the granular temperature: $\dot{\gamma}_{\text {coll }} \sim$ $\mathrm{T}_{\mathrm{g}}^{3 / 2} \sim \dot{x}^{3}$.

According to previous equations

$$
\dot{E}_{\text {coll }}=M \dot{x}^{3}
$$

where

$$
M=24(1-e) \frac{\nu_{\mathrm{s}}^{2} g_{0} \rho_{\mathrm{s}} \Omega d_{\mathrm{p}}^{2}}{\omega^{3} s_{\mathrm{s}}^{2} \pi^{0.5}}
$$

$\dot{E}_{\mathrm{r}}$ is a function of the weight $W_{\mathrm{b}}$ of the sliding mass and the dynamic friction angle $\varphi_{\mathrm{b}}$ at the base of the granular mass. Dispersive and interstitial pressures reduce the friction power dissipation. A constant value is assigned to the interstitial pressure $p_{\mathrm{w}}$ at the base of the granular mass (Iverson 1997); if isopiezic lines are orthogonal to the motion direction

$$
p_{\mathrm{w}}=\gamma_{\mathrm{w}}\left(h-d_{\mathrm{w}}\right) \cos \theta
$$

where $\gamma_{\mathrm{w}}$ is the specific weight of the water; $d_{\mathrm{w}}=0$ if the mass is saturated; and $d_{\mathrm{w}}=h$ if the mass is dry. To simulate a $p_{\mathrm{w}}$ value greater than the hydrostatic value (Musso et al. 2004), $d_{\mathrm{w}}<0$ must be assigned.

If the different (inertial and frictional) regimes acting at the base of the sustained block are taken into account, the interstitial pressure's resultant may be expressed as follows:

$$
U=p_{\mathrm{w}} \bar{r}(\dot{x}) \Omega
$$

The total shear resistance $T_{\max }$ is obtained by adding the frictional shear resistance $T_{\mathrm{fr}}$, acting along the surface $[1-r(\dot{x})] \Omega$, to the resultant of the shear stresses $T_{\text {disp }}$, acting along the surface $r(\dot{x}) \Omega$, related to the dispersive pressures (Federico and Cesali 2014):

$$
\begin{aligned}
& \mathrm{T}_{\max }=\mathrm{T}_{\mathrm{fr}}+\mathrm{T}_{\text {disp }} \\
& \mathrm{T}_{\mathrm{fr}}=\left\{\rho^{\mathrm{b}} g s^{\mathrm{b}}[\dot{x}(t)] \bar{r}(\dot{x}) \Omega \cos \zeta-U\right\} \tan \varphi_{\mathrm{b}}
\end{aligned}
$$

$$
\mathrm{T}_{\text {disp }}=a_{\mathrm{i}} \rho_{\mathrm{s}} \lambda^{2} d_{\mathrm{p}}^{2} \sin \phi \dot{x}^{2} r(\dot{x}) \Omega
$$

The power related to the energies dissipated along the sliding basal surface follows:

$$
\dot{E}_{\mathrm{r}}=\left[\mathrm{T}_{\mathrm{fr}}(\dot{x})+\mathrm{T}_{\mathrm{disp}}(\dot{x})\right] \dot{x}
$$

The power $\dot{E}_{\mathrm{m}}$ related to the change of mass, by assuming that the speed of eroded or deposited material at the instant of entry or exit is null, can be expressed as follows:

$$
\dot{\mathrm{E}}_{\mathrm{m}}=\frac{\mathrm{d} m(x)}{\mathrm{d} t} \dot{x}^{2}
$$

\section{Results of parametric analyses}

The proposed numerical model depends on several parameters pertaining to the micromechanical behaviour: $e$ (restitution coefficient $\in[0,1]), \nu_{\mathrm{s}}$ (solid fraction within the shear layer), $\omega$ (in granular temperature's expression), $d_{\mathrm{p}}$ (average grain diameter), $\eta$ (in expression (20)). Recalling eq. (37), $\omega$ depends on $e$ and $\nu_{\mathrm{s}}$, as shown in Figs. 10 and 11. It is observed that the parameter $\omega$ becomes constant (Fig. 11) for high values of the solid fraction $\left(\nu_{\mathrm{s}}>0.5\right)$. Zhang and Foda (1999) suggested a value 0.8 for $\omega$ and it is obtained for values of $\nu_{\mathrm{s}}$ too low and (or) of the restitution coefficient $e$ close to 1 . The restitution coefficient cannot assume its maximum value $(=1)$ due to the partially inelastic and dissipative nature of the collisions, typically affecting rapid granular masses. Furthermore, it is observed that $\omega \in(0,3.5)$. Thus, parametric analyses allow the definition of a range of possible values for $\omega$ and $e$, as well as calibration of the model. First of all, we investigate the effect of $\omega$ (and then of $e$ and $\nu_{\mathrm{s}}$ ), $d_{\mathrm{p}}$, and $\eta$ referring to the following remaining parameters: $L=700 \mathrm{~m} ; \theta=20^{\circ} ; \alpha=0^{\circ}$, $\varphi_{\mathrm{b}}=25^{\circ}, l=100 \mathrm{~m} ; \Omega=5000 \mathrm{~m}^{2} ; h=25 \mathrm{~m}$; interstitial pressure resultant $U \neq 0\left(d_{\mathrm{w}}=0\right), C_{\mathrm{h}}=C_{1}=0$ (constant mass). The set of selected values is shown in Table 1 (the parameter $\omega$ is obtained through eq. (37), by assigning arbitrary values to $e$ and $\nu_{\mathrm{s}}$ ).

\section{Effect of parameter $\omega$}

Results in terms of the (runout and runup) total distance traveled $(x)$, block and shear layer thicknesses $\left(s^{\mathrm{b}}, s^{\mathrm{s}}\right)$, collisional energy $\left(E_{\text {coll }}\right)$, and energy related to granular temperature $\left(E_{\mathrm{gt}}\right)$, for different values of the parameter $\omega$ are shown in Figs. 12 and 13.

\section{Effect of average grain diameter $d_{p}$}

Results are shown (Figs. 14 and 15) in terms of total runout length of the center of the mass, block and shear layer thicknesses, collisional energy, and energy related to granular temperature, according to $d_{\mathrm{p}}$.

If the average diameter $d_{\mathrm{p}}$ increases, the thickness of the shear layer becomes slightly smaller; as a result, the sum of $s^{\mathrm{b}}$ and $s^{\mathrm{s}}$ is equal to the height $h$ of the debris flow (constant value), and the thickness of the sustained block correspondingly increases. $d_{\mathrm{p}}$ also plays a key role in $E_{\mathrm{gt}}$ end $E_{\text {coll }}$; if $d_{\mathrm{p}}$ increases, the collisional energy $\left(E_{\text {coll }}\right)$ and the energy associated with granular temperature $\left(E_{\mathrm{gt}}\right)$ greatly increase, according to eqs. (42) and (44).

Consequently, the distance traveled and the maximum speed decrease with increasing $d_{\mathrm{p}}$, due to the energy dissipation related to grain collisions, which are more affected by higher diameter.

In Figs. 16 and 17 the other involved energies $\left(E_{\mathrm{p}}, E_{\mathrm{k}}, E_{\mathrm{r}}\right)$, referring to $d_{\mathrm{p}}$ equal to 0.05 and $0.15 \mathrm{~m}$, are shown. If the mass of the debris flow is assumed constant, the energy balance, corresponding to the abscissa $x_{*}$, is given by following expression:

$$
E_{\mathrm{p}, 0}-E_{\mathrm{p}}\left(x_{*}\right)=E_{\mathrm{k}}\left(x_{*}\right)+E_{\mathrm{gt}}\left(x_{*}\right)+E_{\text {coll }}\left(x_{*}\right)+E_{\mathrm{r}}\left(x_{*}\right)
$$

where $E_{\mathrm{p}, 0}$ is the initial potential energy. 
Fig. 10. Parameter $\omega$ versus coefficient of restitution $e$, for different values of $\nu_{\mathrm{s}}$.

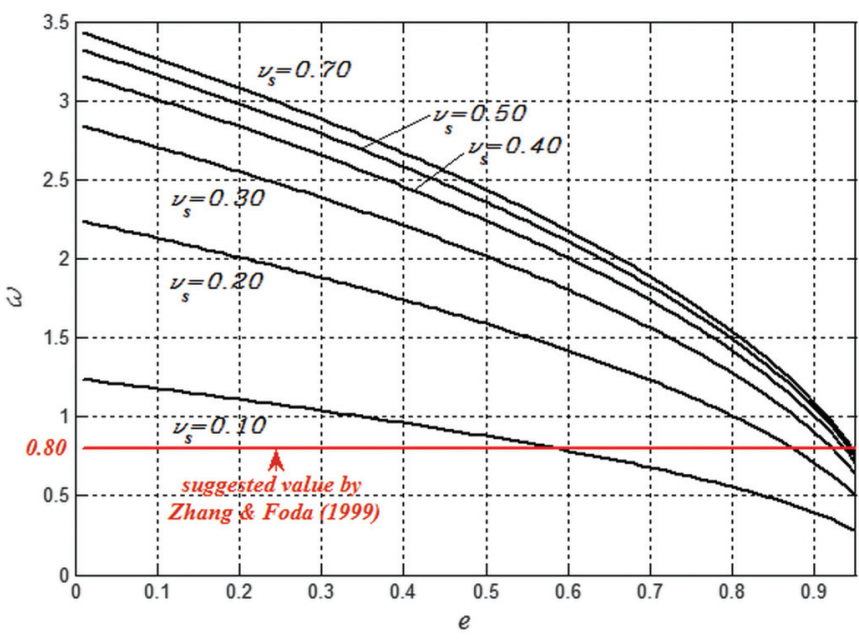

Fig. 11. Parameter $\omega$ versus solid fraction $\nu_{\mathrm{s}}$, for different values of $e$.

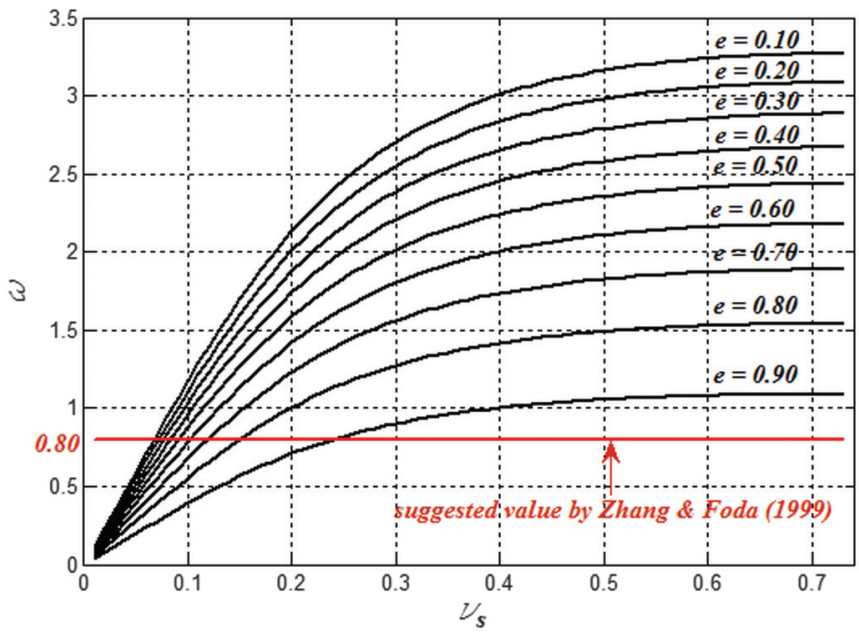

Table 1. Assigned values to $\omega, e, \nu_{\mathrm{s}}, d_{\mathrm{p}}$, and $\eta$.

\begin{tabular}{|c|c|c|}
\hline$\omega\left(e ; \nu_{\mathrm{s}}\right)$ & $d_{\mathrm{p}}(\mathrm{m})$ & $\eta$ \\
\hline \multicolumn{3}{|c|}{ a) $d_{\mathrm{p}}=0.1 \mathrm{~m} ; \eta=0.005$} \\
\hline $3.02(0.2 ; 0.55)$ & - & - \\
\hline $2.58(0.4 ; 0.50)$ & - & - \\
\hline $1.46(0.8 ; 0.45)$ & - & - \\
\hline \multicolumn{3}{|c|}{ b) $\omega=2\left(e=0.6 ; \nu_{\mathrm{s}}=0.4\right) ; \eta=0.005$} \\
\hline - & 0.05 & - \\
\hline - & 0.1 & - \\
\hline - & 0.15 & - \\
\hline \multicolumn{3}{|c|}{ c) $\omega=1.5\left(e=0.8 ; \nu_{\mathrm{s}}=0.5\right) ; d_{\mathrm{p}}=0.05 \mathrm{~m}$} \\
\hline - & - & 0.005 \\
\hline - & - & 0.01 \\
\hline - & - & 0.02 \\
\hline - & - & 0.05 \\
\hline - & - & 0.145 \\
\hline - & - & 0.300 \\
\hline - & - & 0.500 \\
\hline
\end{tabular}

Fig. 12. Curves $\left[s^{\mathrm{b}}, x(t)\right] ;\left[s^{\mathrm{s}}, x(t)\right] ;[v, x(t)]$ for different values of $\omega$.

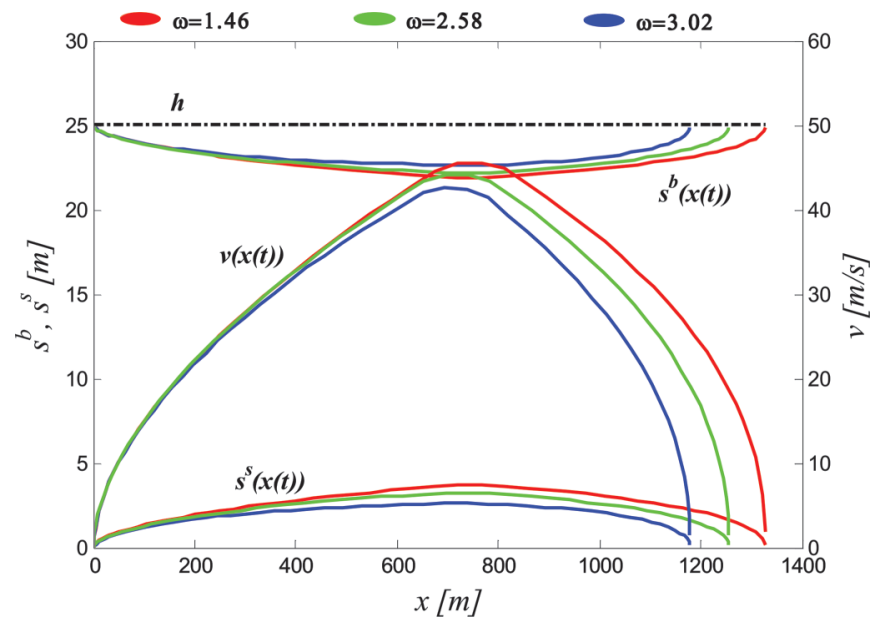

Fig. 13. Collisional energy $\left(E_{\text {coll }}\right)$ and energy related to $T_{g}\left(E_{g t}\right)$ for assigned values of $\omega$.

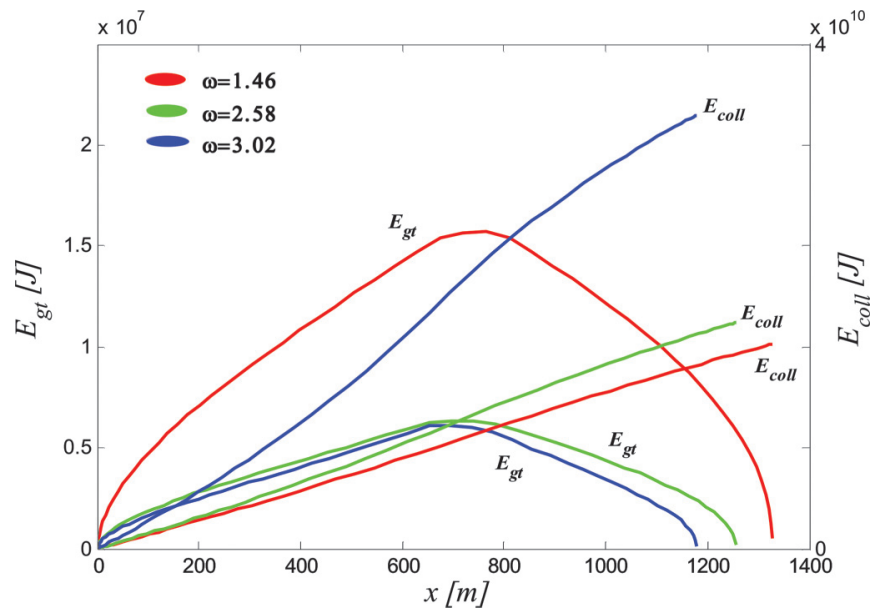

Fig. 14. Curves $\left[s^{b}, x(t)\right] ;\left[s^{s}, x(t)\right] ;[v, x(t)]$ for assigned values of $d_{\mathrm{p}}$.

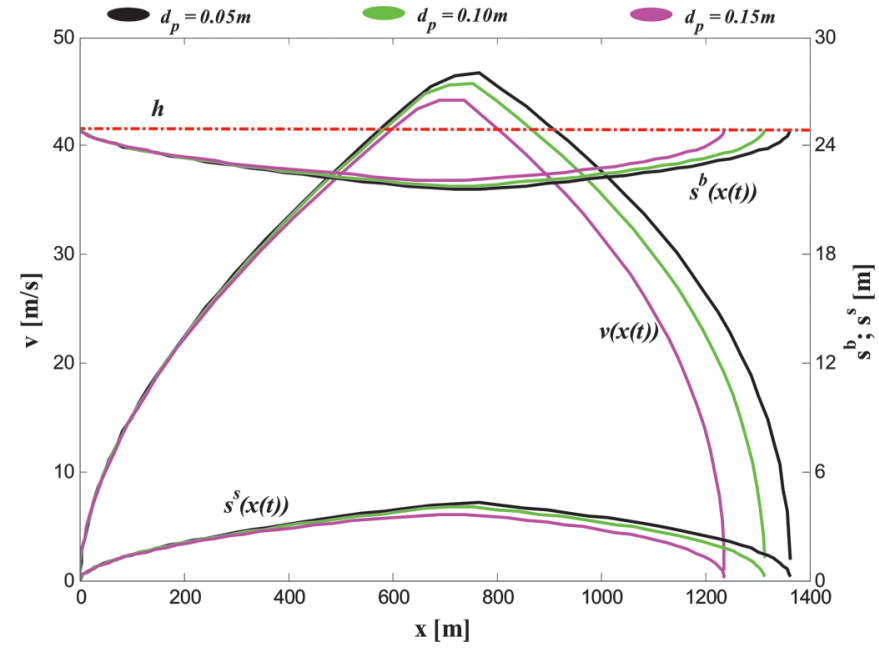

For $d_{\mathrm{p}}=0.15 \mathrm{~m}$ (Fig. 16),

$$
\begin{aligned}
E_{\mathrm{p}, 0}-E_{\mathrm{p}}\left(x_{*}\right)=6.2 \times 10^{11} \mathrm{~J}-1.6 \times 10^{11} \mathrm{~J}=4.6 \times 10^{11} \mathrm{~J} \\
E_{\mathrm{k}}\left(x_{*}\right)+E_{\mathrm{gt}}\left(x_{*}\right)+E_{\text {coll }}\left(x_{*}\right)+E_{\mathrm{r}}\left(x_{*}\right)=2.0 \times 10^{11} \mathrm{~J}+1.3 \times 10^{7} \mathrm{~J} \\
+5.6 \times 10^{9} \mathrm{~J}+2.5 \times 10^{11} \mathrm{~J} \sim 4.6 \times 10^{11} \mathrm{~J}
\end{aligned}
$$


Fig. 15. Collisional energy $\left(E_{\text {coll }}\right)$ and energy related to $T_{g}\left(E_{g t}\right)$ for assigned values of $d_{\mathrm{p}}$.

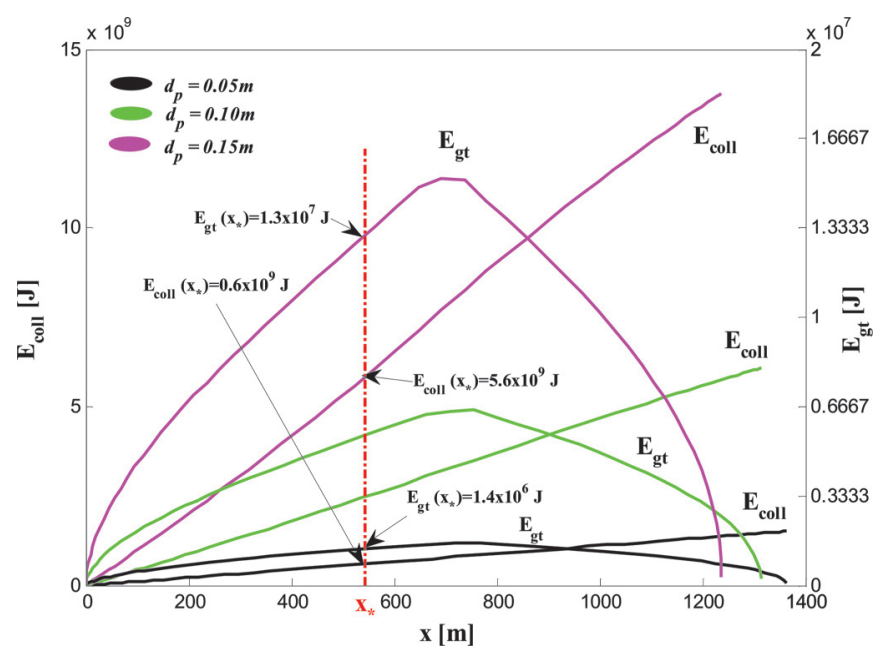

Fig. 16. Potential energy $\left(E_{\mathrm{p}}\right)$, kinetic energy $\left(E_{\mathrm{k}}\right)$, and energy dissipated along the basal surface $\left(E_{\mathrm{r}}\right)$ for $d_{\mathrm{p}}=0.15 \mathrm{~m}$.

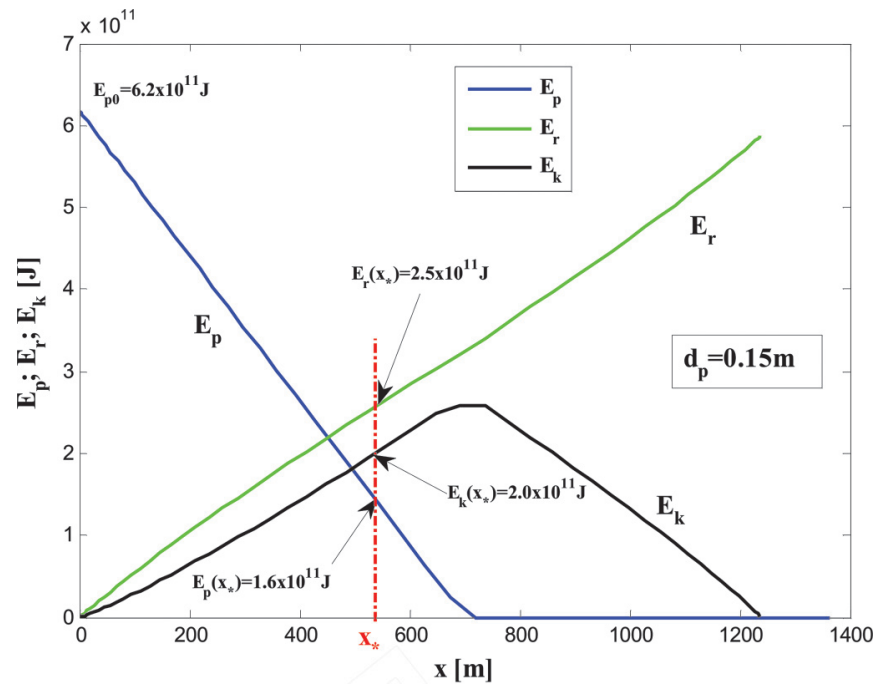

Fig. 17. Potential energy $\left(E_{\mathrm{p}}\right)$, kinetic energy $\left(E_{\mathrm{k}}\right)$, and energy dissipated along the basal surface $\left(E_{\mathrm{r}}\right)$ for $d_{\mathrm{p}}=0.05 \mathrm{~m}$.

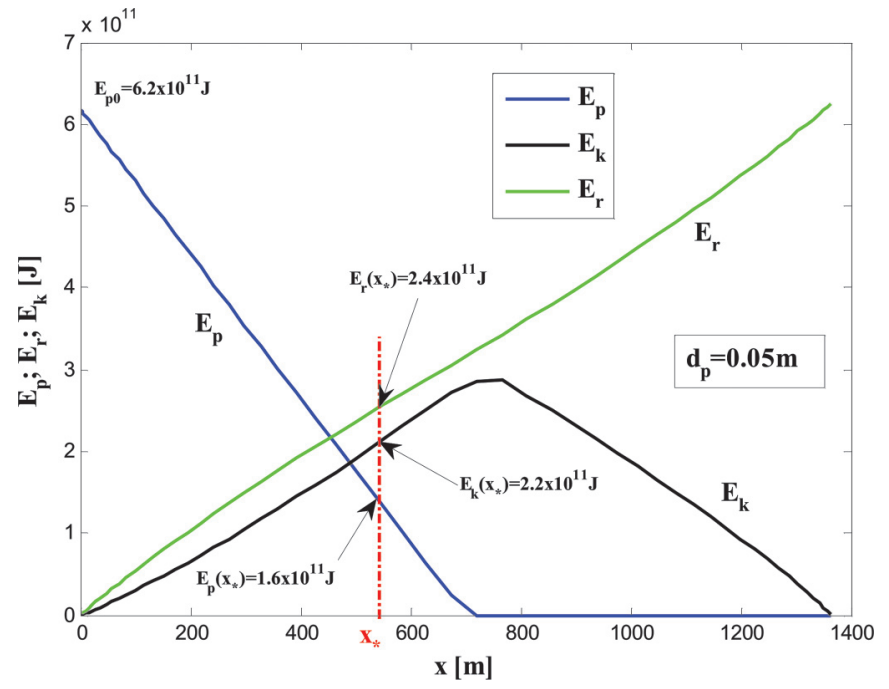

and for $d_{\mathrm{p}}=0.05 \mathrm{~m}$ (Fig. 17),

$$
\begin{array}{r}
E_{\mathrm{p}, 0}-E_{\mathrm{p}}\left(x_{*}\right)=6.2 \times 10^{11} \mathrm{~J}-1.6 \times 10^{11} \mathrm{~J}=4.6 \times 10^{11} \mathrm{~J} \\
E_{\mathrm{k}}\left(x_{*}\right)+E_{\mathrm{gt}}\left(x_{*}\right)+E_{\text {coll }}\left(x_{*}\right)+E_{r}\left(x_{*}\right)=2.2 \times 10^{11} \mathrm{~J}+1.4 \times 10^{6} \mathrm{~J} \\
+6.0 \times 10^{8} \mathrm{~J}+2.4 \times 10^{11} \mathrm{~J} \sim 4.6 \times 10^{11} \mathrm{~J}
\end{array}
$$

By increasing the average grain diameter, $d_{\mathrm{p}}$, rather than increasing, like $E_{\mathrm{gt}}$ and $E_{\text {coll }}$, the kinetic energy, $E_{\mathrm{k}}$, decreases (because of the reduction of the rate of the mass), while the energy dissipated along the basal surface, $E_{r}$, increases (because of the increase of the resultant $T_{\text {disp }}$, related to the dispersive pressures).

\section{Effect of parameter $\eta$}

$\eta$ allows modelling of the shape of the splitting rule function $r(\dot{x})$. Results, in terms of the total runout length and rate of sliding, are shown in Fig. 18.

The maximum rate $\left(v_{\max }\right)$ and the total distance $\left(x_{\max }\right)$ traveled by the center of mass of the debris flow greatly depend on $\eta$ (Fig. 18): $x_{\max }$ and $v_{\max }$ initially increase, if $\eta$ increases $(\eta \leq 0.05)$ and decrease if $\eta$ assumes high values $(\geq 0.145)$.

The influence of $\eta$ and the parameter $v_{\mathrm{cr}}$ on the functions $r(\dot{x})$ and $\bar{r}(\dot{x})$ is also investigated (Figs. 19, 20, and 21).

The parameter $\eta$ modulates the local transition between the inertial and collisional regimes: for high values of $\eta(\eta \geq 0.5)$ the transition becomes more rough and the curves become indistinguishable (Fig. 19). For small values of $\eta(\eta=0.005)$, by changing the critical rate, $v_{\mathrm{cr}}$, the trends tend to a single curve (Fig. 20): if $\eta$ assumes values higher than 0.005 , the curves become easily distinguishable.

If the critical rate $\left(v_{\mathrm{cr}}\right)$ increases, with fixed parameter $\eta$, the transition between the two regimes occurs at higher values of the speed (Fig. 21).

Thus, it is possible to define the range of values of the parameter $\eta$ for the analysis of sliding granular masses through the proposed model: $[0.005,0.5]$.

The influence of the volume $V$ of the sliding mass on the total runout length is further investigated, for the assigned parameters: $L=1000 \mathrm{~m}, \theta=30^{\circ}, \alpha=10^{\circ}, l=100 \mathrm{~m}, \varphi_{\mathrm{b}}=26^{\circ}, \eta=0.005, d_{\mathrm{p}}=0.1 \mathrm{~m}, e=$ 0.7, $\omega=1.85\left(\nu_{\mathrm{s}}=0.55\right), d_{\mathrm{w}}=0$ (saturated flow), and $C_{\mathrm{h}}=C_{1}=0$ (constant mass).

It is observed that the solution depends on the granular volume $V$ : for small values of $V$, the runout length (of the mass center) increases appreciably with $V$; for large values of $V$, the travelled distance progressively becomes almost independent of the sliding mass volume (Fig. 22).

The best fitting of the results obtained through the proposed model is expressed through the functional relationship: $x=$ $663 V^{0.085}$, resembling eq. (9) proposed by Corominas.

Finally, the influence of the mass changes on the total runout length traveled by a debris flow is investigated. The following geometrical and micromechanical parameters are selected: $L=$ $1000 \mathrm{~m}, \theta=25^{\circ}, \alpha=0^{\circ}, \varphi_{\mathrm{b}}=20^{\circ}, l_{0}=100 \mathrm{~m}, \Omega_{0}=1000 \mathrm{~m}^{2}, h_{0}=20 \mathrm{~m}$, $V_{0}=2 \cdot 10^{4} \mathrm{~m}^{3}, v_{\mathrm{cr}, \mathrm{e}}=5 \mathrm{~m} / \mathrm{s}, d_{\mathrm{p}}=0.1 \mathrm{~m}, d_{\mathrm{w}}=0(U \neq 0), e=0.6, \nu_{\mathrm{s}}=0.5$, and $\eta=0.005$. The results are shown in Fig. 23. The total runout length and the rate of the mass depend on the laws assumed to describe the progressive geometry (length $l$, height $h$, basal area $\Omega$ ) changes: if the volume $V$ increases, the total runout length decreases, especially if $h$ also increases; while, if $V$ increases, but $h$ decreases, the rate slightly increases. The reduction of the runout length is due to change of inertia following the loss or acquisition of mass during the sliding (Cannon and Savage 1988; Hungr 1995; Egashira et al. 2001; Iverson 2012). Parametric analyses show that the numerical solution of the proposed model is greatly affected by numerous unconventional (e.g., $\omega$ and $\eta$ ) parameters. Thus, the adopted energy-based approach may not appear suitably applicable compared with well-recognized debris flow mobility analysis 
Fig. 18. Curves $[v, x(t)]$ for assigned values of $\eta$.

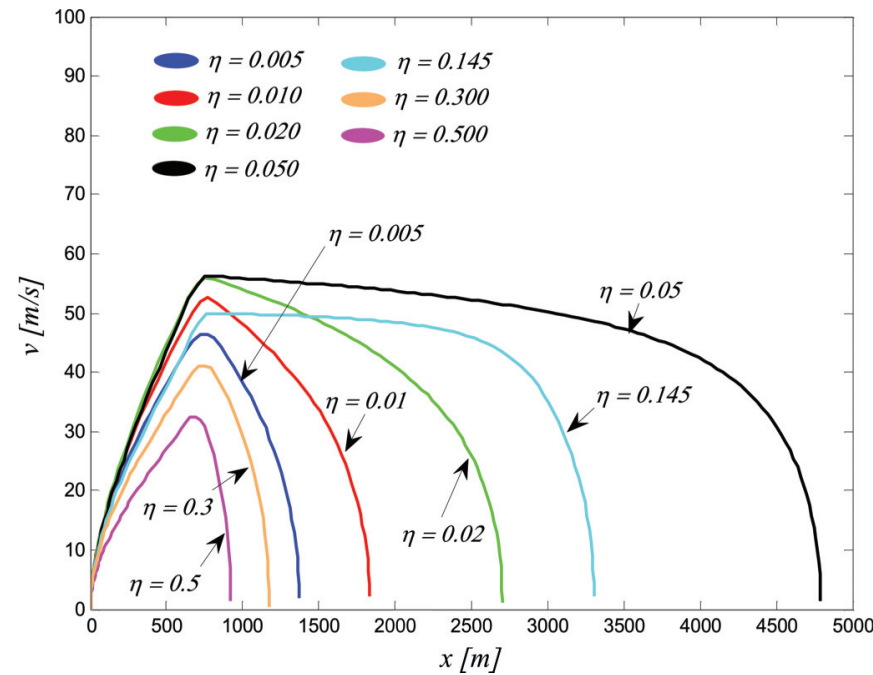

Fig. 19. Functions $r(\dot{x})$ and $\bar{r}(\dot{x})$ versus velocity, for assigned values of $\eta$.

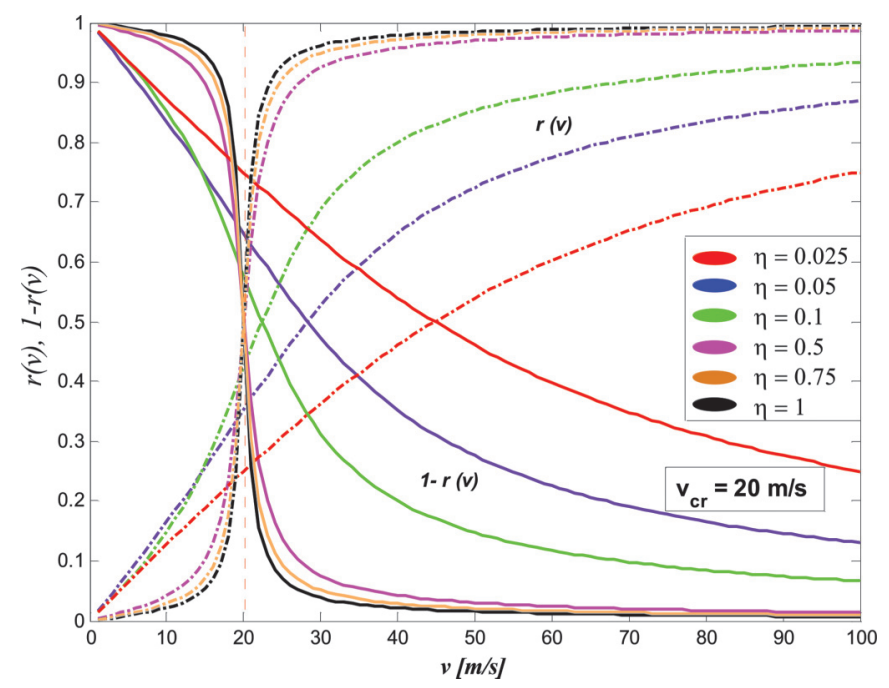

Fig. 20. Function $r(\dot{x})$ for assigned values of $\eta$ and $v_{\text {crit }}$.

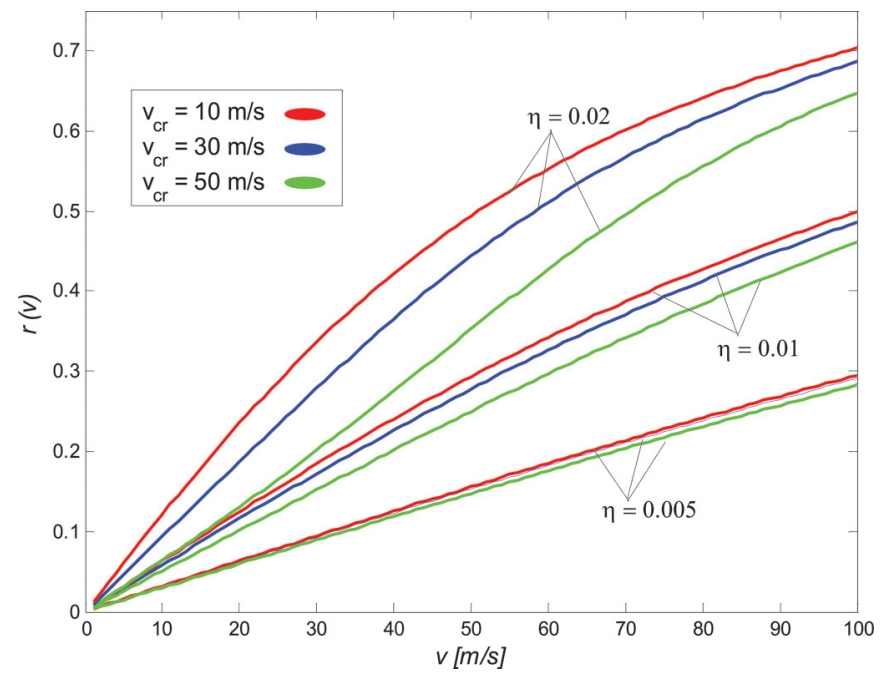

Fig. 21. Functions $r(\dot{x})$ and $\bar{r}(\dot{x})$ for assigned values of $v_{\text {crit }}$.

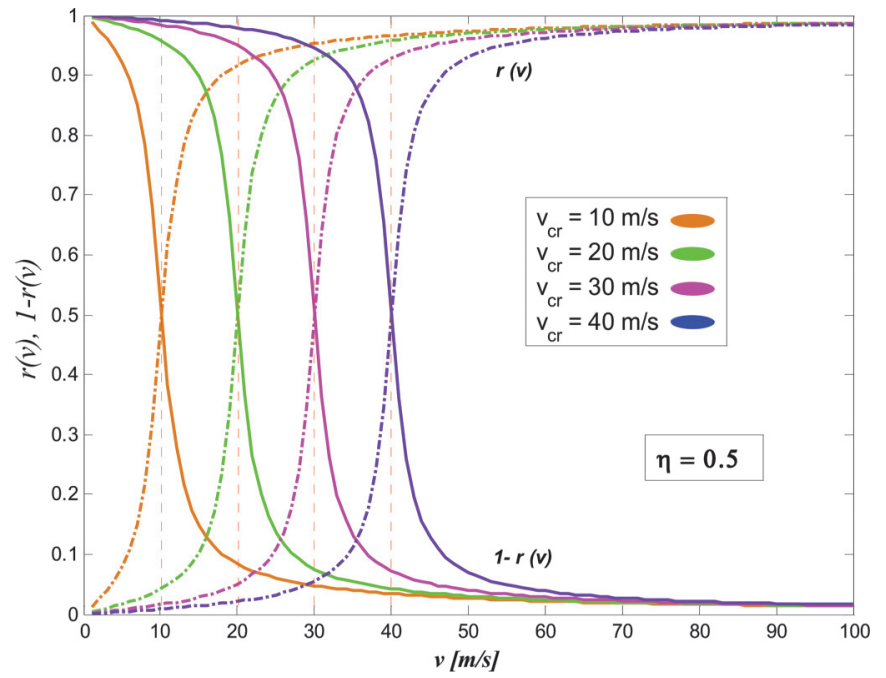

Fig. 22. Total runout length $x_{\max }$ (of mass center) versus volume $V$.

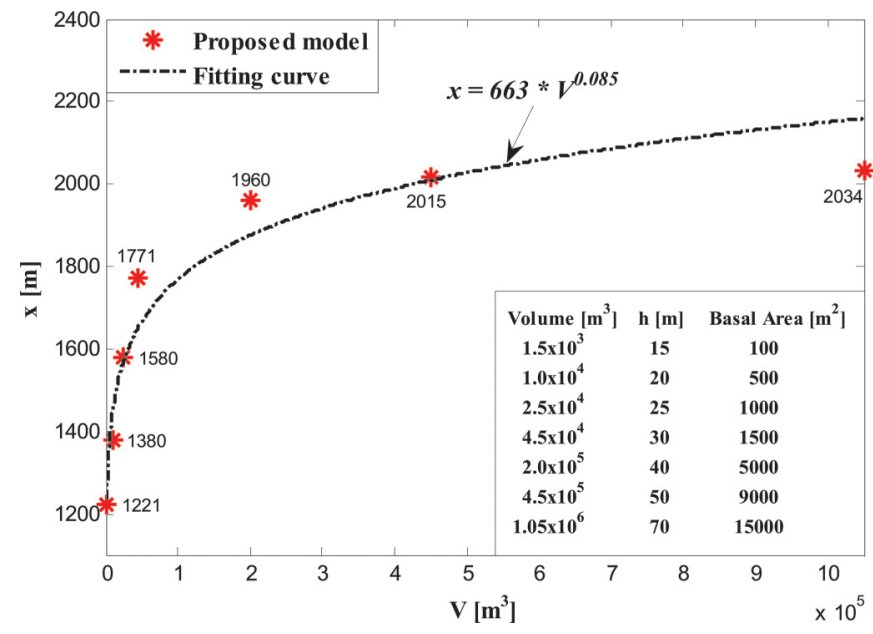

Fig. 23. Total runout length and rate by changing debris flow volume or mass.

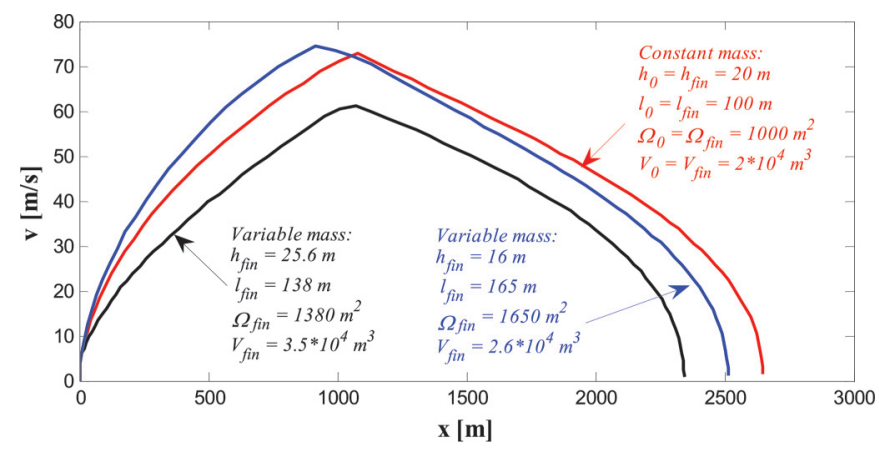

software (e.g., FLO 2D, RAMMS). Although these numerical codes allow simulation of the debris flow deposition, velocity evolution, and area of inundation, they assume traditional rheological laws and neglect the aspects mainly characterizing a granular debris flow, such as the grain inelastic collisions and the development of granular temperature within the shear layer, growing at the base of a sliding granular mass. The code FLO $2 \mathrm{D}$ runs according to the quadratic rheological model proposed by O'Brien and Julien (1988), depending on five parameters (not easy to define) that must 
be assigned, including the slope of channels, concentration by volume, Bingham yield stress, viscosity, and density of sediments, the RAMMS model uses the Voellmy friction approach (originally developed to predict the runout length of snow avalanches), which splits the total friction into a dry Coulomb friction and a turbulent or viscous term, depending on a parameter, which must be appropriately selected.

\section{Favourable conditions for debris flow generation}

The proposed model allows examination of the motion of sliding, high-speed, granular masses, by taking into account

- the global variables, such as the total runout length and the rate of the mass center (macroscopic aspects); and

- the effects of grains collisions, granular temperature, and dispersive pressures, related to the granular nature of the sliding mass (microscopic aspects).

These two complementary aspects depend on several, often coupled, factors (such as $p_{\mathrm{w}}, d_{\mathrm{p}}, \varphi_{\mathrm{b}}, e, \nu_{\mathrm{s}}$ ).

Because the adopted model includes macro and micro, physical and mechanical parameters, describing the current granular behaviour of a debris flow, it appears to be more appropriate than other one-dimensional models (based on the Voellmy rheology or on the equations governing the dynamics of a liquid-solid mixture).

The applicability of an empirical relationship or a dynamic model must be founded on the assumption that the sliding granular mass, along the motion, becomes a debris flow.

The proposed energy-based model, through the evaluation of the role played by some main parameters influencing the mechanical behaviour (frictional-collisional regime) of a debris flow, may highlight the conditions for which a granular mass sliding along an inclined surface evolves as a debris flow.

To this purpose, the coupled role of the parameters $d_{\mathrm{p}}$ (representative grain diameter), $V$ (volume), and $H$ (difference in elevation) is investigated. The remaining parameters $\alpha=0^{\circ}, \varphi_{\mathrm{b}}=15^{\circ}, l=$ $200 \mathrm{~m}$; interstitial pressure resultant $U \neq 0\left(d_{\mathrm{w}}=0\right), C_{\mathrm{h}}=C_{1}=0$ (constant mass), $e=0.8 ; \nu_{\mathrm{s}}=0.57(\omega=1.5)$, and $\eta=0.005$ are selected. It is noted that the total runout length and the rate become almost independent of grain diameter if $d_{\mathrm{p}}$ assumes small values, typically referred to a sand or silt (Fig. 24). For $d_{\mathrm{p}} \leq 2 \times 10^{-3} \mathrm{~m}$, the solution tends to one computed through the Mohr-Coulomb model (Fig. 25).

Figures 26 and 27 show the results in term of energy related to $T_{g}\left(E_{g t}\right)$, collisional energy $\left(E_{\text {coll }}\right)$, and energies dissipated along the sliding surface due to friction, $E_{\mathrm{fr}}$, and dispersive pressures, $E_{\text {disp }}$ $\left(E_{\mathrm{r}}=E_{\mathrm{fr}}+E_{\text {disp }}\right)$.

The energy dissipated along the sliding surface due to friction $\left(E_{\mathrm{fr}}\right)$ assumes greater values than the other energies, for small values of $d_{\mathrm{p}}$, and it is almost independent of $d_{\mathrm{p}}$ (Figs. 26 and 27). If $d_{\mathrm{p}}=0.2 \times 10^{-3} \mathrm{~m}$ is assigned, the energies $E_{\mathrm{gt}}$ and $E_{\text {coll }}$ (Fig. 27a) and the energy dissipated along the sliding surface due to dispersive pressures $E_{\text {disp }}$ (Fig. $27 b$ ) assume very low values: very small $E_{g t}$, $E_{\text {coll }}$, and $E_{\text {disp }}$ denote that the mechanical behaviour of the sliding granular mass is essentially affected by a frictional regime; the collisional regime is negligible.

Possible consolidation phenomena, occurring along the motion of fine-grained materials, are not taken into account. Several models, available in the literature (Hutchinson 1986), allow better description of the mechanical behaviour of fine-grained materials sliding along a slope.

Furthermore, the effect of $H$ (fixed $V$ and $d_{\mathrm{p}}$ ) and $V$ (fixed $H$ and $d_{\mathrm{p}}$ ) is investigated. It is observed that, if $H$ (Figs. 28 and 29) and $V$ (Figs. 30 and 31) decrease, the total runout length, the rate, and the thickness of the shear layer, within which granular temperature and grain collisions occur, greatly decrease. The obtained results show that the collisional regime will not develop in all sliding granular masses along a slope and it depends on some parameters
Fig. 24. Rate versus total runout length for different values of $d_{\mathrm{p}}$, fixed $V$ and $H$.

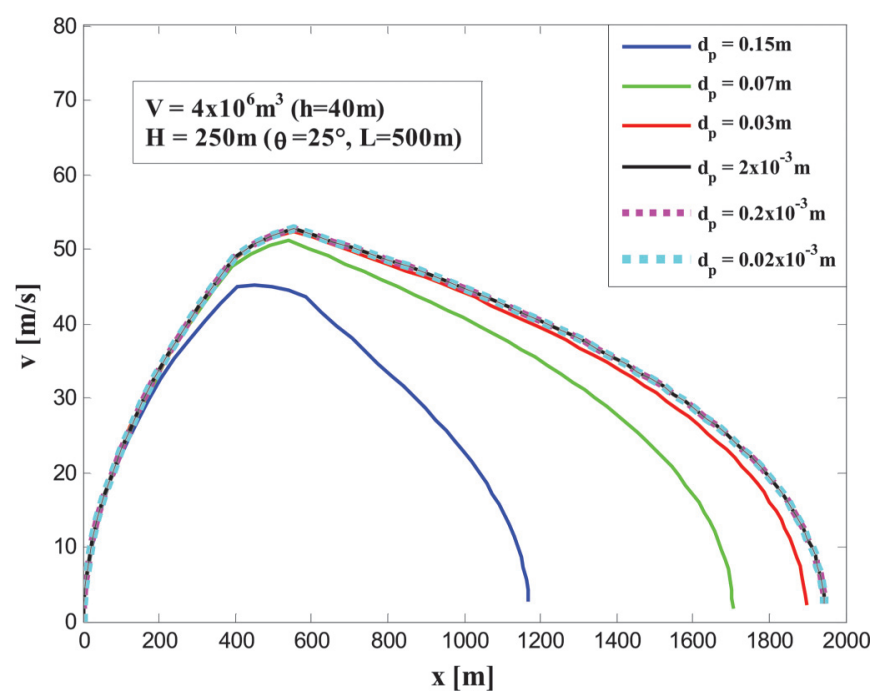

Fig. 25. Rate versus total runout length computed through MohrCoulomb model, fixed $V$ and $H$.

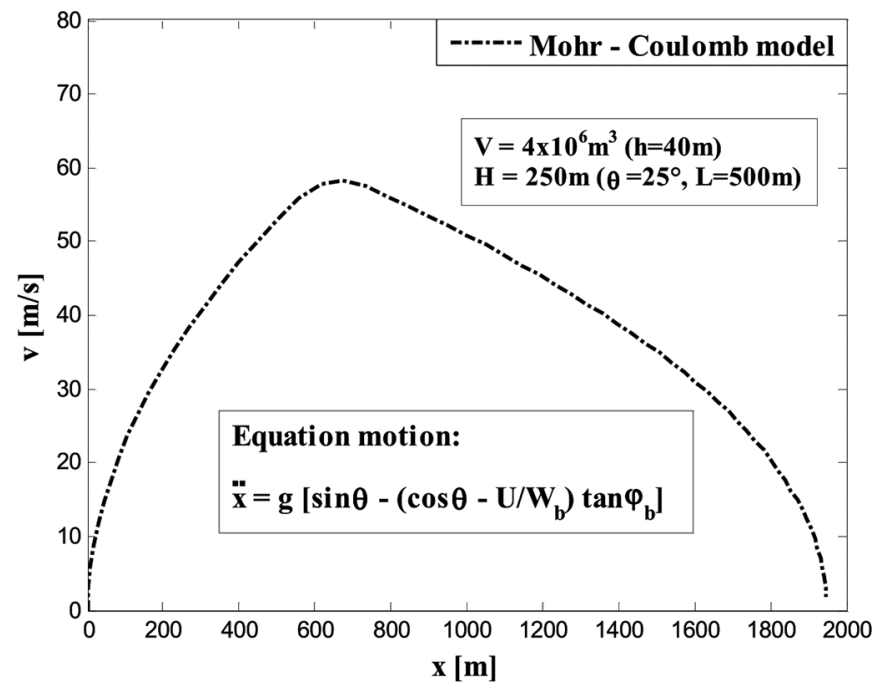

such as $d_{\mathrm{p}}, H$, and $V$ : for small values of these parameters, the collisional regime is almost absent and the mechanical behaviour of the granular mass is mainly affected by the frictional one.

Parametric analyses were carried out to define the values of $V, H$, and $d_{\mathrm{p}}$, for which the collisional regime begins to develop and affect the motion of a sliding granular mass along a slope. To this purpose, the following parameters are introduced:

$$
\begin{aligned}
& r_{\text {part }}^{\mathrm{d}}=\frac{E_{\mathrm{part}}^{\mathrm{d}}}{E_{\mathrm{p}, 0}} \\
& r_{\mathrm{fr}}^{\mathrm{d}}=\frac{E_{\mathrm{fr}}}{E_{\mathrm{p}, 0}}
\end{aligned}
$$

where $E_{\text {part }}^{\mathrm{d}}$ is the energy dissipated due to grain collisions $\left(E_{\text {part }}^{\mathrm{d}}=\right.$ $\left.E_{\text {coll }}+E_{\text {disp }}\right)$. The values of the parameters $\theta=25^{\circ}, \alpha=0^{\circ}, \varphi_{\mathrm{b}}=18^{\circ}$, $\Omega=10000 \mathrm{~m}^{2}, h=30 \mathrm{~m} ; l=100 \mathrm{~m}, L=500 \mathrm{~m}, d_{\mathrm{p}}=0.15 \mathrm{~m}, U \neq 0$ $\left(d_{\mathrm{w}}=0\right), C_{\mathrm{h}}=C_{1}=0$ (constant mass), $e=0.6, \nu_{\mathrm{s}}=0.55(\omega=2.1)$, and $\eta=0.005$ are assigned. $E_{\mathrm{p}, 0}$ assumes parametric values. 
Fig. 26. (a) $E_{\text {coll }}$ and $E_{\mathrm{gt}}$ and (b) $E_{\mathrm{fr}}$ and $E_{\text {disp }}$ versus traveled distance for $d_{\mathrm{p}}=0.07 \mathrm{~m}$, fixed $V$ and $H$.
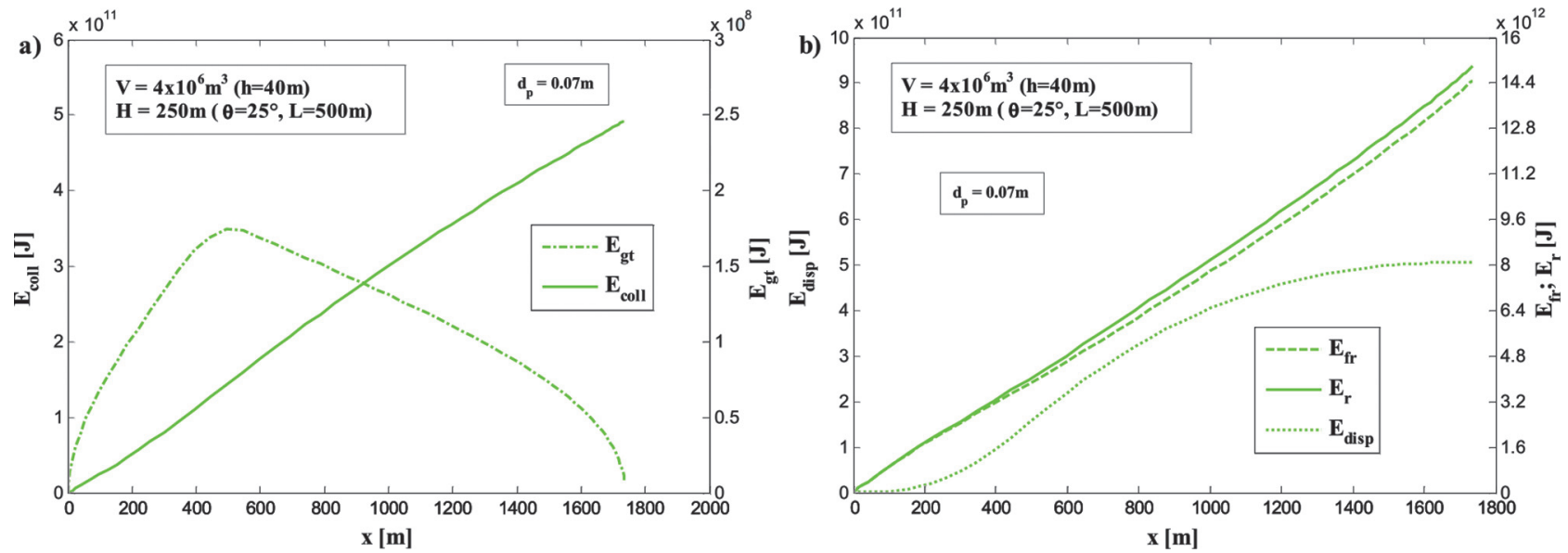

Fig. 27. (a) $E_{\text {coll }}$ and $E_{\mathrm{gt}}$ and $(b) E_{\text {fr }}$ and $E_{\text {disp }}$ versus traveled distance for $d_{\mathrm{p}}=0.2 \times 10^{-3} \mathrm{~m}$, fixed $V$ and $H$.

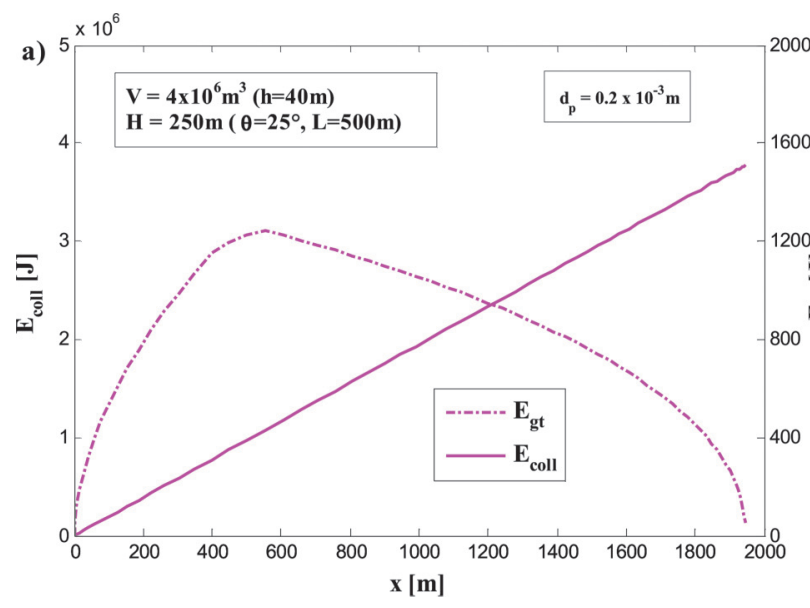

Fig. 28. Rate versus total runout length for different values of $H$, fixed $V$ and $d_{\mathrm{p}}$.

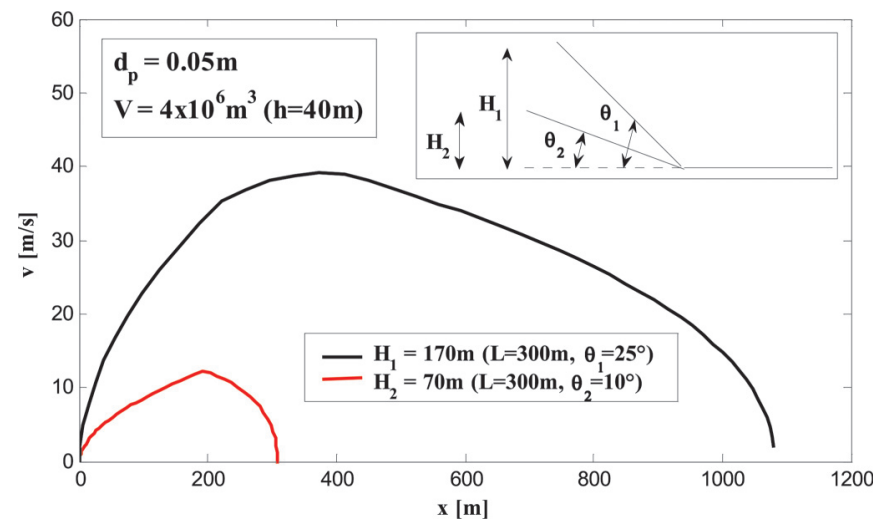

Figure 32 shows the evolution of $r_{\text {part }}^{\mathrm{d}}$ and $r_{\mathrm{fr}}^{\mathrm{d}}$ along the path traveled by the mass: at the end of the motion, the initial potential energy, $E_{\mathrm{p}, 0}$, is entirely dissipated because of friction and collisions and, thus, the sum of $r_{\text {part }}^{\mathrm{d}}$ and $r_{\mathrm{fr}}^{\mathrm{d}}$ must be equal to 1 .

Figure 33 shows the values of $d_{\mathrm{p}}$ for which the mass behaviour changes from frictional into granular (mainly collisional).

It is noted that the granular (mainly collisional) behaviour occurs for $d_{\mathrm{p}} \geq 0.1 \mathrm{~m}$; if $d_{\mathrm{p}}$ ranges between 0.02 and $0.1 \mathrm{~m}$, the sliding mass exhibits a more complex (frictional and collisional) behaviour.

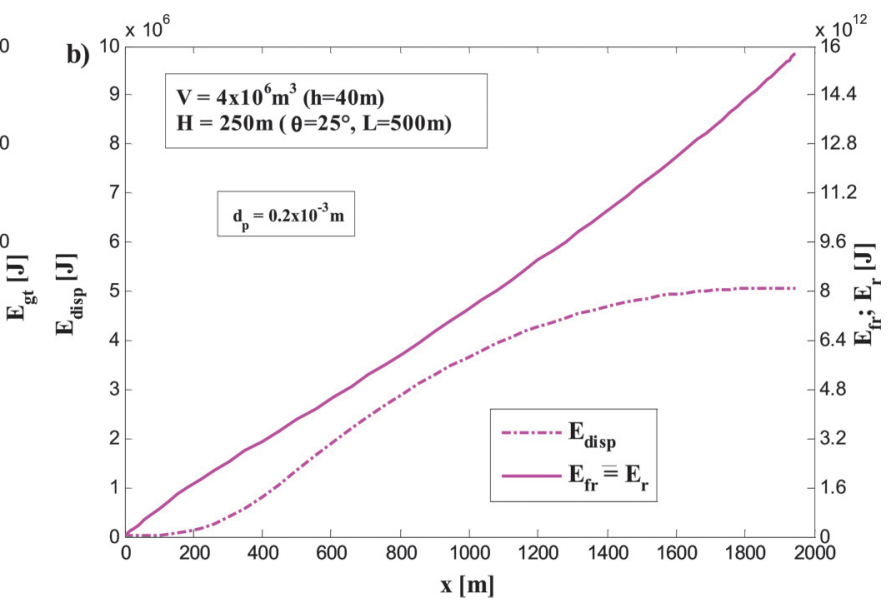

Fig. 29. Shear layer thickness $s^{\mathrm{s}}$ versus traveled distance for different values of $H$, fixed $V$ and $d_{\mathrm{p}}$.

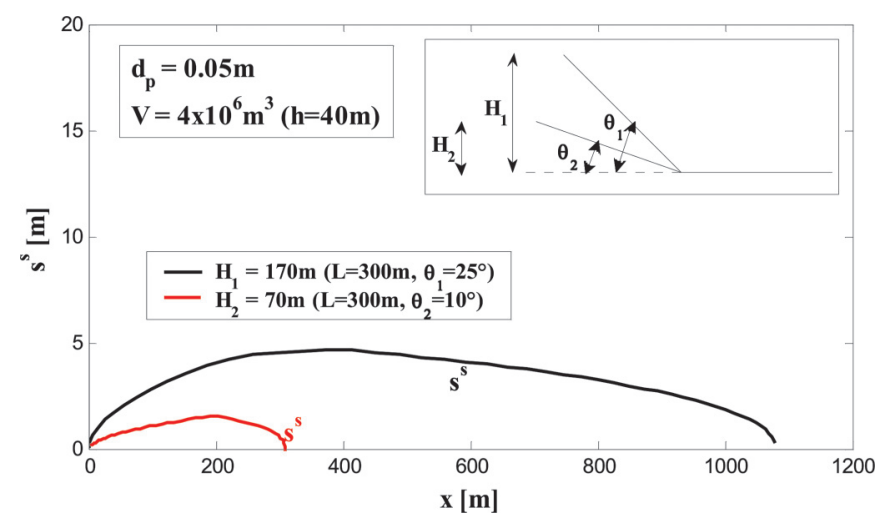

The change from frictional into coupled frictional and collisional behaviour occurs if $d_{\mathrm{p}}$ assumes values ranging between 0.005 and $0.02 \mathrm{~m}$; for small values of $d_{\mathrm{p}}(<0.005 \mathrm{~m})$, the granular mass is affected only by a frictional behaviour.

Thus, the debris flow mechanism (frictional and collisional behaviour) occurs if the volume $V$ of the sliding granular mass and the elevation difference $H$ assume large values $\left(>\sim 10^{3} \mathrm{~m}^{3}\right.$ and $>\sim 100 \mathrm{~m}$, respectively) and, correspondingly, if the diameter $d_{\mathrm{p}}$ assumes values higher than $0.02 \mathrm{~m}$. 
Fig. 30. Rate versus total runout length for different values of $V$, fixed $H$ and $d_{\mathrm{p}}$.

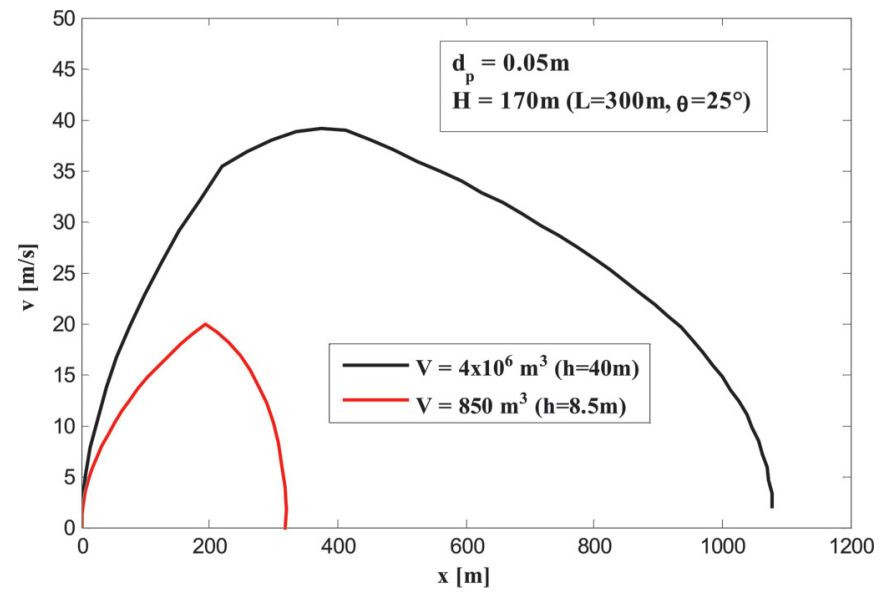

Fig. 31. Shear layer thickness $s^{s}$ versus traveled distance for different values of $V$, fixed $H$ and $d_{\mathrm{p}}$.

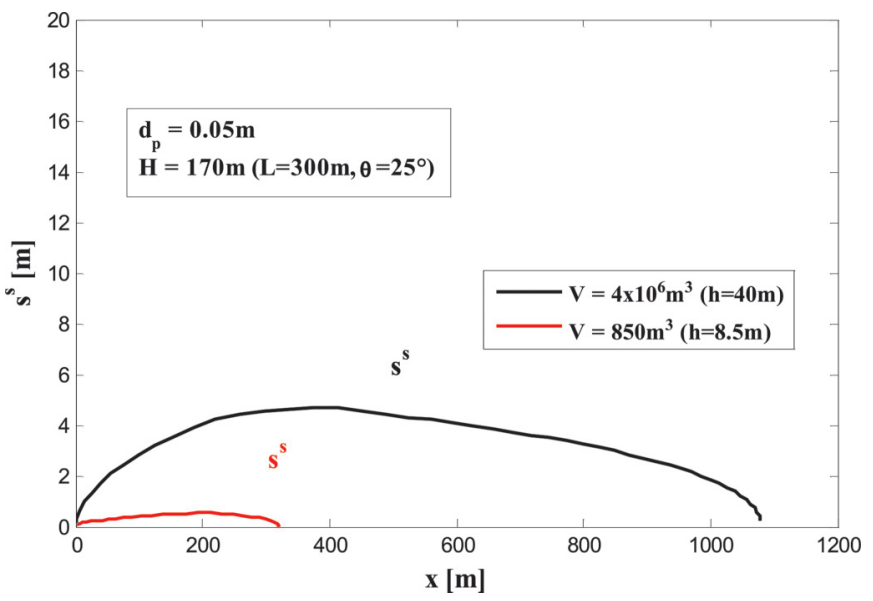

Fig. 32. $r_{\text {part }}^{\mathrm{d}}$ and $r_{\mathrm{fr}}^{\mathrm{d}}$ versus traveled distance.

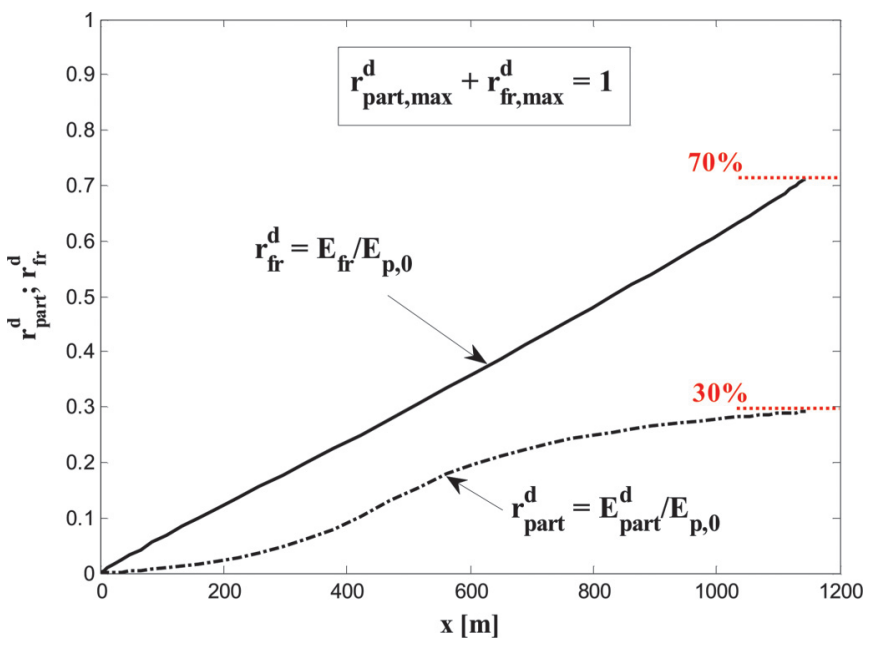

\section{Back-analyses}

\section{Cases}

Through the proposed model, some documented cases of debris flows are back-analyzed: the results of simulations allow elaboration of a simple analytical law; by means of this original law, the previously described empirical relationships are then interpreted.
Fig. 33. $r_{\mathrm{fr}, \max }^{\mathrm{d}}$ versus grain diameter, for different values of $E_{\mathrm{p}, 0}, V$, and $H$.

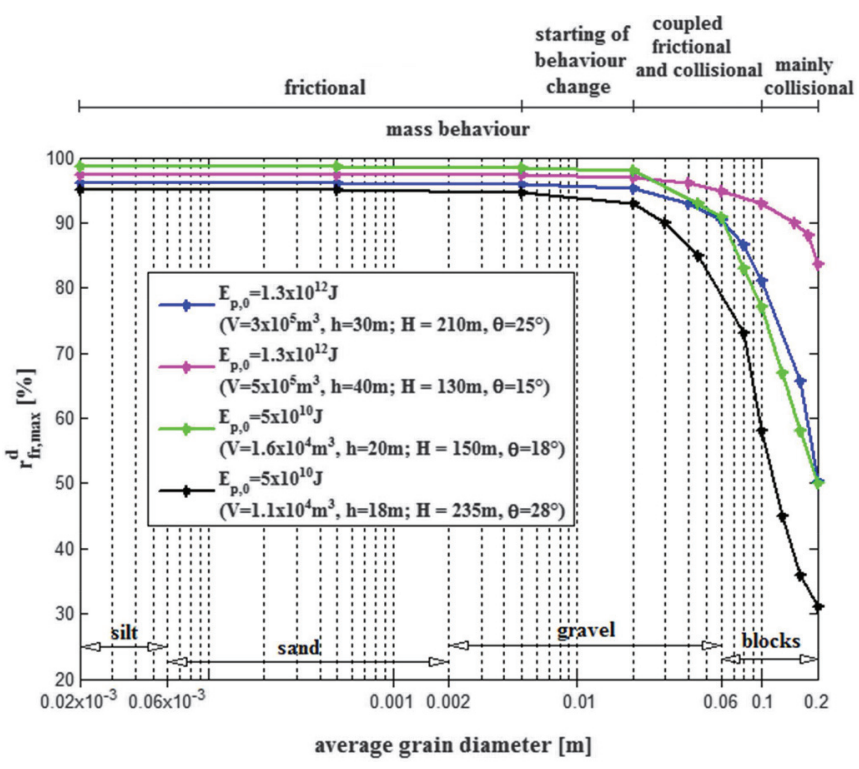

\section{Champlong landslide}

The Champlong landslide occurred in the Val d'Aosta in October 2000. The sliding surface of the roto-translational phenomenon, that caused the instability, has developed within the moraine cover, inducing the detachment of a volume of approximately $10^{4} \mathrm{~m}^{3}$ : this material was subsequently channeled in the underlying impluvium, evolving in debris flow.

The phenomenon of debris flow also involved the deposits lying on the bed of the channel, thereby increasing its volume of about $7000 \mathrm{~m}^{3}$. Geomorphological analyses allowed estimation of the maximum volume moved by the landslide: approximately, $2 \times$ $10^{4} \mathrm{~m}^{3}$ of material (Rosso et al. 2003). Figure 34 shows the elevation profile of the path traveled by the debris flow.

\section{Normash River slide}

A landslide occurred in the headwaters of the Normash River, on the western coast of Vancouver Island, Canada, in April 1999. The initial rock slide involved $3.75 \times 10^{5} \mathrm{~m}^{3}$ of fragments, which collapsed into the valley, perpendicular to the Normash River. After an initial portion (release area) $50^{\circ}$ sloped, the granular mass crossed a stretch approximately $30^{\circ}$ inclined (average first slope angle $38^{\circ}$ ) and continued its propagation on a subhorizontal section (Fig. 35). The rock avalanche then entrained an additional $3.6 \times 10^{5} \mathrm{~m}^{3}$ (Fig. 36a) of saturated clay, silt, sand, and gravel from the colluvial deposits on the lower slopes (Hungr and Evans 2004). The initial depth of the granular mass was approximately equal to $20 \mathrm{~m}$ : the erosion process occurred during the runout along the first slope, while the deposition phenomenon was along the second slope (Fig. 36b). The landslide traveled $2270 \mathrm{~m}$ (global horizontal distance), for a maximum height difference of $560 \mathrm{~m}$, reaching a maximum rate of $40 \mathrm{~m} / \mathrm{s}$.

\section{Mount Cayley debris flow}

In June 1984, a major rockslide and debris flow (estimated volume $7.4 \times 10^{5} \mathrm{~m}^{3}$ ) moved from the western flank of Mount Cayley volcano in southwest British Columbia, Canada. The disintegrating rock mass entrained a further $2 \times 10^{5} \mathrm{~m}^{3}$ and formed a rock avalanche that travelled a horizontal distance of $3.46 \mathrm{~km}$ from its source over a vertical elevation difference of $1.18 \mathrm{~km}$ on an average slope of $20^{\circ}$. It was estimated that velocity approximately reached, at least, $42 \mathrm{~m} / \mathrm{s}$ : in the upper part of its path, velocities may have approached $70 \mathrm{~m} / \mathrm{s}$. The rock avalanche was partially transformed into a debris flow that travelled a further 


\section{Pagination not final (cite DOI) / Pagination provisoire (citer le DOI)}

Fig. 34. Champlong landslide: elevation profile of the traveled path.

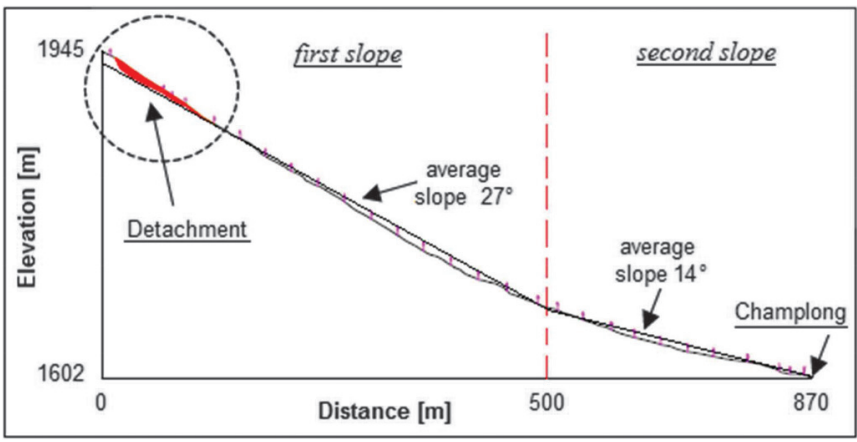

Fig. 35. Normash River slide: flow profile.

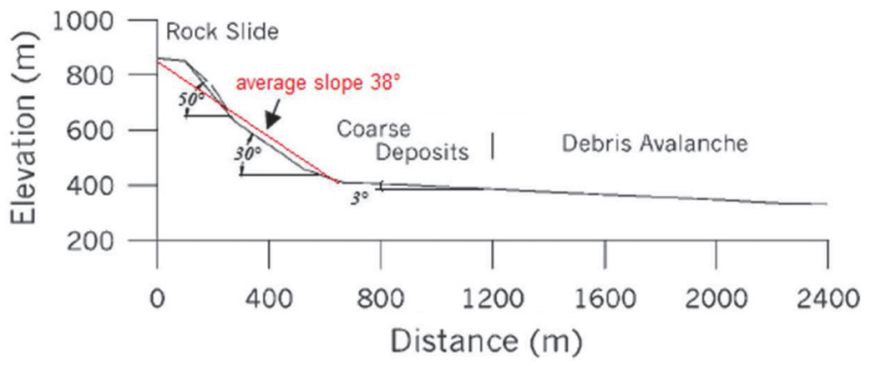

Fig. 36. Normash River slide: (a) mass balance curve and (b) depth profile.

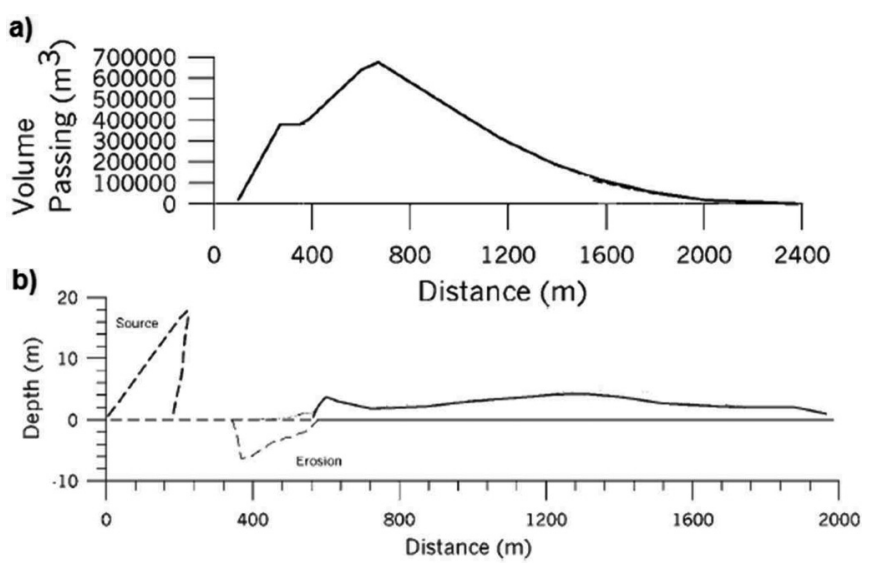

$2.6 \mathrm{~km}$ down Turbid Creek in a narrow path (average slope of $5^{\circ}$ ) up to the Squamish River, temporarily obstructing it (Evans et al. 2001). The longitudinal profile of the rockslide and debris flow is shown in Fig. 37.

\section{Sherman landslide}

The Sherman slide occurred in the Chugach Mountains, Alaska, as a result of an earthquake in March 1964 (Zambrano 2008). A volume of $3 \times 10^{7} \mathrm{~m}^{3}$ of sandstone fell from a peak of Shattered and it moved down to $5 \mathrm{~km}$, through a slight slope covered with snow, rising to a height of $140 \mathrm{~m}$. There is no information about the Sherman slide dynamics or the mechanical behaviour of the material involved. It is only possible to say that the sliding of a granular material on snow is characterized by a smaller friction angle at the base than the other cases. However, Zambrano (2008) provides some information about the volume of material involved and the horizontal distance traveled (Table 2).

\section{Tung Chung debris flow}

The Tung Chung debris flow is one of five landslides that occurred on Lantau Island, Hong Kong, in 1992 and 1993. The land- slide involved an initial volume of $1.5 \times 10^{3} \mathrm{~m}^{3}$ and travelled a horizontal distance $(\bar{L})$ of $450 \mathrm{~m}$. The final volume was estimated approximately equal to $2.3 \times 10^{3} \mathrm{~m}^{3}$ and the maximum velocity of the front of the debris flow to $\sim 25 \mathrm{~m} / \mathrm{s}$ (Ayotte et al. 1999). The path and velocity profiles are shown in Fig. 38.

\section{Results of the analyses}

The input geometrical parameters for back-analyses through the proposed model are shown in Table 3.

The parameters $C_{\mathrm{h}}$ and $C_{1}$ have been chosen to obtain, through the proposed model, the values of the volume $V_{\max }$ and $V_{\text {final }}$ approximately equal to those shown in Table 3 . Results of the simulations are summarized in Tables $4-8$ in which $L_{\text {tot }}, \bar{L}$, and $H$ are defined as the total distance traveled by the front of the debris flow, the total traveled distance projected on a horizontal plane $\left(\bar{L}=(L+l / 2) \cos \theta+\left(L_{\text {tot }}-L\right) \cos \alpha\right)$ and the difference in elevation, previously defined $\left(H=(L+l / 2) \sin \theta-\left(L_{\text {tot }}-L\right) \sin \alpha\right)$, respectively. The critical velocity of erosion, $v_{\mathrm{cr}, \mathrm{e}}$, was estimated through the following expression, deriving from the governing ordinary differential equation (eq. (25)), by imposing some simplified hypotheses (mass and thicknesses of the shear layer and the overlying block assume constant values) and replacing the angle of the first slope $\theta$ with $\beta_{\mathrm{e}}$ :

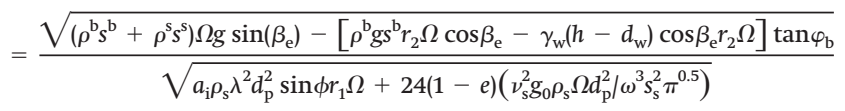

where $r_{1}$ and $r_{2}$ are constant parameters, replacing the functions $r(\dot{x})$ and $\bar{r}(\dot{x})$

$$
r(\dot{x})=r_{1}, \quad \bar{r}(\dot{x})=1-r(\dot{x})=r_{2}
$$

and, to evaluate $v_{\text {cr,e }}$ (eq. (56)), assume the following values: $r_{1}<0.5, r_{2}>0.5$, respectively (at first, for small values of the velocity, the lithostatic forces give a greater contribution in the balance of the force $N_{\text {tot }}$ than the resultant of the colliding forces, and then $\bar{r}>r$, see Fig. 17); $\beta_{\mathrm{e}}$ is defined as the limit angle of erosion. Several authors (Ikeya 1981; Hungr et al. 1984) suggested some values for $\beta_{\mathrm{e}}\left(\in\left[8^{\circ}, 14^{\circ}\right]\right)$. In the proposed model $\beta_{\mathrm{e}}$ was estimated through the following relation (Takahashi 1991):

$$
\beta_{\mathrm{e}}=\arctan \left\{\tan \varphi_{\mathrm{b}}\left[1-2 \frac{\rho_{\mathrm{w}}}{\rho_{\mathrm{bed}}}\left(1+\frac{\rho^{\mathrm{b}}}{\rho_{\text {bed }}}\right)^{-1}\right]\right\}
$$

where $\rho_{\text {bed }}$ is the density of the material lying on the bed of the channel (typically, $1800-2000 \mathrm{~kg} / \mathrm{m}^{3}$ ).

Figures 39-42 show the values of velocity and distance traveled by the mass center of the debris flow, obtained through the proposed model.

\section{Estimate of the total runout length through a semiempirical law}

The results obtained through the proposed model show that the total distance traveled by a debris flow depends on some micromechanical parameters, such as $\omega\left(e\right.$ and $\left.n_{\mathrm{s}}\right), \eta, d_{\mathrm{p}}$, and $\varphi_{\mathrm{b}}$, as well as the interstitial pressure, the involved volume, the mass changes. According to the results obtained from the parametrical analyses, a semiempirical law, expressing the functional relationship between $\bar{L}$ and the following variables, is elaborated:

- $\omega, \eta$. The parameter $\omega \in(0,3.5)$, dependent on the restitution coefficient $e$ and the solid fraction of the shear layer $\nu_{s}$, allows taking the grain inelastic collisions into account and can be evaluated through eq. (37); the parameter $\eta$ allows taking the 


\section{Pagination not final (cite DOI) / Pagination provisoire (citer le DOI)}

Fig. 37. Mount Cayley debris flow: longitudinal profile.

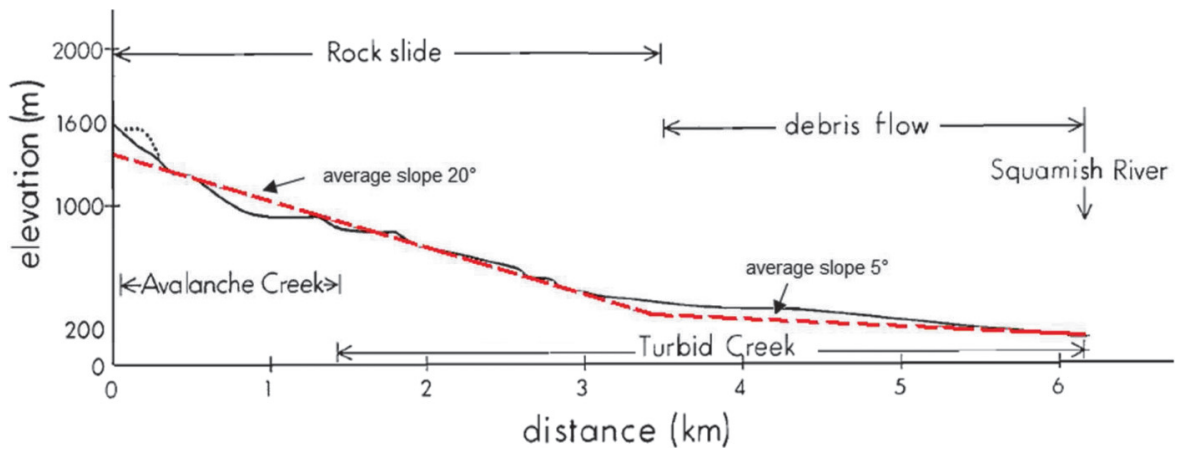

Table 2. Sherman slide, input parameters: $V$, involved volume; $h_{\mathrm{fs}}$, difference in elevation of the first slope; $h_{\mathrm{ss}}$, difference in elevation of the counterslope; $l_{\mathrm{b}}$, runout length projection on the horizontal plane; $L_{\mathrm{p}}$, total distance traveled projection on the horizontal plane (Zambrano 2008).

\begin{tabular}{llllll}
\hline$V\left(\mathrm{~m}^{3}\right)$ & $h_{\mathrm{fs}}(\mathrm{m})$ & $h_{\mathrm{ss}}(\mathrm{m})$ & $l_{\mathrm{b}}(\mathrm{m})$ & $L_{\mathrm{p}}(\mathrm{m})$ & $v_{\max }(\mathrm{m} / \mathrm{s})$ \\
\hline $2.8 \times 10^{7}$ & 600 & 140 & 2000 & $\sim 5000$ & $\sim 75$ \\
\hline
\end{tabular}

Fig. 38. Tung Chung debris flow: path and velocity profiles.
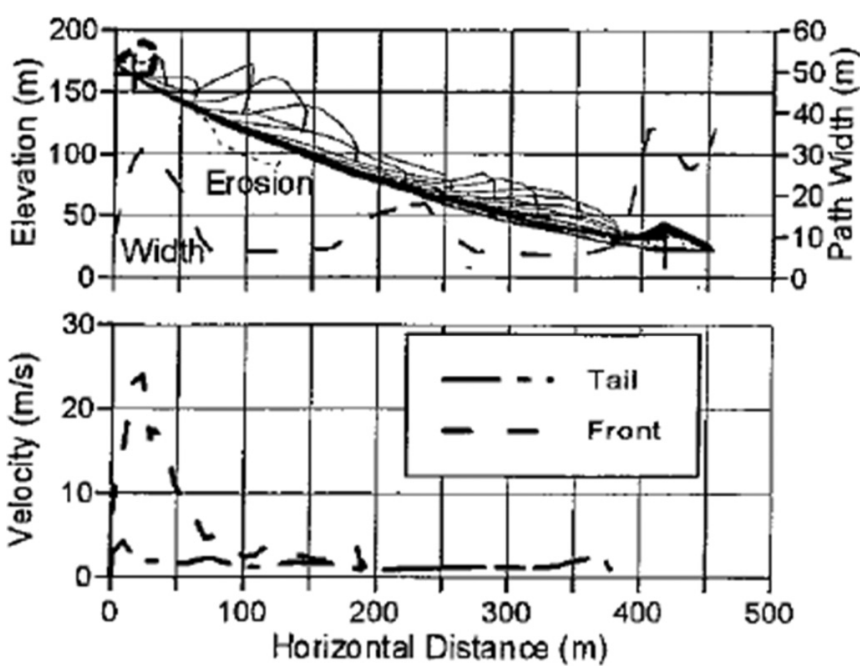

resultant of the colliding forces in the balance of the force $N_{\text {tot }}$ into account and assumes values ranging between 0.005 and 0.5 .

- $p_{\mathrm{w}}=\gamma_{\mathrm{w}}\left(h-d_{\mathrm{w}}\right) \cos \theta$, the interstitial pressure at the base of the granular mass, during the runout phase.

- $\tan \left(\varphi_{\mathrm{b}}\right)$, the tangent of the dynamic friction angle.

- $V_{0}^{0.085}$, the initial volume of the debris flow, according to the functional relationship shown in Fig. 20.

- $d_{\mathrm{p}}$, the average grain diameter.

- $P_{i}$, the percentage of maximum growth of the volume of the debris flow. Back-analyses by Hungr and Evans (2004) highlight that the mass increase of the landslides of considerable volume is smaller than that of granular masses of small volume: it is observed that the material erodible by large landslides is a small fraction of the initial volume.

$$
P_{\mathrm{i}}=\frac{V_{\max }-V_{0}}{V_{0}} 100
$$

\section{- $H$, the difference in elevation.}

The following relation is thus proposed
(60)

$$
\begin{aligned}
\bar{L}=C_{1}+C_{2} d_{\mathrm{p}}+C_{3} \tan \varphi_{\mathrm{b}}+C_{4} p_{\mathrm{w}}+ & C_{5} \omega+C_{6} \eta+C_{7} P_{\mathrm{i}} \\
& +C_{8} V_{0}^{0.085}+C_{9} H(\mathrm{~m})
\end{aligned}
$$

The values of the several variables $\left(H, p_{\mathrm{w}}, V_{0}^{0.085}, \tan \left(\varphi_{\mathrm{b}}\right), d_{\mathrm{p}}, P_{\mathrm{i}}, \omega\right.$, $\eta)$, assigned for the back-analyses of the described cases, were considered in the multiple linear regression method to determinate the multiplier coefficients (Table 9). The constants of regression assume the following values: $C_{1}=-890.6 ; C_{2}=-2.1 \times 10^{3} ; C_{3}=$ $-301.1 ; C_{4}=1.4 ; C_{5}=-146.8 ; C_{6}=-6.3 \times 10^{3} ; C_{7}=-6.3 ; C_{8}=1.0 \times 10^{3}$; and $C_{9}=2.6$. The coefficient of regression $R^{2}$ is equal to 0.99 . Equation (60) shows that the total runout length increases if the interstitial pressure, the initial volume of the granular mass, and $H$ increase, and decreases if the dynamic friction angle, $P_{\mathrm{i}}, \omega, d_{\mathrm{p}}$, and $\eta$ increase.

To compare the empirical relationships proposed by Scheidegger, Li, Corominas, Rickenmann, and Davies to eq. (60), eqs. (5)-(9) are transformed into the form

$$
\bar{L}=\frac{H}{a} V^{b}
$$

where $a$ and $b$ are constants dependent on the considered empirical law (Table 10). Appreciable agreement between eq. (60) and the empirical relationships is observed (Figs. 43-45).

In the same way, factors such as the average grain diameter, $d_{\mathrm{p}}$, the interstitial pressure, $p_{\mathrm{w}}$, and the mass changes, neglected by empirical approaches, the dynamic friction angle greatly affect the traveled distance.

Figure 44 shows that the dynamic friction angle is not the only micromechanical parameter influencing the total runout length, but, for fixed $\varphi_{\mathrm{b}}, \bar{L}$ can be assumed to be different values according to values assigned to $p_{\mathrm{w}}, d_{\mathrm{p}}, \omega$, and $\eta$.

The Rickenmann relationship provides greater values of $\bar{L}$ than those computed through the Corominas' relationships and it is approximated by eq. (60) if small values of $d_{\mathrm{p}}, \varphi_{\mathrm{b}}$, and the porewater excess $\left(d_{\mathrm{w}}<0\right)$ are assumed (Fig. 45).

\section{Interpretation of the results of empirical relationships}

The empirical relationships previously recalled are interpreted through eq. (60), referring to the Aberfan and the Shum Wan Road landslides.

\section{Aberfan landslide}

On 21 October 1966, after several days of heavy rain, more than $150000 \mathrm{~m}^{3}$ of water-saturated debris broke away and flowed downhill (average slope $11^{\circ}$, difference in elevation $\sim 200 \mathrm{~m}$ ) at high speed. The height of the debris flow and the height of water were estimated to be 2 and $0.2 \mathrm{~m}$, respectively (Hutchinson 1986). The debris flow traveled a distance of $760 \mathrm{~m}$ and the velocity, at a 
Table 3. Back analyses through the proposed model: input geometrical parameters.

\begin{tabular}{llllrrrrrr}
\hline Event & $V_{0}\left(\mathrm{~m}^{3}\right)$ & $V_{\max }\left(\mathrm{m}^{3}\right)$ & $V_{\text {fin }}\left(\mathrm{m}^{3}\right)$ & $h_{0}(\mathrm{~m})$ & $l(\mathrm{~m})$ & $\Omega\left(\mathrm{m}^{2}\right)$ & $\theta\left(^{\circ}\right)$ & $\alpha\left({ }^{\circ}\right)$ & $L(\mathrm{~m})$ \\
Tung Chung & $1.5 \times 10^{3}$ & - & $2.3 \times 10^{3}$ & 1.5 & 50 & 1000 & 19 & 0 & 400 \\
Champlong & $10^{4}$ & $2 \times 10^{4}$ & $1.7 \times 10^{4}$ & 4 & 100 & 2500 & 27 & -14 & 500 \\
Normash River & $3.75 \times 10^{5}$ & $7.35 \times 10^{5}$ & - & 20 & 200 & 18750 & 38 & -3 & 610 \\
Mount Cayley & $0.74 \times 10^{6}$ & $0.94 \times 10^{6}$ & - & 45 & 200 & 16450 & 20 & -5 & 3680 \\
Sherman & $2.8 \times 10^{7}$ & - & - & 100 & 1400 & 280000 & 17 & 3 & 2090 \\
\hline
\end{tabular}

Table 4. Tung Chung debris flow back-analysis: results obtained through the proposed model.

\begin{tabular}{llll}
\hline Micromechanical parameters & Erosion parameters & Deposition parameters & Results \\
\hline$d_{\mathrm{p}}=0.05 \mathrm{~m} ; \varphi_{\mathrm{b}}=21^{\circ} ; d_{\mathrm{w}}=0(U \neq 0) ;$ & $C_{\mathrm{h}}=0.0005 \mathrm{~m} / \mathrm{m} ; C_{1}=0.04 \mathrm{~m} / \mathrm{m} ;$ & $C_{\mathrm{h}}=0 \mathrm{~m} / \mathrm{m} ; C_{1}=0 \mathrm{~m} / \mathrm{m} ;$ & $\bar{L}=507 \mathrm{~m} ; V_{\text {fin }}=2.1 \times 10^{3} \mathrm{~m}^{3} ;$ \\
$\nu_{\mathrm{s}}=0.50 ; e=0.8(\omega=1.5) ;$ & $C_{\mathrm{a}}=0.8 \mathrm{~m}^{2} / \mathrm{m} ; v_{\mathrm{cr}, \mathrm{e}}=10.3 \mathrm{~m} / \mathrm{s}$ & $C_{\mathrm{a}}=0 \mathrm{~m}^{2} / \mathrm{m}$ & $L_{\text {tot }}=505 \mathrm{~m} ; H=138 \mathrm{~m}$ \\
$\eta=0.05$ & $\left(r_{1}=0.1 ; r_{2}=0.9\right)$ & & \\
\hline
\end{tabular}

Table 5. Champlong landslide back-analysis: results obtained through the proposed model.

\begin{tabular}{llll}
\hline Micromechanical parameters & Erosion parameters & Deposition parameters & Results \\
\hline$d_{\mathrm{p}}=0.06 \mathrm{~m} ; \varphi_{\mathrm{b}}=19^{\circ} ; d_{\mathrm{w}}=h(U=0) ;$ & $C_{\mathrm{h}}=0.0005 \mathrm{~m} / \mathrm{m} ; C_{1}=0.1 \mathrm{~m} / \mathrm{m} ;$ & $C_{\mathrm{h}}=-0.0002 \mathrm{~m} / \mathrm{m} ;$ & $\bar{L}=805 \mathrm{~m} ; V_{\max }=1.8 \cdot 10^{4} \mathrm{~m}^{3} ;$ \\
$\nu_{\mathrm{s}}=0.58 ; e=0.6(\omega=2.15) ;$ & $C_{\mathrm{a}}=2.5 \mathrm{~m}^{2} / \mathrm{m} ; v_{\mathrm{cr}, \mathrm{e}}=10.0 \mathrm{~m} / \mathrm{s}$ & $C_{1}=+0.01 \mathrm{~m} / \mathrm{m} ;$ & $V_{\text {final }}=1.75 \cdot 10^{4} \mathrm{~m}^{3} ;$ \\
$\eta=0.03$ & $\left(r_{1}=0.1 ; r_{2}=0.9\right)$ & $C_{\mathrm{a}}=+0.25 \mathrm{~m} 2 / \mathrm{m}$ & $L_{\text {tot }}=826 \mathrm{~m} ; H=329 \mathrm{~m}$ \\
$d_{\mathrm{p}}=0.1 \mathrm{~m} ; \varphi_{\mathrm{b}}=23^{\circ} ; d_{\mathrm{w}}=(2 / 3) h(U \neq 0) ;$ & $C_{\mathrm{h}}=0.0004 \mathrm{~m} / \mathrm{m} ; C_{1}=0.08 \mathrm{~m} / \mathrm{m} ;$ & $C_{\mathrm{h}}=-0.0001 \mathrm{~m} / \mathrm{m} ;$ & $\bar{L}=905 \mathrm{~m} ; V_{\max }=1.74 \times 10^{4} \mathrm{~m}^{3} ;$ \\
$\nu_{\mathrm{s}}=0.49 ; e=0.3(\omega=2.8) ;$ & $C_{\mathrm{a}}=2.0 \mathrm{~m}^{2} / \mathrm{m} ; v_{\mathrm{cr}, \mathrm{e}}=9.0 \mathrm{~m} / \mathrm{s}$ & $C_{1}=+0.016 \mathrm{~m} / \mathrm{m} ;$ & $V_{\text {final }}=1.69 \times 10^{4} \mathrm{~m}^{3} ;$ \\
$\eta=0.02$ & $\left(r_{1}=0.3 ; r_{2}=0.7\right)$ & $C_{\mathrm{a}}=+0.4 \mathrm{~m}^{2} / \mathrm{m}$ & $L_{\text {tot }}=930 \mathrm{~m} ; H=354 \mathrm{~m}$ \\
\hline
\end{tabular}

Table 6. Normash River landslide back-analysis: results obtained through the proposed model.

\begin{tabular}{lccc}
\hline Micromechanical parameters & Erosion parameters & Deposition parameters & Results \\
\hline$d_{\mathrm{p}}=0.115 \mathrm{~m} ; \varphi_{\mathrm{b}}=20^{\circ} ; d_{\mathrm{w}}=0(U \neq 0) ;$ & $C_{\mathrm{h}}=0.011 \mathrm{~m} / \mathrm{m} ; C_{1}=0.13 \mathrm{~m} / \mathrm{m} ;$ & $C_{\mathrm{h}}=-1 \times 10^{-6} \mathrm{~m} / \mathrm{m} ;$ & $\bar{L}=2250 \mathrm{~m} ; V_{\max }=7.5 \times 10^{5} \mathrm{~m}^{3} ;$ \\
$\nu_{\mathrm{s}}=0.58 ; e=0.8(\omega=1.5) ;$ & $C_{\mathrm{a}}=12.2 \mathrm{~m}^{2} / \mathrm{m} ; v_{\mathrm{cr}, \mathrm{e}}=9 \mathrm{~m} / \mathrm{s}$ & $C_{1}=-1.3 \times 10^{-4} \mathrm{~m} / \mathrm{m} ;$ & $V_{\text {final }}=6.3 \times 10^{5} \mathrm{~m}^{3} ;$ \\
$\eta=0.05$ & $\left(r_{1}=0.1 ; r_{2}=0.9\right)$ & $C_{\mathrm{a}}=-0.012 \mathrm{~m}{ }^{2} / \mathrm{m}$ & $L_{\text {tot }}=2300 \mathrm{~m} ; H=526 \mathrm{~m}$ \\
$d_{\mathrm{p}}=0.14 \mathrm{~m} ; \varphi_{\mathrm{b}}=25^{\circ} ; d_{\mathrm{w}}=h / 3(U \neq 0) ;$ & $C_{\mathrm{h}}=0.01 \mathrm{~m} / \mathrm{m} ; C_{1}=0.16 \mathrm{~m} / \mathrm{m} ;$ & $C_{\mathrm{h}}=-1.5 \times 10^{-5} \mathrm{~m} / \mathrm{m} ;$ & $\bar{L}=2130 \mathrm{~m} ; V_{\mathrm{max}}=7.15 \times 10^{5} \mathrm{~m}^{3} ;$ \\
$\nu_{\mathrm{s}}=0.51 ; e=0.4(\omega=2.6) ;$ & $C_{\mathrm{a}}=15 \mathrm{~m}^{2} / \mathrm{m} ; v_{\mathrm{cr}, \mathrm{e}}=16.2 \mathrm{~m} / \mathrm{s}$ & $C_{1}=-3.2 \times 10^{-4} \mathrm{~m} / \mathrm{m} ;$ & $V_{\text {final }}=6.0 \times 10^{5} \mathrm{~m}^{3} ;$ \\
$\eta=0.03$ & $\left(r_{1}=0.3 ; r_{2}=0.7\right)$ & $C_{\mathrm{a}}=-0.03 \mathrm{~m} / \mathrm{m}$ & $L_{\text {tot }}=2180 \mathrm{~m} ; H=519 \mathrm{~m}$ \\
$d_{\mathrm{p}}=0.18 \mathrm{~m} ; \varphi_{\mathrm{b}}=16^{\circ} ; d_{\mathrm{w}}=-h / 4(U \neq 0) ;$ & $C_{\mathrm{h}}=0.012 \mathrm{~m} / \mathrm{m} ; C_{1}=0.15 \mathrm{~m} / \mathrm{m} ;$ & $C_{\mathrm{h}}=-1.5 \times 10^{-5} \mathrm{~m} / \mathrm{m} ;$ & $\bar{L}=2390 \mathrm{~m} ; V_{\max }=7.55 \times 10^{5} \mathrm{~m}^{3} ;$ \\
$\nu_{\mathrm{s}}=0.53 ; e=0.6(\omega=2.1) ;$ & $C_{\mathrm{a}}=14 \mathrm{~m}^{2} / \mathrm{m} ; v_{\mathrm{cr}, \mathrm{e}}=24.2 \mathrm{~m} / \mathrm{s}$ & $C_{1}=-3.0 \times 10^{-4} \mathrm{~m} / \mathrm{m} ;$ & $V_{\text {final }}=6.1 \times 10^{5} \mathrm{~m}^{3} ;$ \\
$\eta=0.01$ & $\left(r_{1}=0.1 ; r_{2}=0.9\right)$ & $C_{\mathrm{a}}=-0.028 \mathrm{~m}^{2} / \mathrm{m}$ & $L_{\text {tot }}=2442 \mathrm{~m} ; H=533 \mathrm{~m}$ \\
\hline
\end{tabular}

Table 7. Mount Cayley debris flow back-analysis: results obtained through the proposed model.

\begin{tabular}{lccc}
\hline Micromechanical parameters & Erosion parameters & Deposition parameters & Results \\
\hline$d_{\mathrm{p}}=0.15 \mathrm{~m} ; \varphi_{\mathrm{b}}=23^{\circ} ; d_{\mathrm{w}}=0(U \neq 0) ;$ & $C_{\mathrm{h}}=0.0007 \mathrm{~m} / \mathrm{m} ; C_{1}=0.016 \mathrm{~m} / \mathrm{m} ;$ & $C_{\mathrm{h}}=-0.0002 \mathrm{~m} / \mathrm{m} ;$ & $\bar{L}=5800 \mathrm{~m} ; V_{\max }=10^{6} \mathrm{~m}^{3} ;$ \\
$\nu_{\mathrm{s}}=0.55 ; e=0.5(\omega=2.4) ;$ & $C_{\mathrm{a}}=1.31 \mathrm{~m}^{2} / \mathrm{m} ; v_{\mathrm{cr}, \mathrm{e}}=27 \mathrm{~m} / \mathrm{s}$ & $C_{1}=-0.0048 \mathrm{~m} / \mathrm{m} ;$ & $V_{\text {final }}=9.4 \times 10^{5} \mathrm{~m}^{3} ;$ \\
$\eta=0.005$ & $\left(r_{1}=0.1 ; r_{2}=0.9\right)$ & $C_{\mathrm{a}}=-0.40 \mathrm{~m} / \mathrm{m}$ & $L_{\text {tot }}=5940 \mathrm{~m} ; H=1490 \mathrm{~m}$ \\
$d_{\mathrm{p}}=0.19 \mathrm{~m} ; \varphi_{\mathrm{b}}=25^{\circ} ; d_{\mathrm{w}}=h / 2(U \neq 0) ;$ & $C_{\mathrm{h}}=0.0006 \mathrm{~m} / \mathrm{m} ; C_{1}=0.013 \mathrm{~m} / \mathrm{m} ;$ & $C_{\mathrm{h}}=-0.00025 \mathrm{~m} / \mathrm{m} ;$ & $\bar{L}=5100 \mathrm{~m} ; V_{\mathrm{max}}=9.4 \times 10^{5} \mathrm{~m} \mathrm{~m}^{3} ;$ \\
$\nu_{\mathrm{s}}=0.51 ; e=0.8(\omega=1.5) ;$ & $C_{\mathrm{a}}=1.07 \mathrm{~m}^{2} / \mathrm{m} ; v_{\mathrm{cr}, \mathrm{e}}=12.5 \mathrm{~m} / \mathrm{s}$ & $C_{1}=-0.0039 \mathrm{~m} / \mathrm{m} ;$ & $V_{\text {final }}=9.0 \times 10^{5} \mathrm{~m}^{3} ;$ \\
$\eta=0.03$ & $\left(r_{1}=0.3 ; r_{2}=0.7\right)$ & $C_{\mathrm{a}}=-0.32 \mathrm{~m}^{2} / \mathrm{m}$ & $L_{\mathrm{tot}}=5220 \mathrm{~m} ; H=1427 \mathrm{~m}$ \\
$d_{\mathrm{p}}=0.12 \mathrm{~m} ; \varphi_{\mathrm{b}}=28^{\circ} ; d_{\mathrm{w}}=-h / 5(U \neq 0) ;$ & $C_{\mathrm{h}}=0.0004 \mathrm{~m} / \mathrm{m} ; C_{1}=0.02 \mathrm{~m} / \mathrm{m} ;$ & $C_{\mathrm{h}}=-0.0001 \mathrm{~m} / \mathrm{m} ;$ & $\bar{L}=6172 \mathrm{~m} ; V_{\mathrm{max}}=10^{6} \mathrm{~m}^{3} ;$ \\
$\nu_{\mathrm{s}}=0.57 ; e=0.9(\omega=1.1) ;$ & $C_{\mathrm{a}}=1.65 \mathrm{~m}^{2} / \mathrm{m} ; v_{\mathrm{cr}, \mathrm{e}}=28 \mathrm{~m} / \mathrm{s}$ & $C_{1}=-0.006 \mathrm{~m} / \mathrm{m} ;$ & $V_{\text {final }}=9.5 \times 10^{5} \mathrm{~m}^{3} ;$ \\
$\eta=0.006$ & $\left(r_{1}=0.3 ; r_{2}=0.7\right)$ & $C_{\mathrm{a}}=-0.49 \mathrm{~m}^{2} / \mathrm{m}$ & $L_{\text {tot }}=6310 \mathrm{~m} ; H=1522 \mathrm{~m}$ \\
\hline
\end{tabular}

Table 8. Sherman landslide back-analysis: results obtained through the proposed model.

\begin{tabular}{llcc}
\hline Micromechanical parameters & Erosion parameters & Deposition parameters & Results \\
\hline$d_{\mathrm{p}}=0.08 \mathrm{~m} ; \varphi_{\mathrm{b}}=20^{\circ} ; d_{\mathrm{w}}=0(U \neq 0) ;$ & $C_{\mathrm{h}}=0.0005 \mathrm{~m} / \mathrm{m} ; C_{1}=0.05 \mathrm{~m} / \mathrm{m} ;$ & $C_{\mathrm{h}}=-0.0003 \mathrm{~m} / \mathrm{m} ;$ & $\bar{L}=5290 \mathrm{~m} ; V_{\max }=3.1 \times 10^{7} \mathrm{~m}^{3} ;$ \\
$\nu_{\mathrm{s}}=0.56 ; e=0.8(\omega=1.5) ;$ & $C_{\mathrm{a}}=10 \mathrm{~m}^{2} / \mathrm{m} ; v_{\mathrm{cr}, \mathrm{e}}=8.6 \mathrm{~m} / \mathrm{s}$ & $C_{1}=-0.015 \mathrm{~m} / \mathrm{m} ;$ & $V_{\text {final }}=2.9 \times 10^{7} \mathrm{~m}^{3} ;$ \\
$\eta=0.015$ & $\left(r_{1}=0.1 ; r_{2}=0.9\right)$ & $C_{\mathrm{a}}=-3.0 \mathrm{~m} / \mathrm{m}$ & $L_{\text {tot }}=4713 \mathrm{~m} ; H=441 \mathrm{~m}$ \\
$d_{\mathrm{p}}=0.03 \mathrm{~m} ; \varphi_{\mathrm{b}}=15^{\circ} ; d_{\mathrm{w}}=h / 2(U \neq 0) ;$ & $C_{\mathrm{h}}=0.0008 \mathrm{~m} / \mathrm{m} ; C_{1}=0.02 \mathrm{~m} / \mathrm{m} ;$ & $C_{\mathrm{h}}=-0.0005 \mathrm{~m} / \mathrm{m} ;$ & $\bar{L}=4870 \mathrm{~m} ; V_{\max }=3 \times 10^{7} \mathrm{~m}^{3} ;$ \\
$\nu_{\mathrm{s}}=0.53 ; e=0.6(\omega=2.1) ;$ & $C_{\mathrm{a}}=4 \mathrm{~m}^{2} / \mathrm{m} ; v_{\mathrm{cr}, \mathrm{e}}=23 \mathrm{~m} / \mathrm{s}$ & $C_{1}=-0.006 \mathrm{~m} / \mathrm{m} ;$ & $V_{\text {final }}=2.85 \times 10^{7} \mathrm{~m}^{3} ;$ \\
$\eta=0.009$ & $\left(r_{1}=0.35 ; r_{2}=0.65\right)$ & $C_{\mathrm{a}}=-1.2 \mathrm{~m}^{2} / \mathrm{m}$ & $L_{\text {tot }}=4300 \mathrm{~m} ; H=462 \mathrm{~m}$ \\
\hline
\end{tabular}


Fig. 39. Tung Chung debris flow and Champlong landslide backanalyses: rate versus runout length.

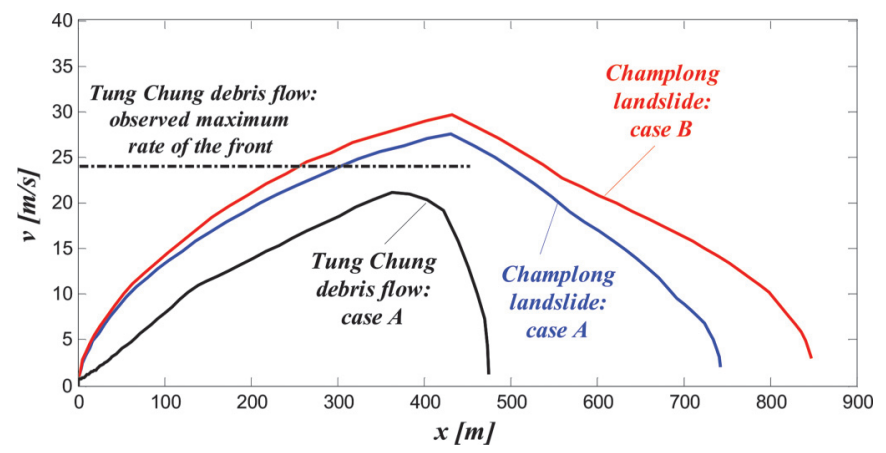

Fig. 40. Normash River slide back-analysis: rate versus runout length.

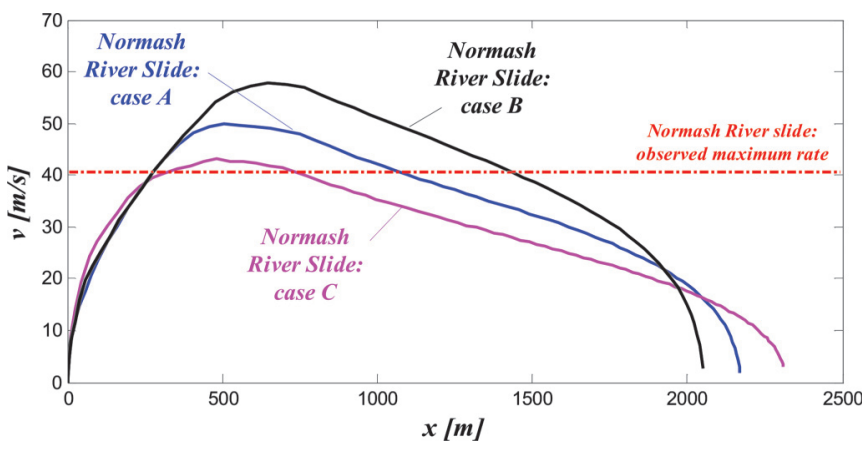

Fig. 41. Mount Cayley debris flow back-analysis: rate versus runout length.

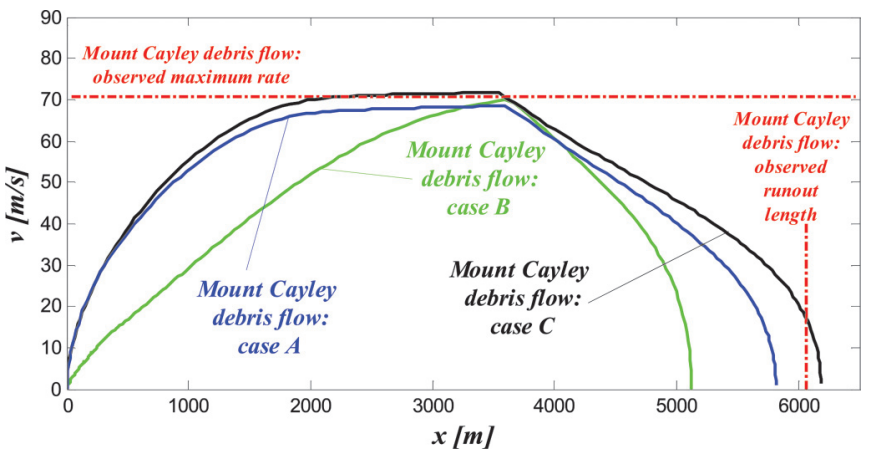

Fig. 42. Sherman landslide back-analysis: rate versus runout length.

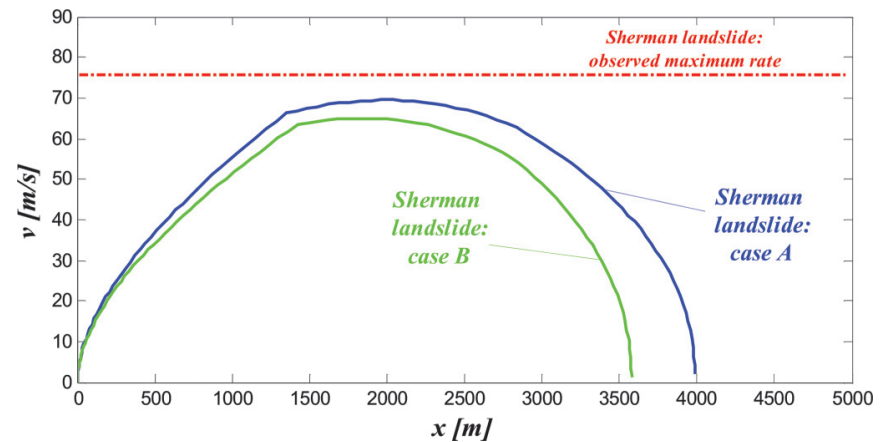

distance of $430 \mathrm{~m}$ after the initial position, was observed by witnesses to range from 5 to $15 \mathrm{~m} / \mathrm{s}$.

According to available data, the following values of the variables in eq. (60) are obtained:
Table 9. Multiple linear regression method: input parameters.

\begin{tabular}{llllllllllr}
\hline & \multicolumn{3}{c}{$\tan \varphi_{\mathrm{b}}$} & $p_{\mathrm{w}}$ & & & & & \\
$\bar{L}(\mathrm{~m})$ & $d_{\mathrm{p}}(\mathrm{m})$ & $\left({ }^{\circ}\right)$ & $(\mathrm{kPa})$ & $\omega$ & $\eta$ & $P_{\mathrm{i}}(\%)$ & $V_{\mathrm{o}}\left(\mathrm{m}^{3}\right)$ & $V_{0}^{0.085}$ & $H(\mathrm{~m})$ \\
\hline 507 & 0.05 & 0.38 & 14.2 & 1.5 & 0.05 & 40 & 1500 & 1.86 & 138 \\
805 & 0.06 & 0.34 & 0 & 2.15 & 0.03 & 80 & 10000 & 2.19 & 329 \\
905 & 0.10 & 0.42 & 11.8 & 2.8 & 0.02 & 74 & 10000 & 2.19 & 354 \\
2250 & 0.115 & 0.36 & 1.6 & 1.5 & 0.05 & 100 & 375000 & 3.0 & 526 \\
2130 & 0.14 & 0.47 & 1 & 2.6 & 0.03 & 90.7 & 375000 & 3.0 & 519 \\
2390 & 0.18 & 0.28 & 2 & 2.1 & 0.01 & 101.3 & 375000 & 3.0 & 533 \\
5800 & 0.15 & 0.42 & 4.2 & 2.4 & 0.005 & 35.1 & 740000 & 3.15 & 1490 \\
5100 & 0.19 & 0.47 & 2.1 & 1.5 & 0.03 & 27 & 740000 & 3.15 & 1427 \\
6172 & 0.12 & 0.53 & 5.1 & 1.1 & 0.006 & 35.1 & 740000 & 3.15 & 1522 \\
5290 & 0.08 & 0.36 & 9.6 & 1.5 & 0.015 & 10.7 & 28000000 & 4.3 & 441 \\
4870 & 0.03 & 0.27 & 4.8 & 2.1 & 0.009 & 7.1 & 28000000 & 4.3 & 462 \\
\hline
\end{tabular}

Table 10. Coefficients in eq. (61) for some empirical laws.

\begin{tabular}{lll}
\hline Method & $a$ & $b$ \\
\hline Scheidegger, eq. (5) & 4.207 & 0.1566 \\
Li, eq. (6) & 4.613 & 0.1529 \\
Corominas, eq. (7) & 0.897 & 0.085 \\
Corominas, eq. (8) & 0.973 & 0.105 \\
Corominas, eq. (9) & 0.893 & 0.108 \\
\hline
\end{tabular}

Fig. 43. Results obtained through the proposed law and relationships proposed by Scheidegger and Li: $\bar{L}$ versus $V$.

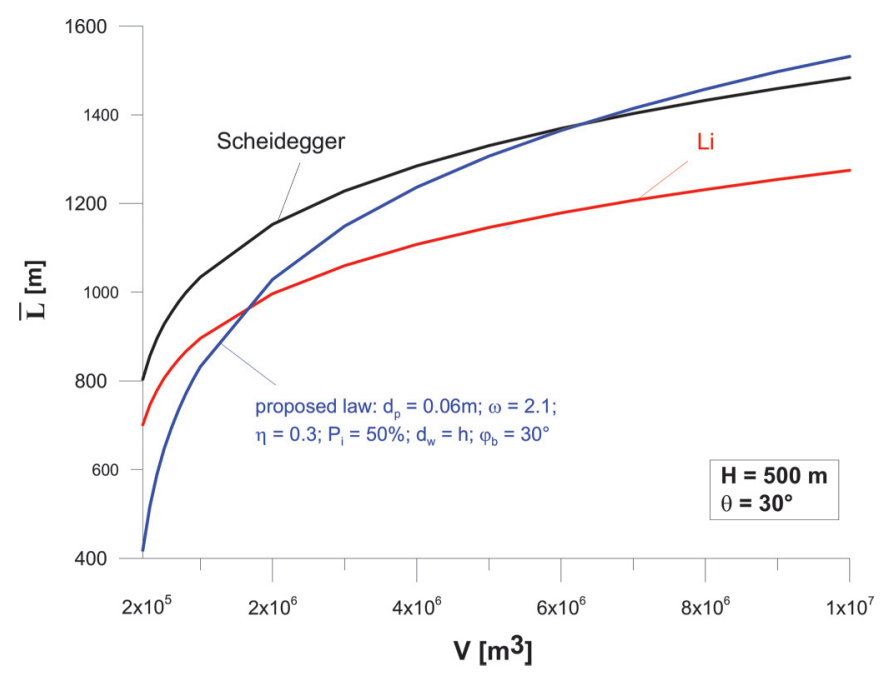

- $V_{0}=1.5 \times 10^{5} \mathrm{~m}^{3}$

- $\mathrm{H} \sim 200 \mathrm{~m}$;

- $\theta=11^{\circ}$

- $h=2 \mathrm{~m}$; and

- $d_{\mathrm{w}}=1.8 \mathrm{~m}$ (partially saturated flow).

The empirical relationships by Scheidegger, Li, Corominas, Rickenmann, and Davies provide the results shown in Table 11: Scheidegger and Li relationships underestimate values of $\bar{L}$; Rickenmann relationship provides a greater value of $\bar{L}$ than that observed in situ; while Corominas and Davies laws provide results closed to $760 \mathrm{~m}$ (Fig. 46). By considering the data provided by Hutchinson, through eq. (60), the observed total runout length $\bar{L}$ is obtained for the following set of parameters: $d_{\mathrm{p}}=0.1 \mathrm{~m} ; \varphi_{\mathrm{b}}=28^{\circ}$; $\omega=3.0\left(e=0.2 ; \nu_{\mathrm{s}}=0.5\right) ; \eta=0.1 ; P_{\mathrm{i}}=30 \%$.

Although Corominas and Davies relationships give values of $\bar{L}$ close to that observed in situ, the corresponding angle $\beta$ (or $\varphi_{\mathrm{b}}$ ), for which these results are obtained, assumes smaller values than those typical for a debris flow (Fig. 46). The values of $\bar{L}$, shown in 
Fig. 44. Results obtained through the proposed law and relationship proposed by Davies: $\bar{L}$ versus $V$.

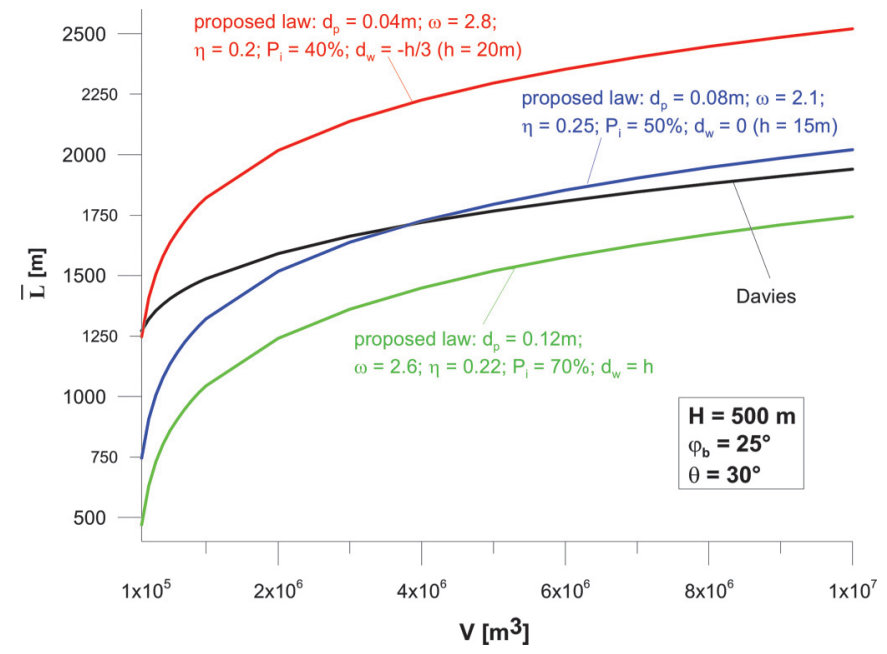

Fig. 45. Results obtained through the proposed law and relationships proposed by Corominas and Rickenmann: $\bar{L}$ versus $V$.

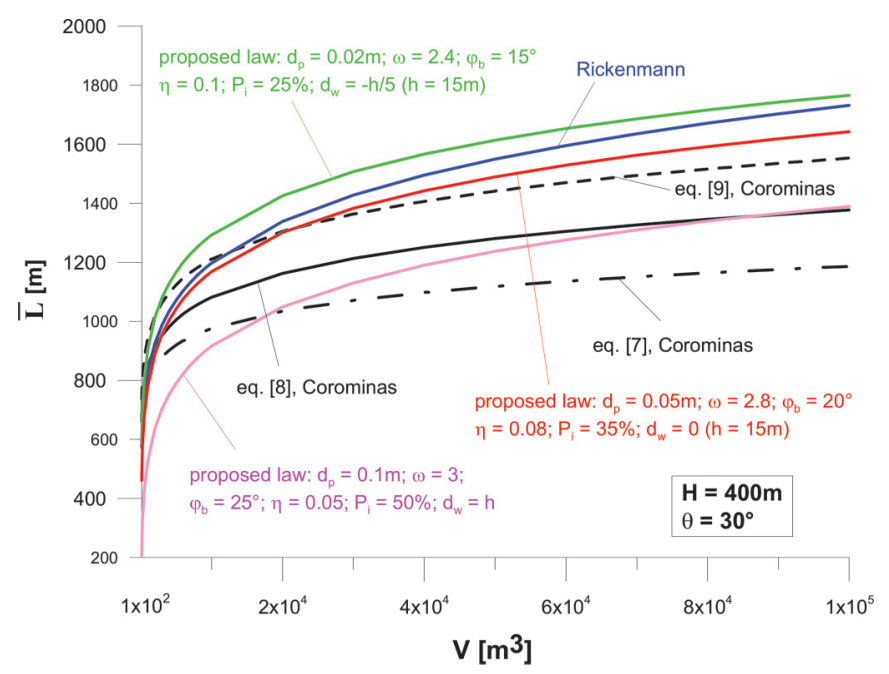

Table 11. Aberfan landslide: results obtained through the empirical relationships.

\begin{tabular}{lr}
\hline Method & $\bar{L}(\mathrm{~m})$ \\
\hline Scheidegger, eq. (5) & 307 \\
Li, eq. (6) & 268 \\
Corominas, eq. (7) & 614 \\
Corominas, eq. (8) & 718 \\
Corominas, eq. (9) & 811 \\
Rickenmann, eq. (10) & 1039 \\
Davies, eq. (11) & 761 \\
\hline
\end{tabular}

Table 11, can be obtained through eq. (60) if particular values are assigned to the physical and mechanical parameters: by imposing $U=0\left(d_{\mathrm{w}}=h\right)$ and assigning high values of $d_{\mathrm{p}}$ and $\varphi_{\mathrm{b}}$, the values of the horizontal distance $\bar{L}$ computed by Scheidegger, Li, and Corominas relationships (eqs. (7) and (8)) are obtained (Fig. 46); while the results obtained by imposing $U \neq 0\left(0 \leq d_{\mathrm{w}}<h\right)$ and assigning small values of $d_{\mathrm{p}}, \varphi_{\mathrm{b}}$, and $P_{\mathrm{i}}$ approximate the values obtained through the other relationships, especially that proposed by Rickenmann.
Fig. 46. Aberfan landslide back-analysis: results obtained through several empirical laws.

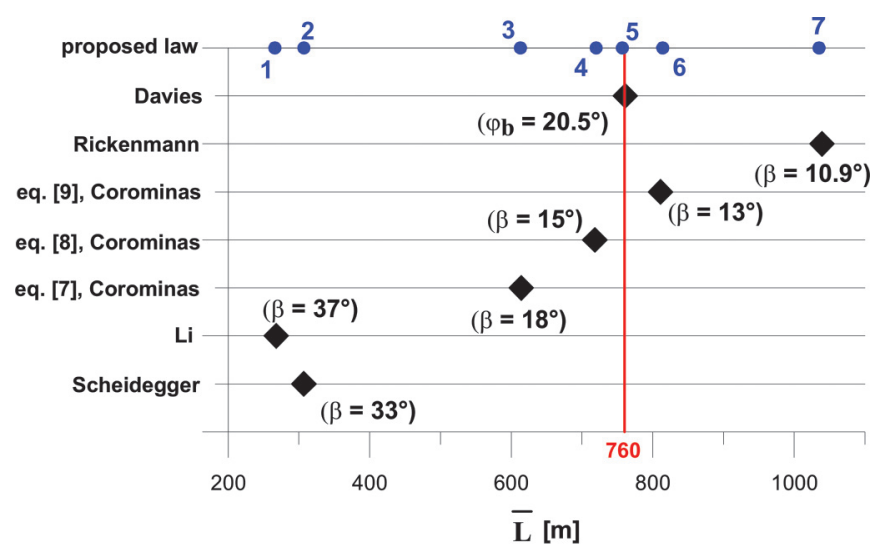

\begin{tabular}{|c|c|c|c|c|c|c|c|}
\hline case & $d_{p}[\boldsymbol{m}]$ & $\boldsymbol{\varphi}_{0}\left[\boldsymbol{}{ }^{\circ}\right]$ & $d_{w}$ & $\boldsymbol{\omega}$ & $\boldsymbol{\eta}$ & $\boldsymbol{P}_{i}[\%]$ & $\bar{L}[\boldsymbol{m}]$ \\
\hline 1 & 0.18 & 41 & $h$ & 3.2 & 0.09 & 70 & 266 \\
2 & 0.15 & 38 & $h$ & 3.1 & 0.11 & 60 & 307 \\
3 & 0.135 & 31 & $h$ & 3.1 & 0.085 & 50 & 613 \\
4 & 0.11 & 29 & $h$ & 2.4 & 0.105 & 40 & 720 \\
$\mathbf{5}$ & $\mathbf{0 . 1}$ & $\mathbf{2 8}$ & $\mathbf{0 . 9 \cdot h}$ & $\mathbf{3}$ & $\mathbf{0 . 1}$ & $\mathbf{3 0}$ & $7 \mathbf{5 7}$ \\
6 & 0.075 & 25 & $h / 2$ & 2.1 & 0.14 & 15 & 814 \\
7 & 0.05 & 20 & 0 & 1.9 & 0.13 & 10 & 1035 \\
\hline
\end{tabular}

It is worth observing that the same results, in terms of $\bar{L}$, computed through the empirical relationships, are obtained through eq. (60) for greater values (and closer to typical ones) of $\varphi_{b}$ than those of $\beta$.

\section{Shum Wan Road landslide}

The Shum Wan Road landslide occurred on 13 August 1995 in Hong Kong; the debris flow was preceded by an intense rainfall event; the involved volume and the height of the debris flow were estimated equal to $26000 \mathrm{~m}^{3}$ and $8 \mathrm{~m}$, respectively (Chen and Lee 2000).

The granular mass can be assumed saturated, because the event occurred after heavy rainfall.

The first slope is inclined on the horizontal of $26^{\circ}$ and the total distance, measured between the highest point of the debris flow in its initial position and the front in its final position, was estimated at about of $205 \mathrm{~m}$. The path profile is shown in Fig. 47.

According to the available data, the following values of the parameters, figuring in eq. (60), are obtained:

- $V_{0}=2.6 \times 10^{4} \mathrm{~m}^{3}$;

- $\mathrm{H} \sim 80 \mathrm{~m}$

- $\theta=26^{\circ}$;

- $h=8 \mathrm{~m}$; and

- $d_{\mathrm{w}}=0$ (saturated flow).

Through eq. (60), the observed horizontal distance $\bar{L}(=205 \mathrm{~m})$ is obtained if the following parameters: $d_{\mathrm{p}}=0.06 \mathrm{~m}, \omega=1.5(e=0.8$; $\left.\nu_{\mathrm{s}}=0.5\right), \varphi_{\mathrm{b}}=30^{\circ}, \eta=0.17$ are imposed, under the assumption of constant mass $\left(P_{i}=0\right)$; if the mass changes $\left(P_{i}=50 \%\right)$, the parameters $d_{\mathrm{p}}=0.13 \mathrm{~m}, \omega=2.4\left(e=0.5 ; \nu_{\mathrm{s}}=0.55\right), \varphi_{\mathrm{b}}=30^{\circ}, \eta=0.075$, must be considered.

In this case, Corominas and Rickenmann relationships are only compared with eq. (60); the other relationships are only valid for $V>10^{5} \mathrm{~m}^{3}$. The results are shown in Table 12. An appreciable difference between the values of $\bar{L}$, computed through Rickenmann and Corominas laws is observed again.

These values can be obtained through eq. (60) if particular values are assigned to the physical and mechanical parameters (Fig. 48) and, thus, they can be considered as specific solutions of 
Fig. 47. Shum Wan Road landslide: path profile.

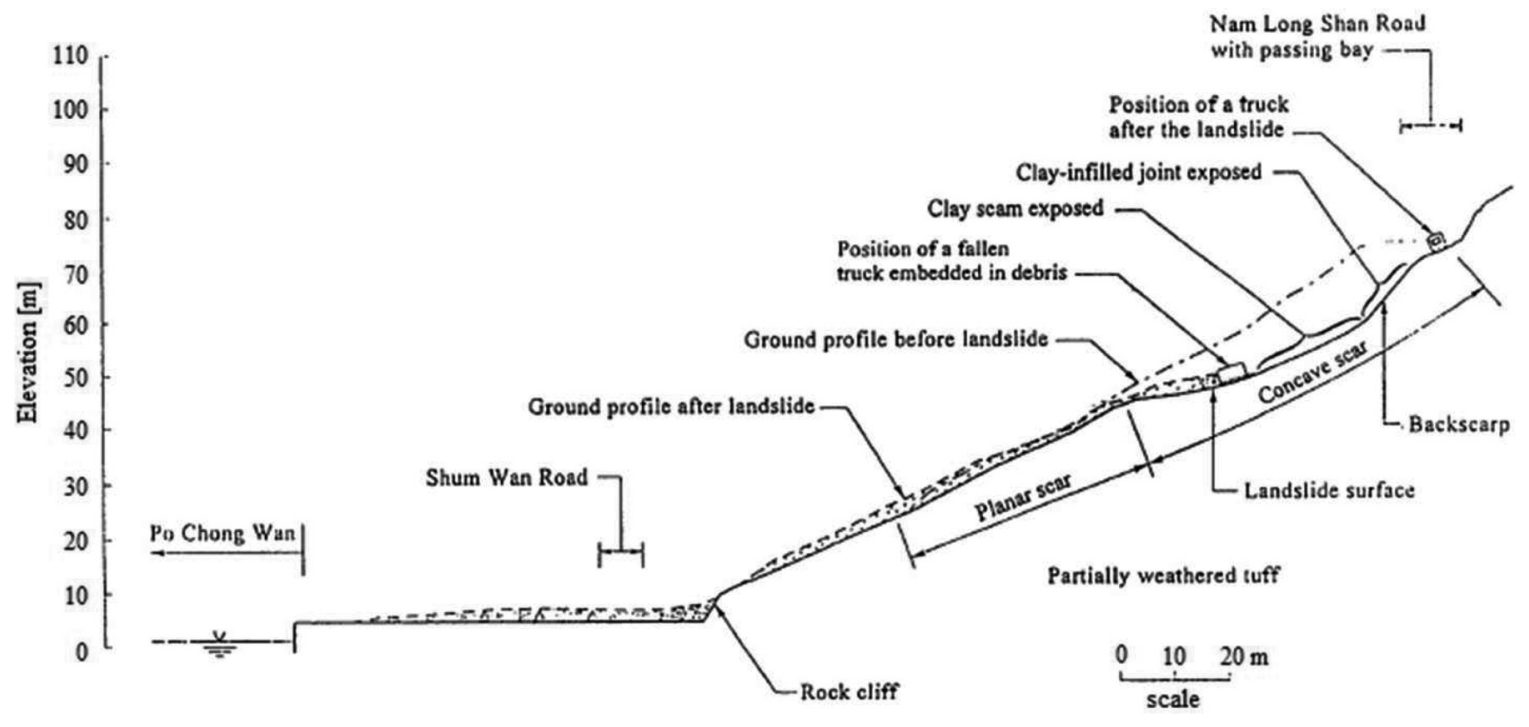

Table 12. Shum Wan Road landslide: results obtained through Rickenmann and Corominas relationships.

\begin{tabular}{lc}
\hline Method & $\bar{L}(\mathrm{~m})$ \\
\hline Corominas, eq. (7) & 212 \\
Corominas, eq. (8) & 239 \\
Corominas, eq. (9) & 269 \\
Rickenmann, eq. (10) & 367 \\
\hline
\end{tabular}

Fig. 48. Shum Wan Road landslide back-analysis: results obtained through several empirical laws.

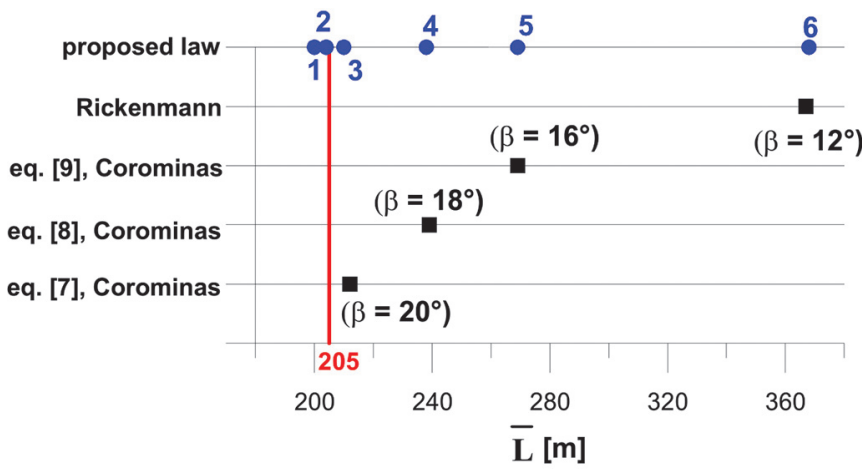

\begin{tabular}{|c|c|c|c|c|c|c|c|}
\hline case & $\boldsymbol{d}_{\boldsymbol{p}}[\boldsymbol{m}]$ & $\left.\boldsymbol{\varphi}_{\boldsymbol{b}} \Gamma^{\circ}\right]$ & $\boldsymbol{d}_{w}$ & $\boldsymbol{\omega}$ & $\boldsymbol{\eta}$ & $\boldsymbol{P}_{\boldsymbol{i}}[\%]$ & $\overline{\boldsymbol{L}}[\boldsymbol{m}]$ \\
\hline 1 & 0.06 & 30 & 0 & 1.5 & 0.17 & 0 & 200 \\
2 & 0.13 & 30 & 0 & 2.4 & 0.075 & 50 & 204 \\
3 & 0.13 & 31 & $h / 2$ & 2.4 & 0.035 & 80 & 210 \\
4 & 0.1 & 26 & 0 & 3 & 0.06 & 60 & 238 \\
5 & 0.05 & 23 & 0 & 1.9 & 0.14 & 20 & 271 \\
6 & 0.02 & 20 & $-h / 5$ & 1.5 & 0.16 & 10 & 368 \\
\hline
\end{tabular}

eq. (60). As in the previous case, the value of $\bar{L}$, computed through the Rickenmann relation (eq. (10)), is obtained for smaller values of the average grain diameter, $d_{\mathrm{p}}$, in the presence of pore-water excess $\left(d_{\mathrm{w}}<0\right)$, as well as for smaller values of $\varphi_{\mathrm{b}}$ than those assigned to obtain the results computed through the Corominas relationships. Only the value obtained through eq. (7) by Corominas is close to that observed in situ (Fig. 48), but it uses a smaller value of the dynamic friction angle $\varphi_{\mathrm{b}}\left(20^{\circ}\right)$ than that assigned in eq. (60) (case $3: 31^{\circ}$ ).
Finally, it is possible to define the fields of applicability of the previously examined empirical approaches: the relationships proposed by Scheidegger and Li seem to be suitable for events affected by dry coarse-grained materials (high values of $d_{\mathrm{p}}$ and $\varphi_{\mathrm{b}}$ ) and remarkable mass changes; the Rickenmann relation often returns greater values of the runout length than those observed, corresponding to sliding granular materials affected by small values of $d_{\mathrm{p}}$ (but greater than $0.02 \mathrm{~m}$ ) and interstitial pressures (saturated flow) or pore-water excess; the Corominas and Davies criteria seem to be appropriate for the preliminarily estimate of the runout length traveled by rapid granular masses affected by intermediate properties compared with the other relations.

\section{Concluding remarks}

The distance traveled by a sliding granular mass depends on several geometrical, physical, and micromechanical parameters as well as on the interstitial pressures and the rheological behaviour taking place within the sliding body. The proposed model is based on the balance of the involved mechanical powers, that are written by taking into account the volume of the sliding granular mass, the slopes of two planar surfaces (runout and runup), an assigned basal fluid pressure, different possibilities for the mass changes and for energy dissipation. Specifically, in a granular material sliding at high rate along a surface, a thin (shear) layer, with variable thickness, whose behaviour is characterized by a regime dominated by the presence of collisions, hosting the "granular temperature" phenomenon, develops in proximity to the basal surface. The travelling of the granular mass is described by a system of ordinary differential equations that have been numerically integrated. Parametric analyses allowed highlighting of the effects of geometrical, physical, and micromechanical parameters, such as the representative diameter of grains $\left(d_{\mathrm{p}}\right)$, the restitution coefficient (e), the density of the solid phase, and the "effective" dynamic friction angle, on the distance traveled by a debris flow.

The main limits of the proposed energy-based model lie $(i)$ in its inability to take into account the effects of the topography of the flow path (channelized or unconfined flow) on the changes in flow depth, spreading of the flow mass along the direction of the motion, and the changes in flow velocity due to curvature; (ii) in the inability to predict the width of the debris fan, affecting the delimitation of the debris flow deposition zone; and (iii) in adopting numerous, also unconventional, parameters, which, however, allow taking the granular nature (frictional and collisional behav- 
iour) of a debris flow into account. By assigning different values to the parameters $V, H$, and $d_{\mathrm{p}}$, the proposed model allowed definition of the favourable conditions for the debris flow mechanism generation: in particular, for larger values of $V$ and $H$ than $\sim 10^{3} \mathrm{~m}^{3}$ and $\sim 100 \mathrm{~m}$, respectively, and for values of $d_{\mathrm{p}}$ higher than $0.02 \mathrm{~m}$. Results of back-analyses of some documented cases allowed elaboration of a semi-empirical law, through which the well-known relationships proposed by Scheidegger, Li, Davies, Rickenmann, and Corominas have been reinterpreted. The great variability of results computed through the empirical criteria makes these approaches applicable, with some difficulty, to predicting the runout length. Further back-analyses allowed the authors to show that the results of the empirical relationships are specific solutions of the semi-empirical proposed expression and, thus, to define their fields of applicability.

\section{References}

Armanini, A. 2010. La modellazione idraulica dei fluidi bifasici solido liquido. XXXII Convegno Nazionale di Idraulica e costruzioni Idrauliche, Palermo.

Ayotte, D., Evans, N., and Hungr, O. 1999. Runout analysis of debris flows and avalanches in Hong Kong. In Proceedings, Slope Stability and Landslides, Vancouver Geotechnical Society Symposium. pp. 39-46.

Bagnold, R.A. 1954. Experiments on a gravity-free dispersion of large solid spheres in a Newtonian fluid under shear. Proceedings of the Royal Society A: Mathematical, Physical and Engineering Sciences, 225: 49-63. doi:10.1098/ rspa.1954.0186.

Benda, L.E., and Cundy, T.W. 1990. Predicting deposition of debris flows in mountain channels. Canadian Geotechnical Journal, 27(4): 409-417. doi:10. 1139/t90-057.

Cannon, S.H. 1993. An empirical model for the volume-change behavior of debris flows. In Proceedings of the National Conference on Hydraulic Engineering. pp. 1768-1773.

Cannon, S.H., and Savage, W.Z. 1988. A mass-change model for the estimation of debris-flow runout. The Journal of Geology, 96: 221-227. doi:10.1086/629211.

Cellino, M., Bianco, G., Arattano, M., and Rosso, M. 1994. Modello cinematico per lo studio della propagazione in alvei naturali di debris flow con notevole variazione del volume in moto. In Proceedings of IV Geoengineering International Congress: Soil and Groundwater Protection.

Chen, H., and Lee, C.F. 2000. Numerical simulation of debris flows. Canadian Geotechnical Journal, 37(1): 146-160. doi:10.1139/t99-089.

Corominas, J. 1996. The angle of reach as mobility index for small and large landslides. Canadian Geotechnical Journal, 33(2): 260-271. doi:10.1139/t96005 .

Cruden, D.M., and Varnes, D.J. 1996. Landslide types and processes. In Landslide investigation and mitigation. TRB Special Report 247. Edited by Turner \& Schuster. National Accademy Press, Washington, D.C. pp. 36-75.

Davies, T.R.H. 1982. Spreading of rock avalanche debris by mechanical fluidization. Rock Mechanics, 15: 9-24. doi:10.1007/BF01239474.

Egashira, S., Honda, N., and Itoh, T. 2001. Experimental study on the entrainment of bed material into debris flow. Physics and Chemistry of the Earth, Part C: Solar, Terrestrial \& Planetary Science, 26: 645-650. doi:10.1016/S14641917(01)00062-9.

Erismann, T.H., and Abele, G. 2001. Dynamics of rockslides and rockfalls. Springer.

Evans, S.G., Hungr, O., and Clague, J.J. 2001. Dynamics of the 1984 rock avalanche and associated distal debris flow on Mount Cayley, British Columbia, Canada: implications for landslide hazard assessment on dissected volcanoes. Engineering Geology, 61: 29-51. doi:10.1016/S0013-7952(00)00118-6.

Federico, F., and Cesali, C. 2013. Modeling of runout length of high-speed granular masses. In Proceedings of the International Conference, Vajont 1963-2013, Padova.

Federico, F., and Cesali, C. 2014. The role of micro-mechanical parameters in the runout length of high-speed granular masses. Modeling and numerical simulations. In Proceedings of the International Symposium on Geomechanics from Micro and Macro, Cambridge, UK.

Heim, A. 1932. Bergsturz und Menschenleben. Fretz and Wasmuth Verlag, Zurich.

Horton, P., Jaboyedoff, M., Zimmermann, M., Mazotti, B., and Longchamp, C. 2008. Flow-R, a model for debris flow susceptibility mapping at a regional scale - some case studies. Natural Hazards and Earth System Sciences, 13: 869-885. doi:10.5194/nhess-13-869-2013.

Hungr, O. 1995. A model for the runout analysis of rapid flow slides, debris flows, and avalanches. Canadian Geotechnical Journal, 32(4): 610-623. doi:10.1139/ t95-063.

Hungr, O., and Evans, S.G. 1996. Rock avalanche run out prediction using a dynamic model. In Proceedings of the 7th International Symposium on Landslides, Trondheim, Norway. Vol 11, pp. 233-238.

Hungr, O., and Evans, S.G. 2004. Entrainment of debris in rock avalanches: an analysis of a long run-out mechanism. Geological Society of America Bulletin, 116: 1240-1252. doi:10.1130/B25362.1.
Hungr, O., Morgan, G.C., and Kellerhals, R. 1984. Quantitative analysis of debris torrent hazards for design of remedial measures. Canadian Geotechnical Journal, 21(4): 663-677. doi:10.1139/t84-073.

Hunter, G., and Fell, R. 2003. Travel distance angle for 'rapid' landslides in constructed and natural soil slopes. Canadian Geotechnical Journal, 40(6): 1123-1141. doi:10.1139/t03-061.

Hutchinson, J.N. 1986. A sliding-consolidation model for flow slides. Canadian Geotechnical Journal, 23(2): 115-126. doi:10.1139/t86-021.

Ikeya, H. 1981. A method of designation for area in danger of debris flow. Erosion and sediment transport in Pacific Rim Steeplands. I.A.H.S. Publ. No. 132. International Association of Hydrological Sciences, Christchurch, New Zealand.

Iverson, R.M. 1997. The physics of debris flows. American Geophysical Union.

Iverson, R.M. 2012. Elementary theory of bed-sediment entrainment by debris flows and avalanches. Journal of Geophysical Research, Earth Surface, 117. doi:10.1029/2011JF002189.

Iverson, R.M., Schilling, S.P., and Vallance, J.W. 1998. Objective delineation of lahar hazard zones downstream from volcanoes. Geological Society of America Bulletin, 110: 972-984. doi:10.1130/0016-7606(1998)110<0972:ODOLIH>2.3. $\mathrm{CO} ; 2$.

Jenkins, J.T., and Savage, S.B. 1983. A theory for the rapid flow of identical, smooth, nearly elastic, spherical particles. Journal of Fluid Mechanics, 130: 187-202. doi:10.1017/S0022112083001044

Korner, H.J. 1980. The energy line method in the mechanics of avalanches. Journal of Glaciology, 26: 501-505.

Legros, F. 2002. The mobility of long-runout landslides. Engineering Geology, 63: 301-331. doi:10.1016/S0013-7952(01)00090-4.

Li, T. 1983. A mathematical model for predicting the extent of a major rockfall. Zeitschrift für Geomorphologie, 24: 473-482.

Lun, C.K.K., Savage, S.B., Jeffrey, D.J., and Chepurniy, N. 1984. Kinetic theories for granular flow: inelastic particles in Couette flow and slightly inelastic particles in a general flow field. Journal of Fluid Mechanics, 140: 233-256. doi:10. 1017/S0022112084000586.

Mills, P., Loggia, D., and Tixier, M. 1999. Model for a stationary dense granular flow along an inclined wall. Europhysics Letters, 45(6): 733-738. doi:10.1209/ epl/i1999-00229-y.

Musso, A., Federico, F., and Troiano, G. 2004. A mechanism of pore pressure accumulation in rapidly sliding submerged porous blocks. Computers and Geotechnics, 31: 209-226. doi:10.1016/j.compgeo.2004.02.001.

O'Brien, J.S., and Julien, P.Y. 1988. Laboratory analyses of mudflow properties. Journal of Hydraulic Engineering, 114(8): 877-887. doi:10.1061/(ASCE)07339429(1988)114:8(877).

Ogawa, S. 1978. Multitemperature theory of granular materials. In Proceedings of the US Japan Seminar on Continuum Mechanical and Statistical Approaches in the Mechanics of Granular Materials, Tokyo. Gakajutsu Bunken Fukyu-Kai.

Park, D., Lee, S., Nikhil, N.V., Kang, S., and Park, J. 2013. Debris flow hazard zonation by probabilistic analysis. International Journal of Innovative Research in Science, Engineering and Technology, 2(6).

Perla, R., Cheng, T.T., and McClung, D.M. 1980. A two-parameter model of snow avalanche motion. Journal of Glaciology, 94: 197-207.

Rickenmann, D. 1999. Empirical relationships for debris flows. Natural Hazards, 19: 47-77. doi:10.1023/A:1008064220727.

Rosso, M., Cavallo, C., Sesenna, R., Citera, E., and Cussotto, M. 2003. Modellazione numerica di un debris flow finalizzata alla progettazione di opere di difesa in ambiente alpino. In Geoingegneria ambientale e mineraria (GEAM). pp. 61-69.

Savage, S.B., and Hutter, K. 1989. The motion of a finite mass of granular material down a rough incline. Journal of Fluid Mechanics, 199: 177-215. doi:10. 1017/S0022112089000340.

Savage, S.B., and Jeffrey, D.J. 1981. The stress tensor in a granular flow at high shear rates. Journal of Fluid Mechanics, 110: 255-272. doi:10.1017| S0022112081000736.

Savage, S.B., and Lun, C.K.K. 1988. Particle size segregation in inclined chute flow of dry cohesionless granular solids. Journal of Fluid Mechanics, 189: 311-335. doi:10.1017/S002211208800103X.

Scheidegger, A.E. 1973. On the prediction of the reach and velocity of catastrophic landslides. Rock Mechanics, 5: 231-236. doi:10.1007/BF01301796.

Seminara, G., and Tubino, M. 1993. Debris flows: meccanica, controllo e previsione. CNR, Gruppo nazionale per la difesa dalle catastrofi idrogeologiche, rapporto tematico.

Straub, S. 1998. Predictability of long runout landslide motion. Springer-Verlag, Berlin.

Takahashi, T. 1991. Debris flow. IAHR Monograph Series. Balkema Publishers, Rotterdam.

Van, Gassen, W., and Cruden, D.M. 1989. Momentum transfer and friction in the debris of rock avalanches. Canadian Geotechnical Journal, 26(4): 623-628. doi:10.1139/t89-075.

Zambrano, O.M. 2008. Large rock avalanches: a kinematic model. Geotechnical and Geological Engineering, 26: 283-287. doi:10.1007/s10706-007-9164-1.

Zhang, D., and Foda, M.A. 1999. Internal wave-granular temperature interaction: an energy balance study on granular flow. Acta Mechanica, 136(3): 155-170. doi:10.1007/BF01179255. 


\section{Pagination not final (cite DOI) / Pagination provisoire (citer le DOI)}

\section{List of symbols}

a Corominas relationship coefficient

$a_{\mathrm{i}}$ Bagnold coefficient (suggested value 0.042)

$B_{c}$ channel width

$b$ Corominas relationship coefficient

$b_{s}$ average shear layer thickness

$C_{\mathrm{h}}$ height rate $(\mathrm{m} / \mathrm{m})$

$C_{1}$ length rate $(\mathrm{m} / \mathrm{m})$

$C_{\Omega}$ basal area rate $\left(\mathrm{m}^{2} / \mathrm{m}\right)$

d differential operator

$d_{\mathrm{p}}$ average grain diameter

$d_{\mathrm{w}}$ depth of the free surface

$\mathrm{d} u / \mathrm{d} y$ velocity gradient

$E_{\text {coll }}$ energy dissipated due to collisions

$E_{\text {disp }}$ energy dissipated along the basal surface due to dispersive pressures

$E_{\text {gt }}$ energy related to granular temperature

$E_{\mathrm{fr}}$ energy dissipated along the basal surface due to friction

$E_{\mathrm{k}}$ kinetic energy

$E_{\mathrm{p}}$ potential energy

$E_{p, 0}$ initial potential energy

$E_{\text {part }}^{\mathrm{d}}$ sum of $E_{\text {coll }}$ and $E_{\text {disp }}$

$E_{\mathrm{r}}$ energy dissipated along the basal surface

$\dot{E}_{\text {coll }}$ power lost due to collisions

$\dot{E}_{\mathrm{gt}}$ power related to granular temperature

$E_{\mathrm{k}}$ kinetic power

$\dot{E}_{\mathrm{k}}^{\mathrm{b}} \quad$ kinetic power of the shear layer

$\dot{E}_{\mathrm{k}}^{\mathrm{s}} \quad$ kinetic power of the block

$\dot{E}_{\mathrm{m}}$ power related to change of mass

$E_{\mathrm{p}}$ potential power

$\dot{E}_{\mathrm{p}}^{\mathrm{b}}$ potential power of the block

$\dot{E}_{\mathrm{p}}^{s}$ potential power of the shear layer pressures

$E_{\mathrm{r}}$ power related to the energies dissipated due to friction and dispersive pressures

$e$ restitution coefficient

$f_{1}, f_{2}$ coefficients in eq. (17)

$g$ gravity acceleration

$g_{0}$ radial distribution function

$\mathrm{H}$ elevation difference between the highest point before sliding and the more advanced point after the sliding of the mass

$H_{\mathrm{b}}$ elevation difference between the centers of mass in their initial and final positions

$h$ total height of the debris flow

$h_{0}$ initial height of the debris flow

$h_{\text {fin }}$ final height of the debris flow

$h_{\mathrm{fs}}$ difference in elevation of the first slope

$h_{\text {ss }}$ difference in elevation of the counterslope

$L$ length of the first slope

$\bar{L}$ total travel distance projected on a horizontal plane

$L_{1}$ distance travelled by the center of mass

$L_{2}$ half of the longitudinal extension of the deposit

$L_{\mathrm{b}}$ horizontal travel distance between the centers of mass in their initial and final positions

$L_{p}$ total distance travelled projection on the horizontal plane

$L_{\text {tot }}$ total distance traveled by the front of the debris flow

$l$ length of the debris flow

$l_{0}$ initial length of the debris flow

$l_{\mathrm{b}}$ runout length projection on the horizontal plane

$l_{\text {fin }}$ final length of the debris flow

$M$ coefficient in expression of the power of energy lost in granular inelastic collisions

$m$ total mass of the debris flow equal to $m^{b}(t)+m^{s}(t)$

$m_{0}$ initial total mass of the debris flow

$m^{\mathrm{b}}$ mass of the block

$m^{\mathrm{s}}$ mass of the shear layer

$m_{\mathrm{g}}^{\mathrm{s}}$ grains' mass within the shear layer

$N_{\text {sav }}$ Savage number
$N_{\text {tot }}$ resulting force in direction orthogonal to the sliding surface

$P_{i}$ percentage of maximum growth of the volume of the debris flow

$p_{\text {dis }}$ dispersive pressure

$p_{\mathrm{w}}$ interstitial pressure

$Q_{1}$ coefficient in expression of the thickness of the block $s^{\mathrm{b}}$

$R^{2}$ coefficient of regression

$r_{1}, r_{2}$ parameters appearing in the expression of $v_{c r, e}$

$r(\dot{x})$ distribution function

$r_{\mathrm{fr}}^{\mathrm{d}}$ ratio between $E_{\mathrm{fr}}$ and $E_{\mathrm{p}, 0}$

$r_{\mathrm{fr}, \max }^{\mathrm{d}}$ maximum value of $r_{\mathrm{fr}}^{\mathrm{d}}$

$r_{\text {part }}^{\mathrm{d}}$ ratio between $E_{\mathrm{part}}^{\mathrm{d}}$ and $E_{\mathrm{p}, 0}$

$s^{\mathrm{b}}$ thickness of the overlying block

$s^{s}$ thickness of the shear layer

$T_{\text {disp }}$ dispersive shear resistance

$T_{\text {fr }}$ friction shear resistance

$T_{g}$ granular temperature

$T_{\max }$ total shear resistance

$U$ interstitial pressure resultant

$u(y)$ grain velocity profile

$V$ volume of the mass

$V_{0}$ initial volume of the debris flow

$V_{\text {fin }}$ final volume of the debris flow after the sliding

$V_{\max }$ maximum volume of the debris flow after the mass change

$v$ rate of the debris flow

$v_{\text {cr }}$ critical velocity for which the inertial regime turns towards a collisional regime

$v_{\mathrm{cr}, \mathrm{e}}$ erosion critical velocity

$v_{\max }$ maximum rate reached by the debris flow

$W_{\mathrm{b}}$ weight of the block

$x$ distance traveled by the center of mass of the debris flow

$x_{\mathrm{e}}$ abscissa at which the sliding granular mass reaches the erosion critical velocity

$x_{\max }$ total distance traveled by the mass center of the debris flow

$\dot{x}$ rate of the sliding mass

$\ddot{x}$ acceleration of the mass

$x_{*}$ selected abscissa to evaluate the involved energies

$y$ normal to the direction of the motion

$\alpha$ second slope or counterslope

$\alpha_{\mathrm{c}}$ critical slope

$\beta$ travel angle

$\beta_{\mathrm{e}}$ limit angle of erosion

$\dot{\gamma}_{\text {coll }}$ power lost due to collisions for unit of volume of the shear layer

$\gamma_{\mathrm{w}}$ specific weight of the interstitial fluid

$\delta$ average slope of a elementary portion of the sliding surface

$\zeta$ angle of the slope

$\eta$ modulator parameter of $r$

$\theta$ first slope

$\lambda$ linear concentration

$\nu_{\max }$ maximum value of the solid fraction

$\nu_{\mathrm{s}}$ shear layer solid fraction

$\rho^{\mathrm{b}}$ density of the block

$\rho^{\mathrm{s}}$ density of the shear layer

$\rho_{\text {bed }}$ density of the material lying on the bed of the channel

$\rho_{\mathrm{s}}$ density of the solid fraction of the debris flow

$\rho_{\mathrm{w}}$ density of the interstitial fluid

$\sigma$ effective normal stress at the base

$\sigma_{\text {lit }}$ lithostatic stress

$\tau_{\text {disp }}$ dispersive shear stress

$\tau_{\text {fr }}$ friction shear stress

$\phi$ internal friction angle ( $\tan \phi=0.32$ )

$\varphi_{\mathrm{b}}$ dynamic friction angle along the sliding surface

$\omega$ Savage and Jeffrey parameter

$\Omega$ basal area of the debris flow

$\Omega_{0}$ initial basal area of the debris flow

$\Omega_{\text {fin }}$ final basal area of the debris flow 